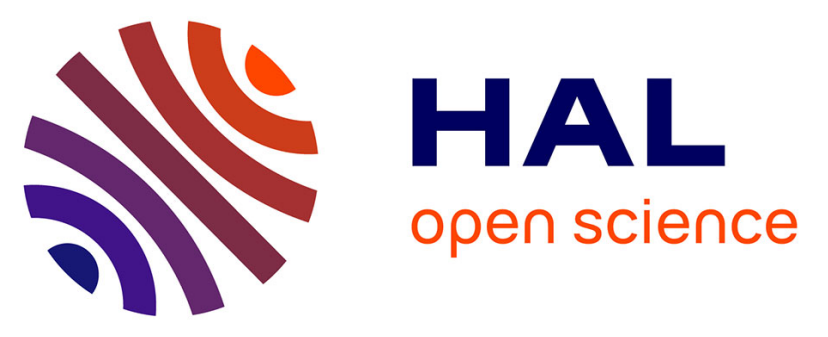

\title{
Synthesis of lipid-carbohydrate-peptidyl-RNA conjugates to explore the limits imposed by the substrate specificity of cell wall enzymes on the acquisition of drug resistance
}

Matthieu Fonvielle, Ahmed Bouhss, Coralie Hoareau, Delphine Patin, Dominique Mengin-Lecreulx, Laura Iannazzo, Nicolas Sakkas, Affaf El Sagheer, Tom Brown, Mélanie Ethève-Quelquejeu, et al.

\section{- To cite this version:}

Matthieu Fonvielle, Ahmed Bouhss, Coralie Hoareau, Delphine Patin, Dominique Mengin-Lecreulx, et al.. Synthesis of lipid-carbohydrate-peptidyl-RNA conjugates to explore the limits imposed by the substrate specificity of cell wall enzymes on the acquisition of drug resistance. Chemistry - A European Journal, 2018, 24 (56), pp.14911-14915. 10.1002/chem.201802360 . hal-01962025

\section{HAL Id: hal-01962025 \\ https://hal.sorbonne-universite.fr/hal-01962025}

Submitted on 20 Dec 2018

HAL is a multi-disciplinary open access archive for the deposit and dissemination of scientific research documents, whether they are published or not. The documents may come from teaching and research institutions in France or abroad, or from public or private research centers.
L'archive ouverte pluridisciplinaire HAL, est destinée au dépôt et à la diffusion de documents scientifiques de niveau recherche, publiés ou non, émanant des établissements d'enseignement et de recherche français ou étrangers, des laboratoires publics ou privés. 


\title{
Synthesis of lipid-carbohydrate-peptidyI-RNA conjugates to explore the limits imposed
}

\section{by the substrate specificity of cell wall enzymes on the acquisition of drug resistance}

\author{
Matthieu Fonvielle $e^{[a] \star}$, Ahmed Bouhss ${ }^{[b]}$, Coralie Hoareau ${ }^{[a]}$, Delphine Patin ${ }^{[b]}$, Dominique Mengin-
}

Lecreul $^{[\mathrm{b}]}$, Laura Iannazzo ${ }^{[\mathrm{c}]}$, Nicolas Sakkas ${ }^{[\mathrm{c}]}$, Affaf el Sagheer, ${ }^{[\mathrm{d}, \mathrm{e}]}$ Tom Brown ${ }^{[\mathrm{e}]}$, Mélanie Ethève-

Quelquejeu[c] *+ and Michel Arthur ${ }^{[\mathrm{a}] *+}$

[a] Dr. Matthieu Fonvielle*, Dr. Michel Arthur*, Coralie Hoareau, INSERM UMRS 1138, Sorbonne Universités, UPMC Univ Paris 06;

Sorbonne Paris Cité, Université Paris Descartes, Université Paris Diderot; Centre de Recherche des Cordeliers, 75006 Paris, France. E-mail: matthieu.fonvielle@crc.jussieu.fr michel.arthur@crc.jussieu.fr

[b] Dr. Ahmed Bouhss, Ms Delphine Patin, Dr. Dominique Mengin-Lecreulx, Institute for Integrative Biology of the Cell (I2BC), CEA, CNRS, Univ Paris-Sud, Université Paris-Saclay, 91198, Gif-sur-Yvette cedex, France. Present adress (AB): Laboratoire Structure-Activité des Biomolécules Normales et Pathologiques (SABNP), Univ Evry, INSERM U1204, Université Paris-Saclay, 91025 Evry, France.

[c] Dr. Laura Iannazzo, Nicolas Sakkas, Dr. Mélanie Ethève-Quelquejeu*, Laboratoire de Chimie et de Biochimie Pharmacologiques et Toxicologiques, Université Paris Descartes, UMR 8601, Paris, F-75005 France; CNRS UMR 8601, Paris, F-75006 France.

[d] Dr. Afaf H.El-Sagheer, Chemistry Branch, Dept. of Science and Mathematics, Faculty of Petroleum and Mining Engineering, Suez University, Suez, 43721 (Egypt)

[e] Dr. Tom Brown, Department of Chemistry, University of Oxford, 12 Mansfield Road, Oxford, OX1 3TA, UK

${ }^{\left[{ }^{\star}\right]}$ Correspondence should be addressed to M.F. (email: matthieu.fonvielle@crc.jussieu.fr) or M.A. (email: michel.arthur@crc.jussieu.fr)

${ }^{[+]}$These authors contributed equally to this work.

Abstract: Conjugation of RNA with multiple partners to obtain mimics of complex biomolecules is limited by the identification of orthogonal reactions. Here, lipid-carbohydrate-peptidyl-RNA conjugates were obtained by post-functionalization reactions, solid-phase synthesis, and enzymatic steps, to generate molecules mimicking the substrates of $\mathrm{FmhB}$, an essential peptidoglycan synthesis enzyme of 
Staphylococcus aureus. Mimics of Gly-tRNA ${ }^{\text {Gly }}$ and lipid intermediate II (undecaprenyl-diphosphodisaccharide-pentapeptide) were combined in a single "bi-substrate" inhibitor $\left(\mathrm{IC}_{50}=56 \mathrm{nM}\right)$. The synthetic route was exploited to generate substrates and inhibitors containing D-Lac instead of D-Ala at the C-terminus of the pentapeptide stem, a modification responsible for vancomycin resistance in the enterococci. The substitution impaired recognition of peptidoglycan precursors by FmhB. The associated fitness cost may account for limited dissemination of vancomycin resistance genes in S. aureus.

Various RNA conjugates have been synthesized to develop new therapeutic strategies and to investigate basic biological processes. ${ }^{[1]}$ These molecules combine an oligonucleotide with carbohydrates, peptides, small molecules, aptamers, or lipids. ${ }^{[1 \mathrm{a}]}$ Carbohydrate-oligonucleotide and small molecule-oligonucleotide conjugates have been mostly used to target specific receptors or to increase uptake in target organs. ${ }^{[2]}$ Aptamer-RNAs were developed to improve the combined delivery of drugs and siRNAs in multidrug-resistant cancer cells. ${ }^{[3]}$ Peptidyl-RNAs have played pivotal roles in mechanistic and structural studies of ribosomal and non-ribosomal peptide synthesis. ${ }^{[4]}$ Peptidyl-RNA conjugates were also developed to increase the cellular uptake of siRNA. ${ }^{[5]}$ Lipid-RNA conjugates were designed to increase the lipophilicity of negatively charged oligonucleotides and to leverage lipoproteinmediated endocytosis. ${ }^{[2]}$ All of these conjugates offer interesting properties and access to novel chemical space. ${ }^{[1 a]}$ Various types of linkers have been used to conjugate RNAs to the various partners, including amide, amine, oxyamine, oxyimine, carbamate, and triazoles, which are chemically and biologically stable. ${ }^{[6]}$ Bioreversible linkers rely on disulfide bridges. ${ }^{[7]}$ The conjugation is mostly performed at the $5^{\prime}$ and 3' ends of the RNA, rather than internally, with the molecules attached to the nucleobase or to the ribose.

There are limited examples of the conjugation of a single RNA molecule with multiple partners. This type of adduct is required to investigate the biosynthesis of bacterial cell walls since its major component, the peptidoglycan, is assembled from a precursor combining a disaccharide $[\beta-1,4$-linked $N$-acetylglucosamine and N-acetyl-muramic acid, (GlcNAc-MurNAc)], a phospholipid carrier (undecaprenyl-

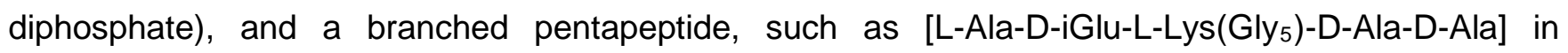
Staphylococcus aureus (Figure 1a and b). Since the pentaglycine side-chain is assembled from glycyl- 
tRNAs by amino acid transferases of the Fem family there is interest in developing lipid-carbohydratepeptidyl-RNA conjugates (Figure 1c) to investigate the interaction of the enzymes with their substrates. The biological question addressed in our study concerns the acquisition of resistance to the glycopeptide antibiotic vancomycin in S. aureus by replacement of the terminal D-Ala residue by D-Lac. The substitution reduces the affinity of the drugs for peptidoglycan by 1,000 fold leading to high-level resistance (Figure 1d). Since the resistance mechanism is widespread in the enterococci but only sporadically detected in S. aureus in spite of easy horizontal gene transfer between these bacteria ${ }^{[8]}$ our specific aim is to evaluate whether the D-Ala to D-Lac substitution is tolerated by the $S$. aureus transferase FmhB responsible for incorporation of the first residue of the penta-glycine side chain..$^{[9]}$ We focus on FmhB since this enzyme is essential presumably because the side-chain of peptidoglycan precursors directly participates in the peptidoglycan cross-linking reaction (Figure 1e). ${ }^{[9-10]}$ To investigate the specificity of FmhB, we have synthesized D-Ala- and D-Lac-containing substrates analogues (Figure 2) and lipid-carbohydrate-peptidyl-RNA conjugates acting as inhibitors (Figure 1c). This strategy was designed to assess the impact of the D-Ala to D-Lac substitution both on the catalytic efficacy of the transfer of Gly from Gly-tRNA ${ }^{\text {Gly }}$ to the peptidoglycan precursors and on the affinity of FmhB for inhibitors that mimic both substrates of the enzyme (referred to as "bi-substrates"). The target inhibitor molecules (Figure 1c) comprise soluble analogues of the peptidoglycan precursors (Lipid II) covalently-linked by a triazole to the acceptor arm of tRNA ${ }^{\text {Gly }}$. Our synthesis strategy enables to modulate the length of the RNA and lipid moieties in order to obtain ligands with suitable size and solubility for investigating enzyme activity and affinity. It also enables to selectively modify the terminal residue of the peptide (D-Ala versus D-Lac). One of the major difficulty for obtaining the desired lipid-carbohydrate-peptidyl-RNA conjugates is the identification of orthogonal reactions compatible with the various functional groups specifically present in each component of the multi-RNA conjugates. In our synthetic strategy, we overcome these problems by developing post-functionalization of RNA and peptides moieties as well as a combination of enzymatic and chemical reactions (Figure 1c). 


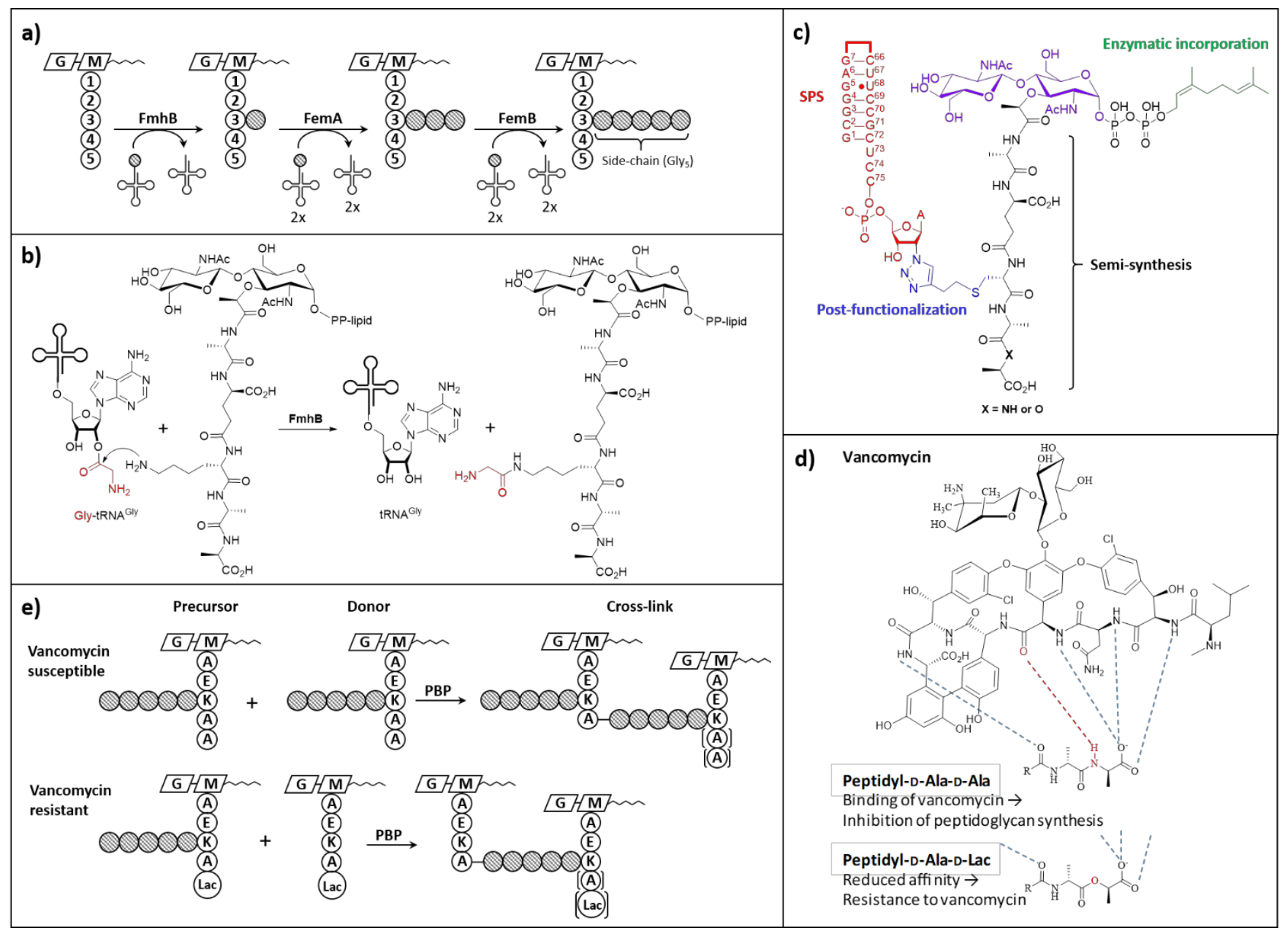

Figure 1. a) Assembly of the pentaglycine side-chain of peptidoglycan precursors by amino-acyl transferases of the Fem family. (b) Reaction catalyzed by FmhB. (c) Target lipid-carbohydrate-peptidylRNA conjugates developed as bi-substrate inhibitors. (d) Hydrogen bonding interaction between vancomycin and the peptidyl-D-Ala-D-Ala extremity of peptidoglycan precursors. Substitution of the Cterminal D-Ala by D-Lac prevents formation of the hydrogen bond indicated in red. (e) Penicillin Binding Protein (PBP) mediated cross-linking for vancomycin-susceptible and -resistant strains of Staphyloccocus aureus. ${ }^{[11]}$ 


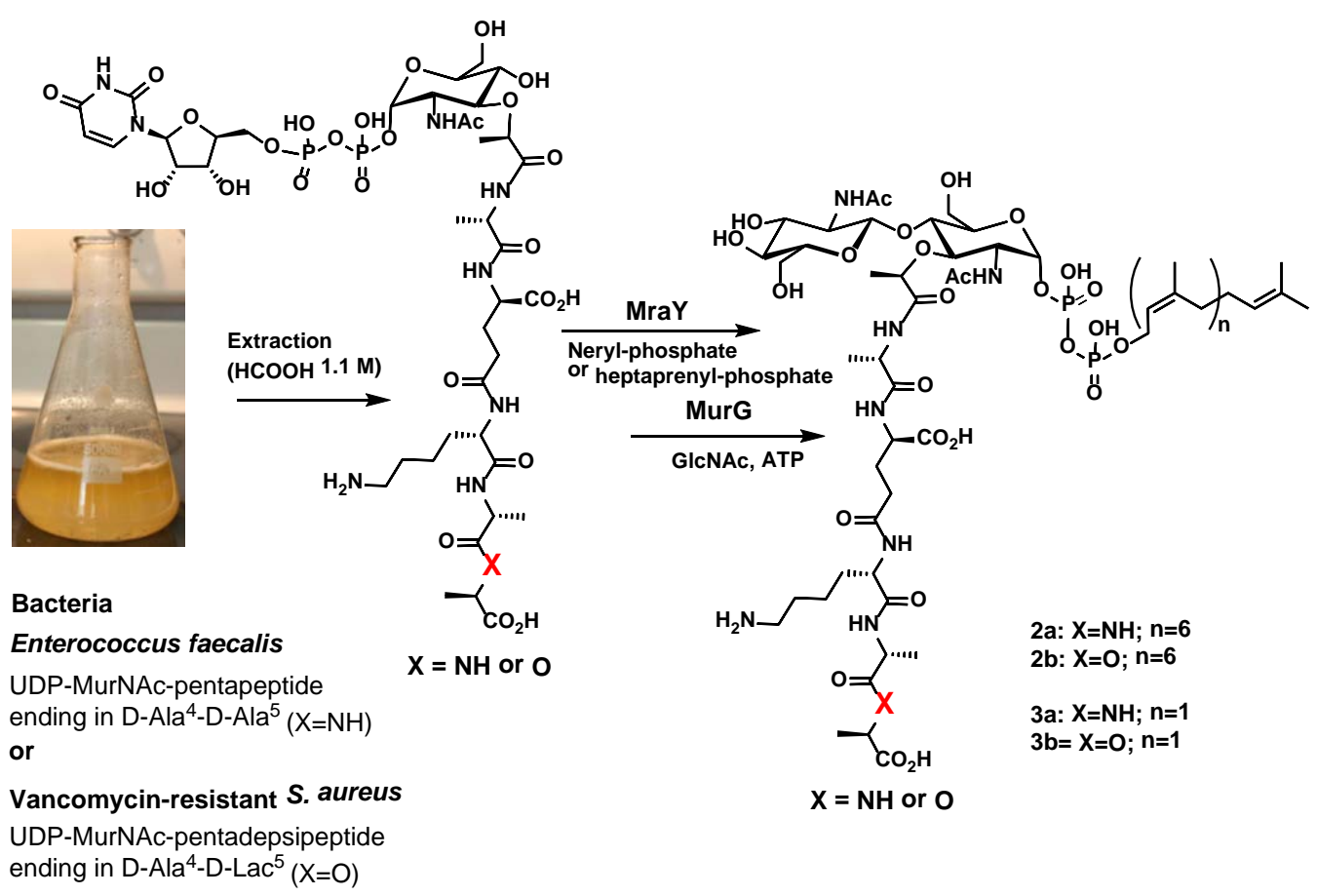

Figure 2. Semi-synthesis of lipid II analogues. MraY, Phospho- $N$-acetylmuramoyl-pentapeptidetransferase. MurG, $\mathrm{N}$-acetylglucosamine- transferase.

To generate the D-Ala- and D-Lac-ending substrates of FmhB, the soluble nucleotide precursors were extracted from vancomycin-susceptible (D-Ala ${ }^{5}$ ) and vancomycin-resistant (D-Lac ${ }^{5}$ ) bacteria (Figure 2). Transfer of the phospho-MurNAc-peptide moiety to the lipid and addition of GlcNAc were obtained enzymatically ${ }^{[12]}$ For these substrates, we used commercially available heptaprenyl-phosphate instead of the natural undecaprenyl-phosphate lipid carrier (bactoprenyl). Transfer of $\left[{ }^{14} \mathrm{C}\right] \mathrm{Gly}$ from $\left[{ }^{14} \mathrm{C}\right] \mathrm{Gly}$ tRNA $^{\text {Gly }}$ to the heptaprenyl-containing lipid II analogue was tested by a coupled assay involving acylation of tRNA ${ }^{\text {Gly }}$ by purified glycyl-tRNA synthetase (GlyRS). The product was identified by thin layer chromatography (Supplementary information, Figure S5). This analysis revealed that substitution of DAla by D-Lac at the C-terminus of the lipid II analogues reduces the catalytic efficacy of FmhB by 4.6 fold (Figure 3a).

There are several limitations resulting from the insolubility of the heptaprenyl-containing substrates including uncertainty regarding the concentrations of lipid II analogues actually accessible to FmhB and time consuming solvent extractions required for purification. In order to gain access to soluble lipid II analogues, we replaced heptaprenyl-phosphate by neryl-phosphate in the synthesis procedure. The 
resulting neryl-containing lipid II analogues were effectively used as substrates by FmhB revealing again a reduced catalytic efficacy for D-Lac-ending substrates (7 fold; Figure $3 b$ and Table 1 ).
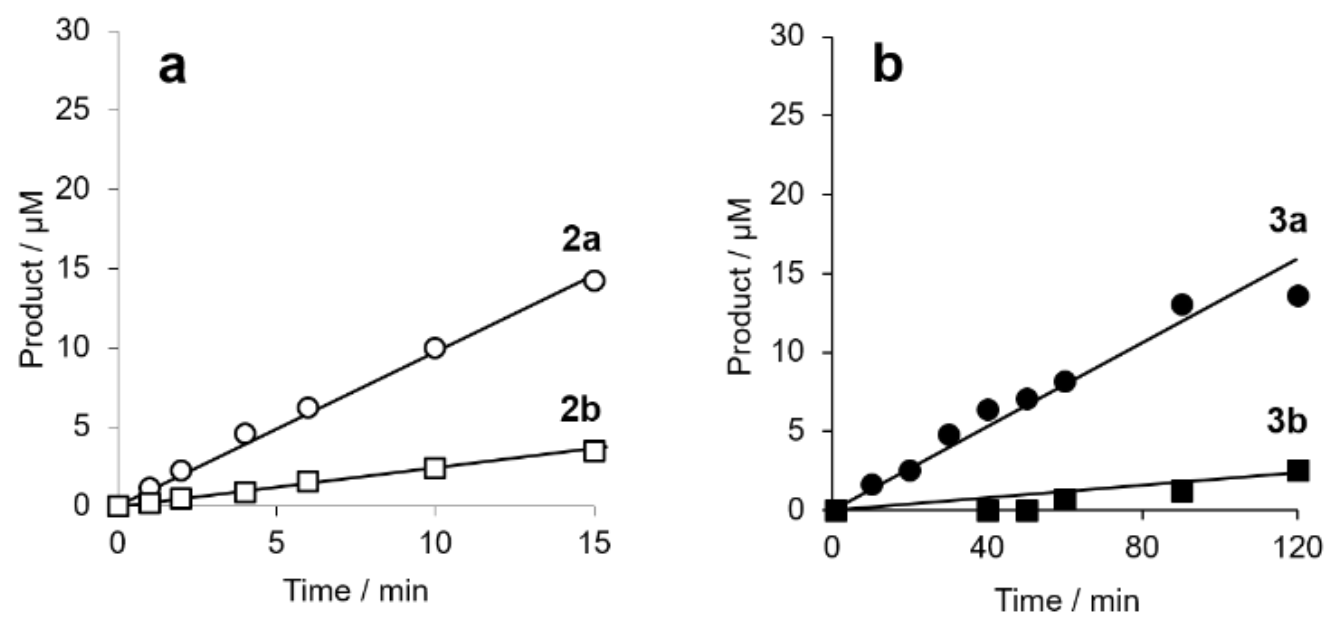

Figure 3. Catalytic efficacy of FmhB for the transfer of Gly from Gly-tRNA ${ }^{\text {Gly }}$ to lipid II analogues ending in D-Ala or D-Lac. (a) and (b), transfer of Gly from heptaprenyl- and neryl-containing substrates (30 $\mu \mathrm{M})$ was tested with FmhB concentrations of $50 \mathrm{nM}$ and $170 \mathrm{nM}$, respectively. Circles, D-Ala-ending substrate; squares, D-Lac-ending substrate.

Lipid-carbohydrate-peptidyl-RNA conjugates mimicking both the Gly-tRNA ${ }^{\text {Gly }}$ and lipid II (lipidcarbohydrate-peptide) substrates were synthesized in order to explore the impact of the D-Ala to D-Lac substitution on the affinity of FmhB for peptidoglycan precursors (Figure 2). The presence of the carbohydrate and lipid parts have been shown to be essential for the activity of the FmhB transferase. ${ }^{[13]}$ The synthesis of the Lipid II moiety started by four enzymatic reactions for sequential addition of L-Ala, D-Glu, meso-cystine, and D-Ala-D-Ala or D-Ala-D-Lac to UDP-MurNAc by Mur synthetases (Figure 4). Meso-cystine is a structure analogue of meso-2,6-diaminopimelic acid (DAP), which is recognized by the enzyme MurE and enables post-functionalization of the peptide via formation of a dehydroalanine. ${ }^{[14]}$ For this purpose, we have developed a new one-pot reaction based on reduction of meso-cystine into cysteine by a soluble phosphine followed by its conversion to dehydroalanine by 2,5-dibromohexanediamide. By this approach, a dehydroalanine residue was introduced at the $3^{\text {rd }}$ position of the stem peptide. In the following step, 1,4-addition of 1-thio butynyl to the dehydroalanine afforded two stereoisomers containing an alkyne function at the extremity of the side-chain of the $3^{\text {rd }}$ 
residue. The $(R)$ diastereoisomer was purified by rpHPLC as previously described. ${ }^{[15]}$ MraY and MurG were permissive for the transfer of the phospho-MurNAc-peptide moieties to heptaprenyl-phosphate and neryl-phosphate and the subsequent addition of GICNAc, respectively, generating the corresponding alkyne-containing lipid II analogues. ${ }^{[12]}$ For the RNA moiety, 2'-azido-5'-dimethoxytrityl-benzoyl adenosine was coupled to a resin for solid phase synthesis of an 18-mer mimicking the acceptor arm of tRNAGly. ${ }^{[4 a]}$ During solid phase synthesis, a hexaethylene glycol linker was incorporated to stabilize the hairpin duplex formed by the RNA strand. The alkyne-containing lipid II analogues were coupled to the azido-containing RNA by the Cu'-catalyzed Huisgen-Sharpless cycloaddition reaction in the presence of a metal ligand (THPTA) ${ }^{[15]}$ The resulting triazole-containing lipid-carbohydrate-peptidyl-RNA conjugates were purified by denaturing polyacrylamide gel electrophoresis and by rpHPLC for heptaprenyl- and neryl-containing molecules, respectively (Supplementary Information).

Our next objective was to assess the impact of the substitution of the C-terminal D-Ala by D-Lac on the inhibition of FmhB by lipid-carbohydrate-peptidyl-RNA conjugates ("bi-substrates"). The conjugates were tested as FmhB inhibitors in the GlyRS-FmhB coupled assay (Figure 5). Substitution of D-Ala by D-Lac at the C-terminus of the peptide stems of the conjugates led to a 15 -fold increase in the $\mathrm{IC}_{50}$ values (from $56 \pm 6 \mathrm{nM}$ to $820 \pm 50 \mathrm{nM}$ for neryl-containing analogues; Table 1). This difference highlights the contribution of the D-Ala-D-Ala amide bond to the binding energy to the enzyme. $I_{50} \mathrm{~S}$ of $56 \pm 6 \mathrm{nM}$ and $5 \pm 3 \mathrm{nM}$ were determined for D-Ala-ending heptaprenyl- and neryl-PP-disaccharide-pentapeptideRNA conjugates indicating that shortening of the lipid moiety (7 versus 2 prenyl groups) leads to a ca. 11-fold reduction in affinity (Supplementary Information and Table 1). This mirrors the 7- and 10-fold reduction observed with the substrates (Table 1).

Table 1. Impact of replacement of D-Ala by D-Lac on the catalytic activity of FmhB and its inhibition by bi-substrates

\begin{tabular}{lcc}
\hline & \multicolumn{2}{c}{ C-terminal residue } \\
\cline { 2 - 3 } Substrate or inhibitor & D-Ala & D-Lac \\
\hline Heptaprenyl-containing substrate (turnover, $\mathrm{min}^{-1}$ ) & $0.95 \pm 0.02$ & $0.20 \pm 0.01$ \\
Neryl-containing substrate (turnover, $\mathrm{min}^{-1}$ ) & $0.14 \pm 0.01$ & $0.020 \pm 0.005$ \\
Heptaprenyl-containing inhibitor $\left(\mathrm{IC} \mathrm{F}_{50}, \mathrm{nM}\right)$ & $5 \pm 3$ & $\mathrm{ND}$ \\
Neryl-containing inhibitor $\left(\mathrm{IC}_{50}, \mathrm{nM}\right)$ & $56 \pm 6$ & $820 \pm 50$ \\
\hline
\end{tabular}




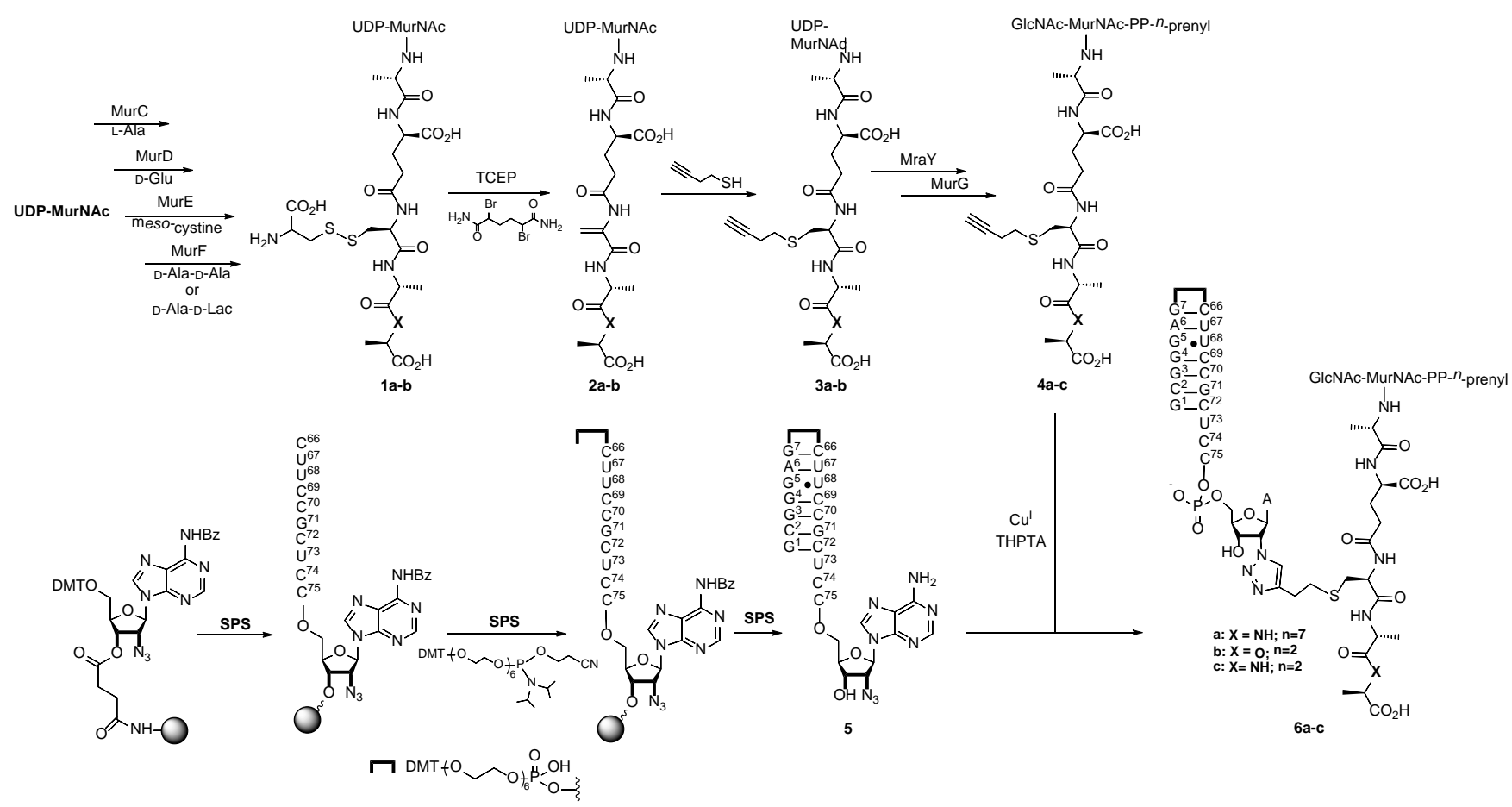

Figure 4. Synthesis of the $n$-prenyl-carbohydrate-peptidyl-RNA conjugates. $X=N H(D-A l a)$ or $X=O$ (DLac); $n=2$ (neryl); $n=7$ (heptaprenyl). THPTA, tris(3-hydroxypropyltriazolylmethyl)amine. TCEP, tris(2carboxyethyl)phosphine..

Tota $^{[10 a, 16]}$ and enzymatic ${ }^{[12]}$ synthesis of lipid II have been described previously and were mostly used to incorporate fluorescent tags. Here, we report a hybrid strategy using dehydroalanine-containing lipid analogues for post-functionalization. This approach was used to generate lipid-carbohydratepeptidyl-RNA conjugates mimicking the lipid II and Gly-tRNA ${ }^{\text {Gly }}$ substrates of the FmhB transferase from S. aureus. Variability was introduced in the sequence of the peptide and in the number of isoprenyl repeats in the lipid moiety. Solid-phase synthesis of the RNA moiety offers the possibility to modulate the size and the sequence of the RNA moiety. The 1,4 addition of the thiol to dehydroalanine also offers a versatile access to bi-substrates containing linkers with various lengths and structures. Our lipidcarbohydrate-peptidyl-RNA conjugates provide a versatile tool to study the tRNA-dependent amino acyltransferases involved in peptidoglycan synthesis.

In this study, we investigated the specificity of the FmhB aminoacyl-transferase by comparing substrates and inhibitors differing by the presence of D-Ala or D-Lac at the C-terminus of the stem peptide. Testing the substrates indicated that the D-Ala to D-Lac substitution impairs the activity of FmhB. Testing the inhibitors indicated that the substitution reduced the affinity of FmhB for the peptidoglycan 
precursor analogues. Structural analyses of peptidoglycan purified from vancomycin-resistant S. aureus showed that a high portion of the stem peptides were devoid of the pentaglycine side-chain..$^{[9,11]}$ Our data indicate that impaired activity of FmhB accounts for the presence of incomplete stem peptides lacking the pentaglycine side-chain. Such incomplete precursors are only used as acyl donors by the transpeptidases responsible for the formation of peptidoglycan cross-links (Figure 1e). Our data also indicate that the production of D-Lac-ending precursors may have a fitness cost by impairing the assembly of peptidoglycan precursors. Such a fitness cost could account for the lack of dissemination of vancomycin-resistance staphylococci in spite of the sporadic detection of this type of strain in patients treated with vancomycin. The origin of this fitness cost is not known. The presence of incomplete sidechain only in the "donor" stem of dimers suggests that impaired activity of the transpeptidases might be involved.

a
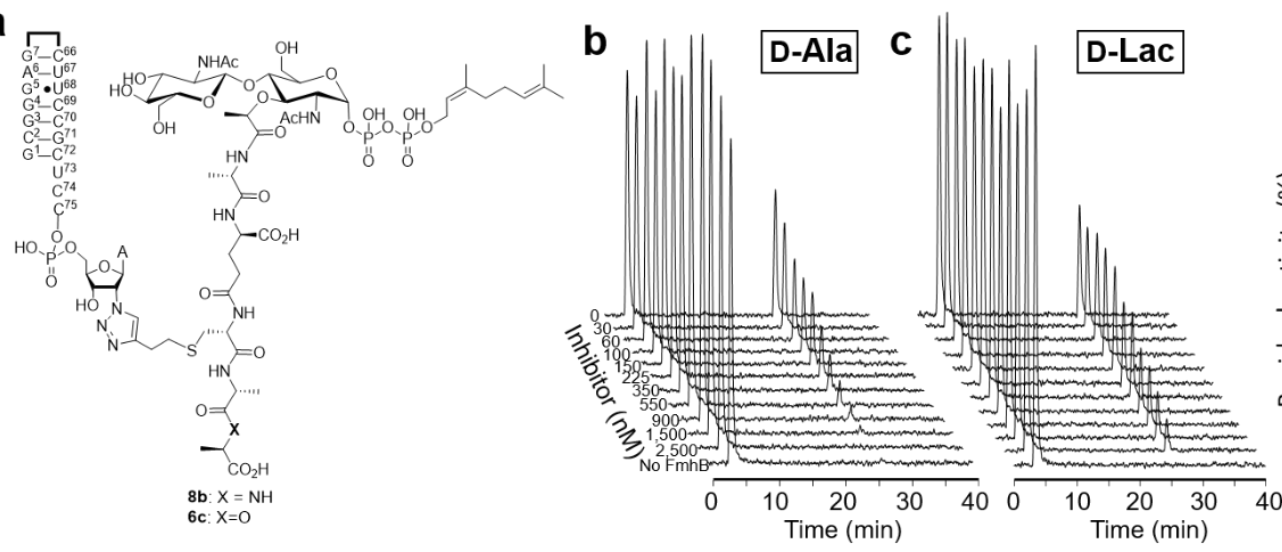

d

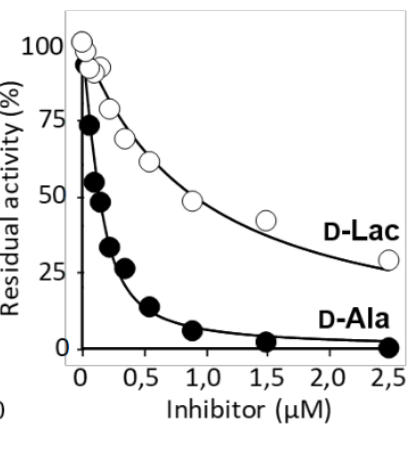

Figure 5. Inhibition of FmhB by lipid-carbohydrate-peptidyl-RNA conjugates. (a) Structure of the inhibitors. $X=N H(D-A l a)$ or $X=O$ (D-Lac). (b and c) Separation of $\left[{ }^{14} \mathrm{C}\right]$ Gly from $\left[{ }^{14} \mathrm{C}\right]$ Gly-lipid II analogues by rpHPLC coupled to a radioflow detector to assess the extent of inhibition of FmhB by increasing concentrations of inhibitors $\mathbf{8 b}$ and $\mathbf{8 c}$ ending in D-Ala and D-Lac, respectively. (d) \% inhibition of FmhB by increasing concentrations of $\mathbf{8 b}$ and $\mathbf{8 c}$ (close and open circle, respectively). The $\mathrm{IC}_{50}$ values (56 $\pm 6 \mathrm{nM}$ and $820 \pm 50 \mathrm{nM}$ for $\mathbf{8 b}$ and $\mathbf{8 c}$, respectively) were deduced by fitting the Morrison equation to the data.

\section{Acknowledgements}


This work was supported by the project SyntRNA from ANR program to MEQ and MA (ANR-17-CE070041-01). NS was funded by a DGA-MRIS scholarship.

Keywords: Fem $・$ RNA conjugates $\bullet$ Staphylococcus aureus $\bullet$ VanA $\bullet$ vancomycin

[1] a) E. Valeur, S. M. Gueret, H. Adihou, R. Gopalakrishnan, M. Lemurell, H. Waldmann, T. N. Grossmann, A. T. Plowright, Angew. Chem. Int. Ed. Engl. 2017, 56, 10294-10323; b) J. Winkler, Therapeutic delivery $\mathbf{2 0 1 3}, \mathbf{4}, \mathbf{7 9 1 - 8 0 9 .}$

[2] a) M. Manoharan, Antisense Nucleic Acid Drug Dev. 2002, 12, 103-128; b) N. S. Kruglova, M. I. Meschaninova, A. G. Venyaminova, M. A. Zenkova, V. V. Vlassov, E. L. Chernolovskaya, Molecular Biology 2010, 44, 254-261; c) J. Baillet, V. Desvergnes, A. Hamoud, L. Latxague, P. Barthélémy, 2018, Advanced Materials, 1705078.

[3] a) G. Zhu, G. Niu, X. Chen, Bioconjug. Chem. 2015, 26, 2186-2197; b) H. Jeong, S. H. Lee, Y. Hwang, H. Yoo, H. Jung, S. H. Kim, H. Mok, Macromolecular bioscience 2017, 17, 1600343

[4] a) M. Fonvielle, I. Li de La Sierra-Gallay, A. H. El-Sagheer, M. Lecerf, D. Patin, D. Mellal, C. Mayer, D. Blanot, N. Gale, T. Brown, H. van Tilbeurgh, M. Etheve-Quelquejeu, M. Arthur, Angew. Chem. Int. Ed. Engl. 2013, 52, 7278-7281; b) S. Terenzi, E. Biala, N. Q. Nguyen-Trung, P. Strazewski, Angew. Chem. Int. Ed. Engl. 2003, 42, 2909-2912; c) H. Moroder, J. Steger, D. Graber, K. Fauster, K. Trappl, V. Marquez, N. Polacek, D. N. Wilson, R. Micura, Angew. Chem. Int. Ed. Engl. 2009, 48, 4056-4060.

[5] a) M. R. Alam, X. Ming, M. Fisher, J. G. Lackey, K. G. Rajeev, M. Manoharan, R. L. Juliano, Bioconjug. Chem. 2011, 22, 1673-1681; b) M. R. Alam, V. Dixit, H. Kang, Z. B. Li, X. Chen, J. Trejo, M. Fisher, R. L. Juliano, Nucleic Acids Res. 2008, 36, 2764-2776.

[6] a) M. Arthur, M. Ethève-Quelquejeu, Chemistry of organo-hybrids: synthesis and characterization of functional nano-objects. (Eds.: E. Lacôte, B. Charleux, C. Coperet), Wiley-VCH, 2015; b) E. Paredes, M. Evans, S. R. Das, Methods 2011, 54, 251-259.

[7] A. Ardana, A. K. Whittaker, K. J. Thurecht, Macromolecular Research 2017, 25, 599-614.

[8] P. C. Appelbaum, International journal of antimicrobial agents 2007, 30, 398-408. 
[9] A. Severin, K. Tabei, F. Tenover, M. Chung, N. Clarke, A. Tomasz, J. Biol. Chem. 2004, 279, 33983407.

[10] a) J. Nakamura, H. Yamashiro, H. Miya, K. Nishiguchi, H. Maki, H. Arimoto, Chem. Eur. J. 2013, 19, 12104-12112; b) V. Srisuknimit, Y. Qiao, K. Schaefer, D. Kahne, S. Walker, J. Am. Chem. Soc. 2017, 139, 9791-9794.

[11] D. Panesso, P. J. Planet, L. Diaz, J.-E. Hugonnet, T. T. Tran, A. Narechania, J. M. Munita, S. Rincon, L. P. Carvajal, J. Reyes, A. Londoño, H. Smith, R. Sebra, G. Deikus, G. M. Weinstock, B. E. Murray, F. Rossi, M. Arthur, C. A. Arias, Emerging infectious diseases 2015, 21, 1844-1848.

[12] L. Y. Huang, S. H. Huang, Y. C. Chang, W. C. Cheng, T. J. Cheng, C. H. Wong, Angew. Chem. Int. Ed. Engl. 2014, 53, 8060-8065.

[13] T. Schneider, M. M. Senn, B. Berger-Bachi, A. Tossi, H. G. Sahl, I. Wiedemann, Mol. Microbiol. 2004, 53, 675-685.

[14] J. M. Chalker, S. B. Gunnoo, O. Boutureira, S. C. Gerstberger, M. Fernadez-Gonzalez, J. G. L. Bernardes, L. Griffin, A. Hailu, C. J. Schofield, B. G. Davis, Chem. Sci. 2011, 2, 1666-1676.

[15] M. Fonvielle, D. Mellal, D. Patin, M. Lecerf, D. Blanot, A. Bouhss, M. Santarem, D. Mengin-Lecreulx, M. Sollogoub, M. Arthur, M. Etheve-Quelquejeu, Chem. Eur. J. 2013, 19, 1357-1363.

[16] a) M. S. VanNieuwenhze, S. C. Mauldin, M. Zia-Ebrahimi, B. E. Winger, W. J. Hornback, S. L. Saha, J. A. Aikins, L. C. Blaszczak, J. Am. Chem. Soc. 2002, 124, 3656-3660; b) Y. Zhang, E. J. Fechter, T. S. Wang, D. Barrett, S. Walker, D. E. Kahne, J. Am. Chem. Soc. 2007, 129, 3080-3081. 


\section{Supplementary information}

Synthesis of lipid-carbohydrate-peptidyl-RNA conjugates to explore the limits imposed by the substrate specificity of cell wall enzymes on the acquisition of drug resistance

Matthieu Fonvielle ${ }^{[a] *}$, Ahmed Bouhss ${ }^{[b]}$, Coralie Hoareau ${ }^{[a]}$, Delphine Patin ${ }^{[b]}$, Dominique MenginLecreul $^{[b]}$, Laura lannazzo ${ }^{[c]}$, Nicolas Sakkas ${ }^{[c]}$, Affaf el Sagheer ${ }^{[d, e]}$, Tom Brown ${ }^{[e]}$, Mélanie EthèveQuelquejeu $^{[\mathrm{c}]^{*}}$ and Michel Arthur ${ }^{[\mathrm{a}] *}$

[a] Dr. Matthieu Fonvielle*, Dr. Michel Arthur*, Coralie Hoareau, INSERM UMRS 1138, Sorbonne Universités, UPMC Univ Paris 06; Sorbonne Paris Cité, Université Paris Descartes, Université Paris Diderot; Centre de Recherche des Cordeliers, 75006 Paris, France. E-mail: matthieu.fonvielle@crc.jussieu.fr michel.arthur@crc.jussieu.fr

[b] Dr. Ahmed Bouhss, Ms Delphine Patin, Dr. Dominique Mengin-Lecreulx, Institute for Integrative Biology of the Cell (I2BC), CEA, CNRS, Univ Paris-Sud, Université Paris-Saclay, 91198, Gif-sur-Yvette cedex, France.

[c] Dr. Laura lannazzo, Nicolas Sakkas, Dr. Mélanie Ethève-Quelquejeu*, Laboratoire de Chimie et de Biochimie Pharmacologiques et Toxicologiques, Université Paris Descartes, UMR 8601, Paris, F-75005 France; CNRS UMR 8601, Paris, F-75006 France.

[d] Dr. Afaf H.El-Sagheer, Chemistry Branch, Dept. of Science and Mathematics, Faculty of Petroleum and Mining Engineering, Suez University, Suez, 43721 (Egypt)

[e] Dr. Tom Brown, Department of Chemistry, University of Oxford, 12 Mansfield Road, Oxford, OX1 3TA, UK.

${ }^{\left[{ }^{*}\right]}$ Correspondence should be addressed to M.F. (email: matthieu.fonvielle@crc.jussieu.fr) or M.A. (email: michel.arthur@crc.jussieu.fr)

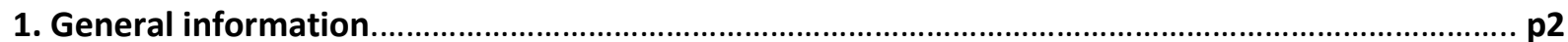

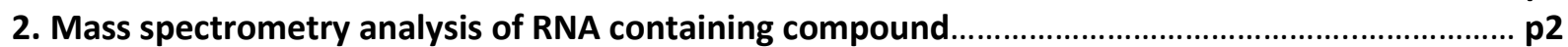

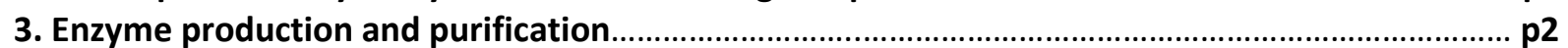

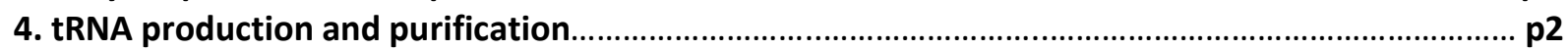

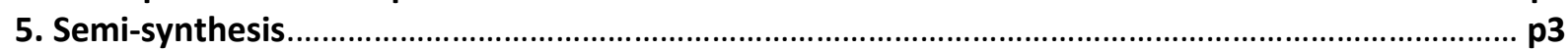

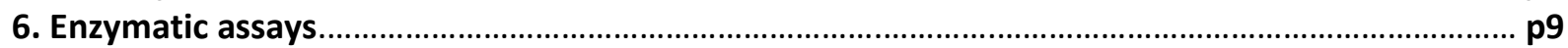

7- Mass spectrometry analyses of synthesized compounds.......................................................... p12

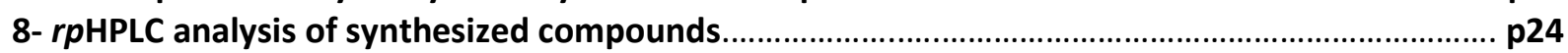

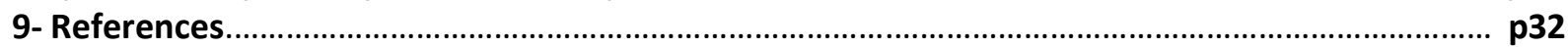




\section{General information}

Solvents were dried using standard methods and distilled before use. Unless otherwise specified, materials were purchased from commercial suppliers and used without further purification. Spectra were recorded on a Bruker AVANCE 400 spectrometer for ${ }^{1} \mathrm{H}(250 \mathrm{MHz}),{ }^{13} \mathrm{C}(63 \mathrm{MHz})$, in $\mathrm{CDCl}_{3}$. Chemical shifts $(\delta)$ are expressed in ppm relative to residual 7.24 for ${ }^{1} \mathrm{H}$ and 77.23 for ${ }^{13} \mathrm{C}$, as internal references. Mass spectroscopy (MS) spectra were carried out on a LCQ-Deca XP-Max spectrometer in positive or negative ionization mode. Heptaprenyl-phosphate was purchased from the Institute of Biochemistry and Biophysics of the Polish Academy of Sciences, Warsaw, Poland.

\section{Mass spectrometry analysis of RNA-containing compounds}

Mass spectrometry analyses of tRNA ${ }^{\text {Gly }}$, azido-RNA, and lipid-carbohydrate-peptidyl-RNA conjugates were performed by LC-MS. Liquid chromatography (LC) was performed by anionic $r p H P L C$ using a DNAPac RP column ( $4 \mu \mathrm{m} ; 2.1 \times 50 \mathrm{~mm}$; Thermo Fisher Scientific) at a flow rate of $300 \mu \mathrm{l} / \mathrm{min}$ with a 0 to $50 \% \mathrm{MeOH}$ linear gradient applied from 2 to $10 \mathrm{~min}$ in Solution $\mathrm{A}$ [Solution $\mathrm{A}$, triethylamine $(15 \mathrm{mM})$ and 1,1,1,3,3,3-hexafluoro-2-propanol (400 mM)]. For mass spectrometry (MS), liquid chromatography was coupled to a LCQ Deca XP-Max mass spectrometer operating in the negative mode.

\section{Enzyme production and purification}

The FmhB glycyl transferase from S. aureus strain Mu50 was produced in E. coli BL21 (DE3) pREP4GroEL as a fusion protein with a C-terminal hexa-histidine tag (GSHHHHHH). FmhB was purified from a clarified lysate by metal affinity (Ni Sepharose 6 Fast flow; General Electrics) and size exclusion chromatography (DEX 75 HR 26/60; General Electrics) in 100 mM phosphate buffer (pH 7.5) containing $500 \mathrm{mM} \mathrm{KCl}$. FmhB was concentrated (10 mg mL ${ }^{-1}$; Amicon Ultra, cutoff $10 \mathrm{kDa}$; Millipore) and stored at $-20^{\circ} \mathrm{C}$ following addition of one volume of glycerol per volume of purified FmhB.

The glycyl-tRNA synthetase of $S$. aureus strain Mu50 was produced in E. coli BL21 (DE3) pREP4GroEL and purified in two steps by metal affinity (Ni Sepharose 6 Fast flow; General Electrics) and anion exchange chromatography (Resource Q; General Electrics), as previously described. ${ }^{[1]}$

The translocase MraY from Aquifex aeolicus (for the synthesis of the lipid intermediate I) and the MurG transferase from E. coli (for the subsequent addition of GIcNAc) were purified as previously described. ${ }^{[2]}$

The concentration of proteins was determined by the Bradford assay (Biorad) using BSA as a standard.

\section{4. tRNA production and purification}

The sequence of the tRNA ${ }^{\text {Gly }}$ used in this study (5'GCGGGAGUAGUUCAACUUUUAGAACACGUUCCUUCCCGGAACGAGGUAUAGGUGUAAAUCCUAUCUUC CGCUCCA-3') corresponds to one of the five tRNA ${ }^{\text {Gly }}$ of $S$. aureus. ${ }^{[3]}$ The matrix used for in vitro transcription was obtained by PCR using three overlapping oligonucleotides that cover the entire sequence of the tRNA and enable the introduction of the T7 promoter (underlined) (5'TTIAATACGACTCACTATAGCGGGAGTAGTTCAACTTTTAGAACA-3', 5' ATAGGATTTACACCTATACCTCGTTCCGGGAAGGAACGTGTTCTAAAAGTTGAACTA-3', and 5'TGGAGCGGAAGATAGGATTTACACCTATA-3'). In vitro transcription of the resulting PCR product $(100 \mu \mathrm{l})$ was performed at $37^{\circ} \mathrm{C}$ for $4 \mathrm{~h}$ in a total volume of $450 \mu \mathrm{l}$ containing NTPs (4 mM each; JenaBioscience), GMP (20 mM), T7 RNA polymerase (45 $\mu \mathrm{g})$, Triton X-100 (0.05\% v/v), $\mathrm{MgCl}_{2}(15 \mathrm{mM})$, spermidine (2 $\mathrm{mM})$, dithiothreitol $(10 \mathrm{mM})$, and Tris- $\mathrm{HCl}(40 \mathrm{mM}, \mathrm{pH} 7.5)$. The reaction mixture was incubated for 20 min at $65^{\circ} \mathrm{C}$, DNAse was added (30 U; RQ1 RNase-Free DNAse, Promega), and incubation was

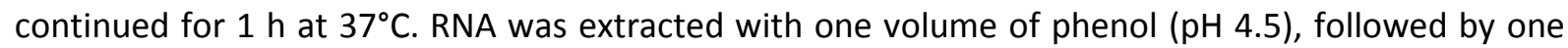
volume of phenol/chloroform $(1 / 1 \mathrm{v} / \mathrm{v})$, and precipitated with 5 volumes of ethanol. RNA was 
centrifuged at $4^{\circ} \mathrm{C}$, dissolved in $100 \mu$ of buffer $\mathrm{A}$ ( $25 \mathrm{mM}$ Tris- $\mathrm{HCl}, \mathrm{pH} 7.5 ; 300 \mathrm{mM} \mathrm{NaCl} ; 5 \mathrm{mM} \mathrm{MgCl}$ ), incubated for $1 \mathrm{~min}$ at $85^{\circ} \mathrm{C}$ and cooled to room temperature for $1 \mathrm{~h}$. The RNA was purified by sizeexclusion chromatography (Superdex ${ }^{\circledast} 75$ HR 10/30, General Electrics) in buffer A. The tRNA was further purified by anion exchange chromatography (DNAPAc PA100; Dionex) with a linear gradient $(25 \mathrm{mM}$ to $2.5 \mathrm{M})$ of ammonium acetate $(\mathrm{pH} 8.0)$ containing $0.5 \%$ acetonitrile $(\mathrm{v} / \mathrm{v})$. The tRNA was lyophilized twice and dissolved in RNAse-free water (Sigma). The purity was assessed by denaturing ( 7 $\mathrm{M}$ urea) polyacrylamide gel electrophoresis (12\%) and by anion exchange chromatography as described above. The concentration of tRNA was determined by amino-acylation as described below (p10).

\section{Semi-synthesis.}

Synthesis of RNAs by solid phase synthesis. The azido-RNA helix used in this study, corresponding to the acceptor arm of $S$. aureus tRNA ${ }^{\text {Gly }}$ described above, was obtained by solid phase synthesis as previously described. ${ }^{[4]}$ The helix consisted of a 7-mer ( $5^{\prime}$-GCGGGAG-3') covalently bound to an 11-mer (5'-CUUCCGCUCCA $\left.-3^{\prime}\right)$ by a hexapolyethylene glycol linker. The ribose at the $3^{\prime}$-terminus of the 11mer contained a 2'-azido moiety. Production of the resin substituted by the 2'-azido nucleotide, the coupling reactions, and the final deprotection step were performed as previously described. ${ }^{[4]}$

Synthesis of D-alanyl-D-lactate (Scheme S1). Synthesis of the depsipeptide D-Ala-D-Lac was performed in two steps. In the first step, Boc-D-Ala-OH $\left(3.8 \mathrm{mmol}, 720 \mathrm{mg}\right.$ ) was dissolved in dry THF at $0^{\circ} \mathrm{C}$. Carbonyldiimidazole $(3.8 \mathrm{mmol}, 617 \mathrm{mg}$ ) was added and the reaction was allowed to proceed for 30 min. D-Lac-OtBu $(3.4 \mathrm{mmol}, 500 \mathrm{mg})$ was dissolved in dry DCM $(10 \mathrm{~mL})$ and slowly added to the Boc-DAla acyl imidazole solution at $0^{\circ} \mathrm{C}$. The mixture was incubated for $24 \mathrm{~h}$ at room temperature. The reaction was quenched with $10 \mathrm{~mL}$ of $2 \mathrm{M}$ acid acetic. The organic phase was washed with $20 \mathrm{~mL}$ of 1 $\mathrm{M} \mathrm{HCl}, 20 \mathrm{~mL}$ of $1 \mathrm{M} \mathrm{NaHCO}_{3}$, and $20 \mathrm{~mL}$ of brine. The organic extract was dried over anhydrous $\mathrm{Na}_{2} \mathrm{SO}_{4}$, filtered, and solvents were removed under reduced pressure. The Boc-D-Ala-D-LacOt-Bu product was recovered as a clear oil ( $1 \mathrm{~g}, 92 \%$ yield) and was used without further purification. In the second step, crude Boc-D-Ala-D-LacOt-Bu ( $3.14 \mathrm{mmol}, 1 \mathrm{~g})$ was dissolved in $10 \mathrm{~mL}$ of DCM, cooled at $0^{\circ} \mathrm{C}, 10 \mathrm{~mL}$ of TFA were slowly added, and the solution was stirred at room temperature for $1 \mathrm{~h}$. DCM and TFA were removed under reduced pressure and D-Ala-D-Lac was recovered as a clear oil $(329 \mathrm{mg}$, $65 \%$ yield). ${ }^{1} \mathrm{H}$ NMR (

$250 \mathrm{MHz}, \mathrm{D}_{2} \mathrm{O}$ ): $\delta 1.58$ (d, 3H, $7 \mathrm{~Hz}$ ); 1.52 (d, 3H, $\left.7 \mathrm{~Hz}\right) ; 4.25$ (q, $\left.1 \mathrm{H}, 7 \mathrm{~Hz}\right) ; 5.19$ (q, $\left.\left.1 \mathrm{H}, 7 \mathrm{~Hz}\right) . \mathrm{MS}_{(\mathrm{ESI}}{ }^{+}\right)$ calculated for $\mathrm{C}_{6} \mathrm{H}_{12} \mathrm{NO}_{4}{ }^{+}$162.1, found 162.1 .

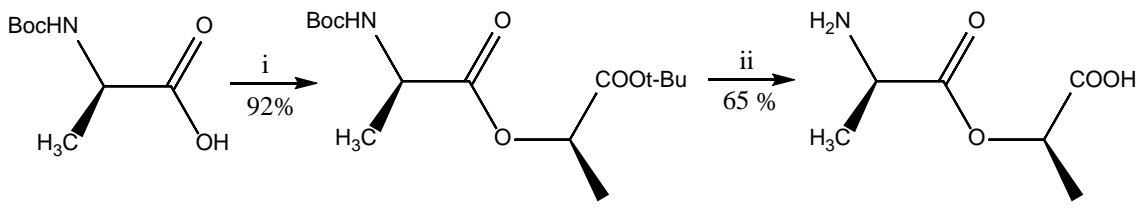

Scheme S1. (i) CDI; D-LacOt-Bu; (ii) TFA/DCM (1/1 v/v)

Synthesis of alkyne-containing UDP-MurNAC-peptide analogues ending in D-Ala or D-Lac (Scheme S2, $6 a$ and $6 b)$.

Semi-synthesis of the analogues involved five steps, as previously described. ${ }^{[5]}$ (i) One pot addition of L-Ala, D-Glu, meso-cystine to uridine di-phospho- $N$-acetyl-muramic acid (UDP-MurNAc) by synthetases MurC, MurD, and MurE, respectively. (ii) Addition of D-Ala-D-Ala or D-Ala-D-Lac to UDP-MurNActripeptide by synthetase MurF. (iii) Reduction of the cystinyl residue of the resulting UDP-MurNAcpentapeptide and -depsipentapeptide analogues by DTT (20 mM) in Tris- $\mathrm{HCl}(50 \mathrm{mM}$; pH 8.0) at RT for $2 \mathrm{~h}$. Yields: $90 \%$ for both D-Ala- and D-Lac-ending anlogues. (iv) Oxidation-elimination of the sulfhydryl 
group of L-Cys with O-mesitylenesulfonylhydroxylamine (MSH) $(20 \mathrm{mM})$ in DMF-phosphate buffer (50 $\mathrm{mM}$; $\mathrm{pH} 8.0)(4 / 6, \mathrm{v} / \mathrm{v})$ for 2 hours at RT. Yield: $28 \%$ for $5 \mathrm{a}$ ( $\mathrm{v}$ ) Addition of 3-butyne-1-thiol $(50 \mathrm{mM})$ to the resulting dehydroalanyl residue $(0.5 \mathrm{mM})$ in DMF-phosphate buffer $(100 \mathrm{mM}$; pH 8.0) $(1 / 19, \mathrm{v} / \mathrm{v})$ for $2.5 \mathrm{~h}$ at $37^{\circ} \mathrm{C}$. After addition of 1 volume of buffer $\mathrm{A}$ ( $50 \mathrm{mM}$ ammonium acetate, $\mathrm{pH} 5.0$ ), the desired isomer (depicted in Scheme 2) was purified by rpHPLC (EC 250/4.6 Nucleosil 100-5 $\mathrm{C}_{18}$; Macherey Nagel) with a linear gradient of acetonitrile ( 0 to $5 \%$ ) in ammonium acetate ( $50 \mathrm{mM} ; \mathrm{pH} 5.0)$ applied between 10 and $40 \mathrm{~min}$ at a flow rate of $1 \mathrm{~mL} \mathrm{~min}^{-1}$. The $S$ and $R$ isomers eluted at 34.7 and $36.9 \mathrm{~min}$ for the analogues ending in D-Ala (Figure S1). The S and R isomers eluted at 35.5 and $39.7 \mathrm{~min}$ for the D-Lac-ending analogues. The final products, $\mathbf{6 a}$ and $\mathbf{6 b}$, were lyophilized twice and dissolved in RNAse free water (Sigma-Aldrich). Purity of the two diastereoisomers was assessed by mass spectrometry and analytical $r p H P L C$ with a linear gradient of acetonitrile (0 to $15 \%)$ in ammonium acetate $\left(50 \mathrm{mM}\right.$; pH 5.0) applied between 10 and $40 \mathrm{~min}\left(260 \mathrm{~nm}, 1 \mathrm{~mL} \mathrm{~min}^{-1} ; \mathrm{RT}=24.4 \mathrm{~min}\right.$ and 26.8 min for the $(R)$ diastereoisomers ending in D-Ala (6a) and D-Lac (6b), respectively. Concentrations were determined by spectrophotometry $\left(\varepsilon_{260 \mathrm{~nm}}=10,000 \mathrm{M}^{-1} \mathrm{~cm}^{-1}\right)$. Yields: $19.3 \%$ and $19.6 \%$ for $\mathbf{6 a}$ and $\mathbf{6 b}$, respectively.
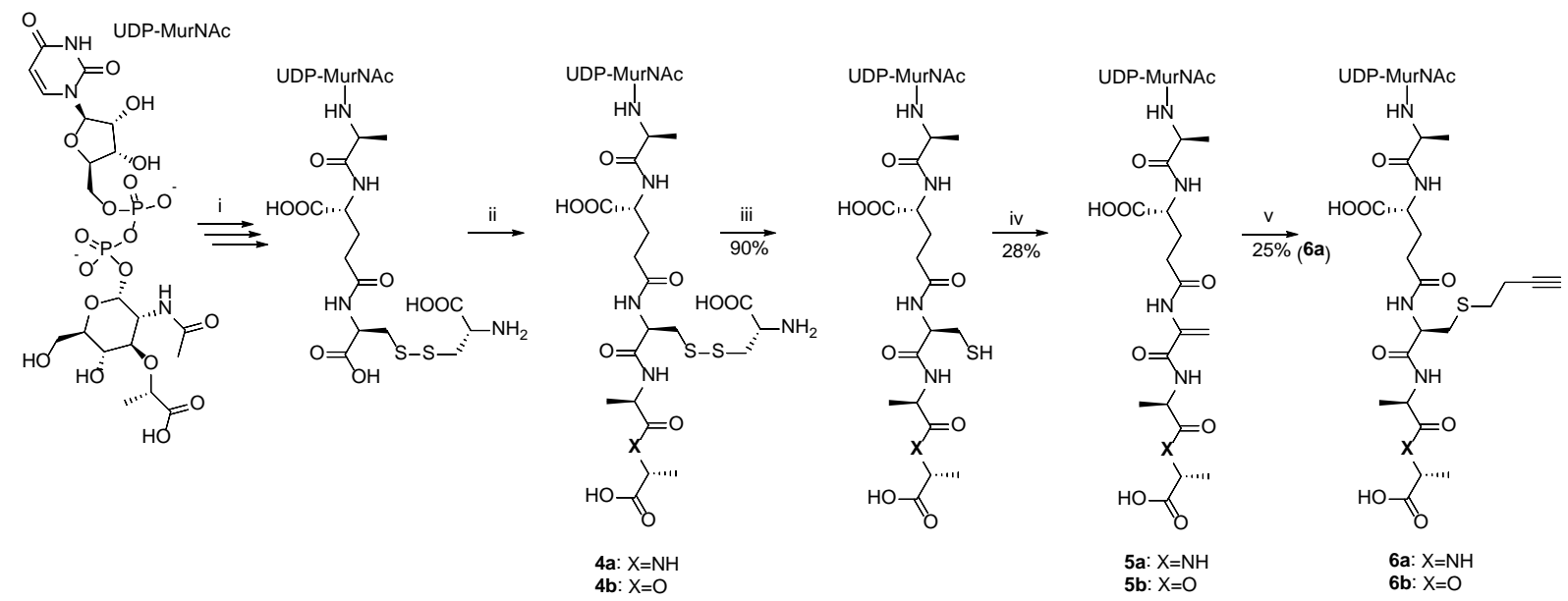

Scheme S2. (i) 1. L-Ala, MurC; 2. D-Glu, MurD; 3. meso-cystine, MurE; (ii) D-Ala-D-Ala or D-Ala-D-Lac, MurF; (iii) DTT, Tris-HCl buffer, pH 8.0, 2 h, RT; (iv) MSH, DMF, 2 h, RT; (v) 3-butyne-1-thiol, DMF, 2 h, $37^{\circ} \mathrm{C}$.

Alternative one pot procedure for conversion of meso-cystine to dehydroalanine in nucleotide precursors (Scheme S3, 5a and 5b). The preceding procedure requires purification of the intermediate obtained by reduction of meso-cystine since DTT is not compatible with MSH-mediated oxidationelimination. A less effort-consuming method was therefore developed based on the one pot reaction depicted in Scheme 3. The method is based on disulfide reduction by a water soluble tris(2carboxyethyl)phosphine (TCEP) coupled to 2,5-dibromohexanediamide. Briefly, the mixture comprised meso-cystine-containing precursors ending in D-Ala or D-Lac $(0.5 \mathrm{M})$, TCEP $(20 \mathrm{mM})$, tris- $(2,5-$ dibromohexanediamide) (100 mM), potassium phosphate $(100 \mathrm{mM}, \mathrm{pH} 8.0)$, and $20 \%$ DMF. The solution of tris-(2,5-dibromohexanediamide) was freshly prepared in DMF. Incubation was performed for $1 \mathrm{~h}$ at $37^{\circ} \mathrm{C}$. The products of the reaction were purified in two steps. (i) Size-exclusion chromatography (SuperDexpeptide 10/300 GL, general Electrics) in water ( $260 \mathrm{~nm}, 1 \mathrm{~mL} \mathrm{~min}^{-1}$; RT = $8.1 \mathrm{~min}$ ). (ii) $r p H P L C$ (EC 250/22 Nucleosil 100-5 C 18 ; Macherey Nagel) with a linear gradient of acetonitrile (0 to $15 \%)$ in ammonium acetate $(50 \mathrm{mM}$; pH 5.0) applied between 10 and $40 \mathrm{~min}$ (260 $\left.\mathrm{nm}, 10 \mathrm{~mL} \mathrm{~min}^{-1}\right)$. RTs $=16.8 \mathrm{~min}$ and $18.6 \mathrm{~min}$ for $\mathbf{5 a}$ and $\mathbf{5 b}$, respectively. Yields: $30 \%$ and $22 \%$ (calculated for two steps) for $\mathbf{5 a}$ and $\mathbf{5 b}$, respectively. 


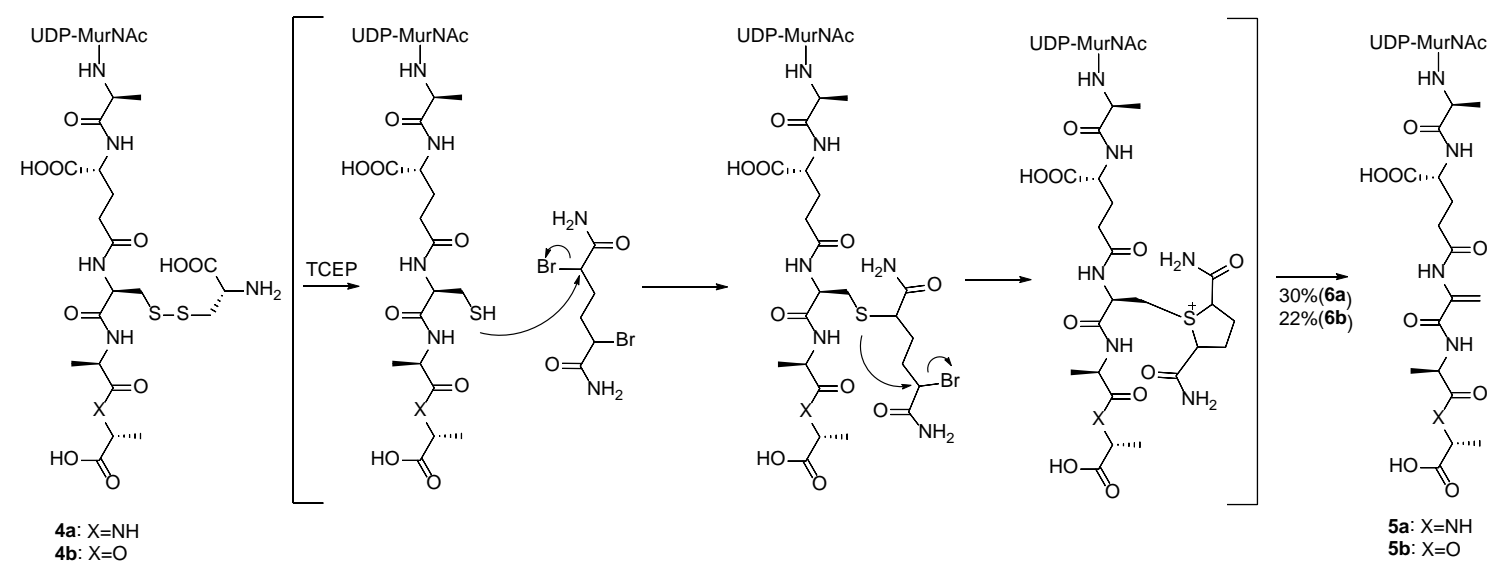

Scheme S3. Mechanism for one pot conversion of meso-cystine to dehydroalanine
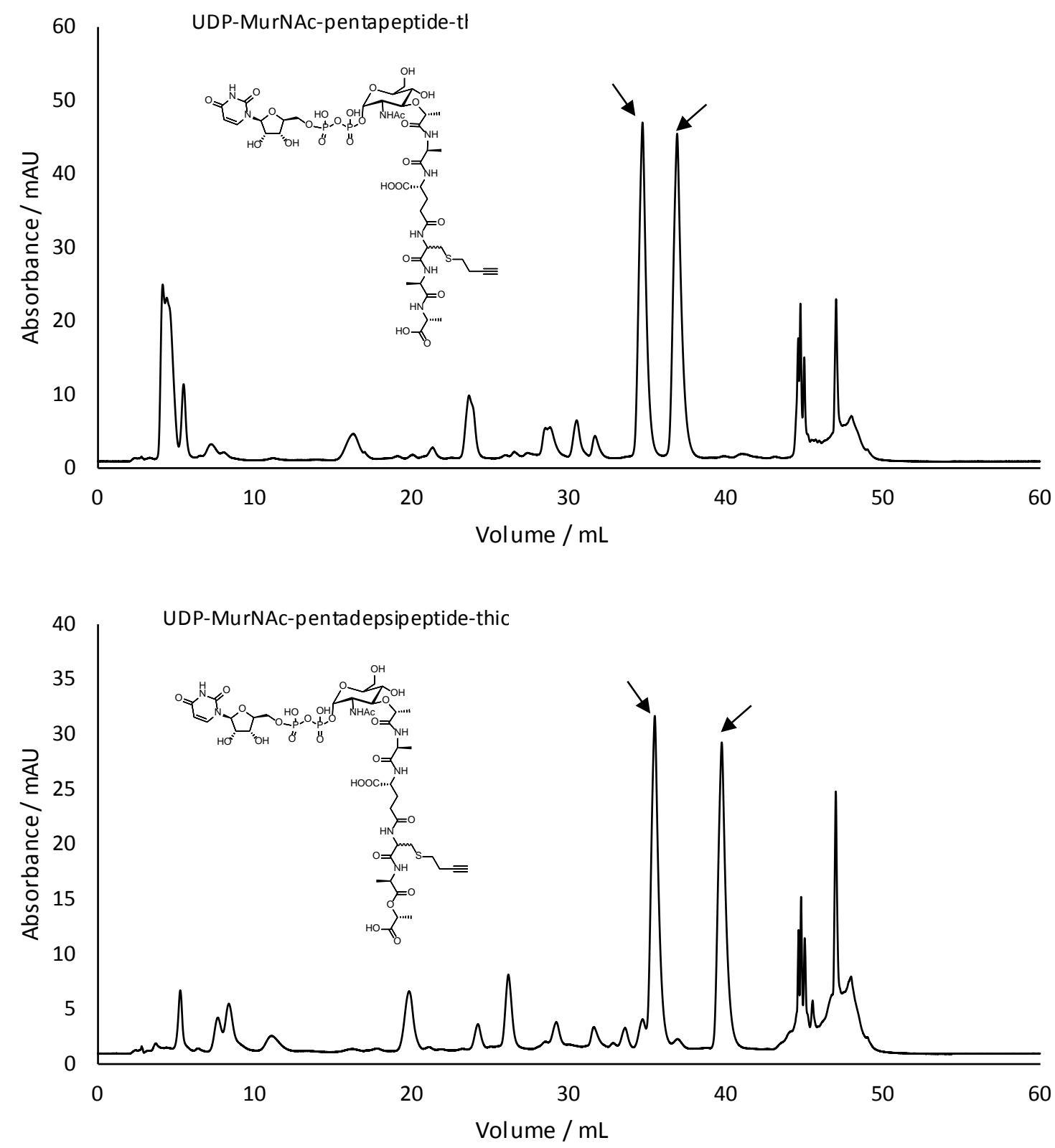
Figure S1. $r p H P L C$ resolution of diastereoisomers generated by 1,4-addition of 3-butyne-1-thiol to the dehydroalanine of UDP-MurNAc-peptide analogues.

Purification of nucleotide precursors from bacterial extracts (1a and 1b). UDP-MurNAcpentapeptide (ending in D-Ala-D-Ala, 1a) or UDP-MurNAc-pentadepsipeptide (ending in D-Ala-D-Lac, 1b) were purified from vancomycin-susceptible E. faecalis ${ }^{[6]}$ and vancomycin-resistant $S$. aureus, ${ }^{[7]}$ as previously described. ${ }^{[8]}$ Briefly, bacteria were grown at $37^{\circ} \mathrm{C}$ in $2 \mathrm{~L}$ of brain heart infusion (BHI) broth, containing $50 \mu \mathrm{g} \mathrm{mL} \mathrm{L}^{-1}$ of vancomycin to induce production of UDP-MurNAc-pentadepsipeptide $\mathbf{1 b}$ by the $S$. aureus strain. Bacteria were grown to an optical density of 0.7 at $600 \mathrm{~nm}$ and further incubated in the presence of bacitracin $\left(200 \mu \mathrm{g} \mathrm{mL}^{-1}\right)$ for $30 \mathrm{~min}$ at $37^{\circ} \mathrm{C}$. Bacteria were collected by centrifugation and ice-cold formic acid ( $30 \mathrm{~mL}, 1.1 \mathrm{M}$ ) was rapidly added to the pellet. Peptidoglycan precursors were extracted for $30 \mathrm{~min}$ at $4^{\circ} \mathrm{C}$ under gentle agitation. After centrifugation $(7,000 \times \mathrm{g} ; 15 \mathrm{~min})$ the supernatant was filtrated, desalted on a G-25 column, and lyophilized. Peptidoglycan precursors were purified by rpHPLC with a preparative C18 column (5 $\mu \mathrm{m} ; 22 \times 250 \mathrm{~mm}$; Nucleosil, Macherey-Nagel) equilibrated with ammonium formate buffer $\left(50 \mathrm{mM}\right.$; pH 5.0) at a flow rate of $10 \mathrm{~mL} \mathrm{~min}^{-1}$. A linear gradient of methanol was applied from 0 to $20 \%$ between 10 and 40 min. Fractions containing the precursors were identified by mass spectrometry and lyophilized. The precursors were dissolved in water and quantified by UV absorption at $260 \mathrm{~nm}\left(\varepsilon_{260 \mathrm{~nm}}=10,000 \mathrm{M}^{-1} \cdot \mathrm{cm}^{-1}\right)$. Yield: $500 \mathrm{nmol}$ per litter of bacterial culture.

Synthesis of heptaprenyl-containing lipid II analogues (Scheme S4, 2a, 2b, and 7a). Synthesis of the lipid II analogues containing a heptaprenyl moiety, instead of the undecaprenyl moiety present in the peptidoglycan precursors, was performed in a one pot enzymatic reaction containing MraY from $A$. aeolicus, MurG from E. coli, nucleotide precursors, and heptaprenyl-phosphate, as previously described ${ }^{[9]}$ with minor modifications. Briefly, the synthesis of the lipid II analogues was performed for $18 \mathrm{~h}$ at $37^{\circ} \mathrm{C}$ in a volume of $40 \mu$ containing Tris- $\mathrm{HCl}(50 \mathrm{mM}$; pH 8.0), heptaprenyl-phosphate ammonium salt (15 mM), UDP-MurNAc-pentapeptide (12.5 mM), UDP-MurNAc-pentadepsipeptide or the alkyne containing analogue of the former nucleotide $(12.5 \mathrm{mM})$, uridine $5^{\prime}$-diphospho- $\mathrm{N}$ acetylglucosamine (UDP-GIcNAc) sodium salt (15 mM; Sigma-Aldrich), $\mathrm{MgCl}_{2}$ (10 mM), $\mathrm{NaCl}(50 \mathrm{mM})$, $\mathrm{N}, \mathrm{N}$-dimethyldodecylamine $\mathrm{N}$-oxide (LDAO; $10 \mathrm{mM}$; Sigma-Aldrich), dimethyl sulfoxide (DMSO; $2 \% \mathrm{v} / \mathrm{v}$; Sigma-Aldrich), MraY $\left(1 \mathrm{mg} \mathrm{mL}^{-1}\right)$, and MurG $\left(0.5 \mathrm{mg} \mathrm{mL}^{-1}\right)$. The reagents were added to lyophilized heptaprenyl-phosphate. Cefoxitine $\left(40 \mu \mathrm{g} \mathrm{mL}^{-1}\right)$ and meropenem $\left(40 \mu \mathrm{g} \mathrm{mL}^{-1}\right)$ were also present in the

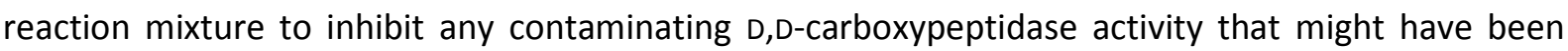
present in the MraY or MurG preparations. After $18 \mathrm{~h}$ of incubation, the reaction mixture was centrifuged $(12,000 \times \mathrm{g}$ for $10 \mathrm{~min}$ at room temperature), $80 \mu \mathrm{l}$ of buffer $\mathrm{A}$ ( $20 \mathrm{mM}$ ammonium carbonate containing $50 \%$ methanol $(\mathrm{v} / \mathrm{v})$ were added to the supernatant, and the lipid II analogues were purified by rpHPLC (EC 250/4.6 Nucleosil 100-5 $\mathrm{C}_{8}$; Macherey Nagel) with a linear gradient (0 to $100 \%$ ) of buffer B ( $80 \%$ methanol, $20 \%$ isopropanol; v/v) applied between $5 \mathrm{~min}$ and $35 \mathrm{~min}$ at a flow rate of $1 \mathrm{~mL} \mathrm{~min}$. The lipid II analogues were detected by the absorbance at $214 \mathrm{~nm}$ and analyzed by mass spectrometry in the negative mode (LCQ Deca XP-Max; Thermofisher). The concentration of lipid II analogues was determined by amino acid analysis after acid hydrolysis and injection into a Hitachi L8800 amino acid analyzer equipped with a 2620 MSC-PS column. 

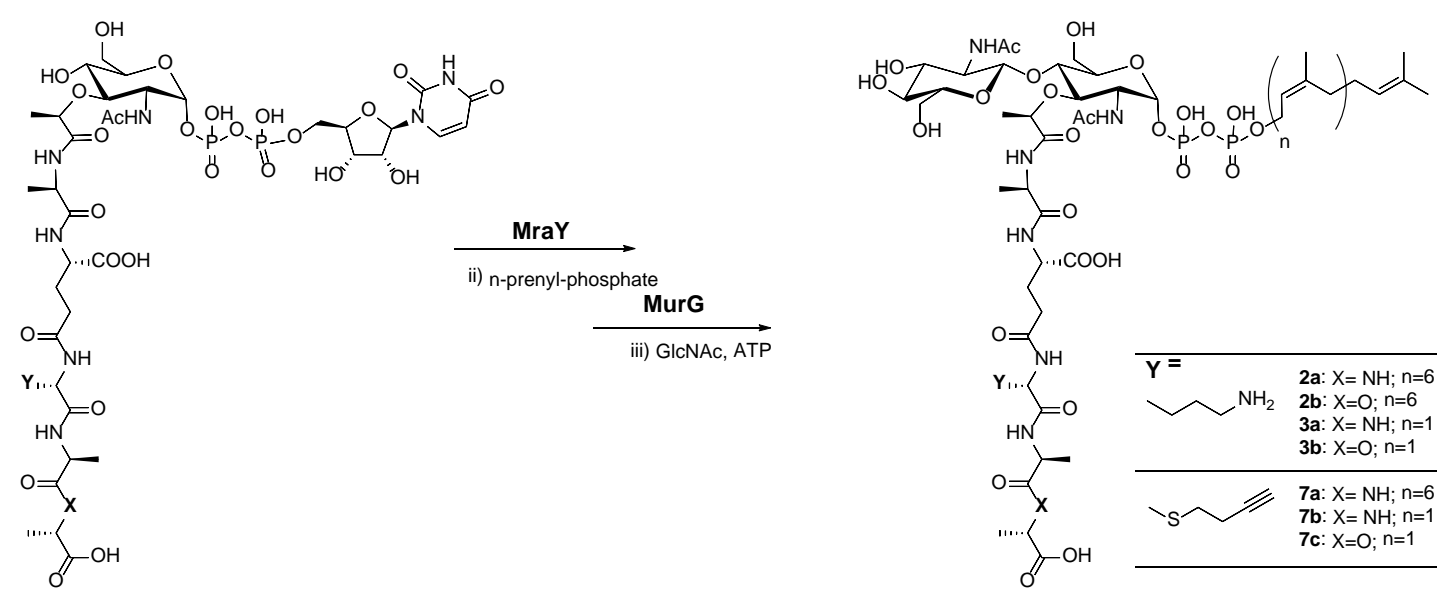

Scheme S4. One pot enzymatic synthesis of lipid II analogues. heptaprenyl-phosphate, $n=6$; nerylphosphate $n=1$.

Synthesis of neryl-containing lipid II analogues used as substrates of FmhB (Scheme S4, 3a, 3b, 7b, and 7c). Soluble lipid II analogues containing a neryl group were obtained in a one pot enzymatic reaction containing MraY from A. aeolicus, MurG from E. coli, nucleotide precursors ending in D-Ala ${ }^{5}$ or D-Lac ${ }^{5}$, and neryl-phosphate $(Z, w)$ (Sigma-Aldrich), as previously described, ${ }^{[9]}$ with minor modifications. Briefly, the synthesis of lipid II analogues was performed in a volume of $40 \mu \mathrm{l}$ containing Tris- $\mathrm{HCl}(50 \mathrm{mM} ; \mathrm{pH} 8.0)$, neryl-phosphate litium salt $(15 \mathrm{mM})$, nucleotide precursors $(12.5 \mathrm{mM})$, uridine $5^{\prime}$-diphospho- $N$-acetylglucosamine (UDP-GlcNAc) sodium salt (15 mM; Sigma-Aldrich), $\mathrm{MgCl}_{2}$ $(10 \mathrm{mM}), \mathrm{NaCl}(50 \mathrm{mM})$, Tween20 $(5 \mathrm{mM}), \operatorname{MraY}\left(1 \mathrm{mg} \mathrm{mL}^{-1}\right)$, MurG $\left(0.5 \mathrm{mg} \mathrm{mL}^{-1}\right)$. The reagents were added to lyophilized neryl-phosphate lithium salt. Cefoxitine $\left(40 \mu \mathrm{g} \mathrm{mL}^{-1}\right)$ and meropenem $\left(40 \mu \mathrm{g} \mathrm{mL}^{-}\right.$ $\left.{ }^{1}\right)$ were also present in the reaction mixture to inhibit any contaminating D,D-carboxypeptidase activity that might have been present in the MraY or MurG preparations.

After $18 \mathrm{~h}$ of incubation at $37^{\circ} \mathrm{C}$, the reaction mixture was centrifuged $(12,000 \times \mathrm{g}$ for $10 \mathrm{~min}$ at room temperature), $80 \mu \mathrm{l}$ of buffer $\mathrm{A}$ ( $20 \mathrm{mM}$ ammonium carbonate) were added to the supernatant, and the lipid II analogues were purified by rpHPLC (EC 250/4.6 Nucleosil 100-5 C $_{8}$; Macherey Nagel) with a linear gradient of methanol (0 to 50\%) in buffer A applied between $6.5 \mathrm{~min}$ and $36.5 \mathrm{~min}$ at a flow rate of $1 \mathrm{~mL} \mathrm{~min}{ }^{-1}$. The lipid II analogues, detected by the absorbance at $214 \mathrm{~nm}$ and identified by mass spectrometry in the negative mode (LCQ Deca XP-Max; Thermofisher), were lyophilized and dissolved in RNAse free water (Sigma-Aldrich). The concentration of lipid II analogues was determined by amino acid analysis after acid hydrolysis and injection into a Hitachi $\mathrm{L} 8800$ amino acid analyzer equipped with a 2620 MSC-PS column. The purity of the lipid II analogues was assessed by rpHPLC (EC 250/4.6 Nucleosil 100-5 $\mathrm{C}_{18}$; Macherey Nagel) with a linear gradient of acetonitrile (0 to $50 \%$ ) in ammonium formate (10 mM; pH 5.0) applied between 6.5 and $36.5 \mathrm{~min}$ at a flow rate of $1 \mathrm{~mL} \mathrm{~min}$.

Synthesis of heptaprenyl-PP-disaccharide-peptide-RNA (8a, Scheme S5). For the heptaprenylcontaining analogue, the Huisgen-Sharpless cycloaddition reaction was performed in a volume of 20 $\mu \mathrm{l}$ containing the lipid II analogue $(110 \mu \mathrm{M})$, the azido-RNA helix $(62 \mu \mathrm{M}$; figure S2b), tris(3hydroxypropyltriazolylmethyl)amine (THPTA) $(3.5 \mathrm{mM})$, copper sulfate $(0.5 \mathrm{mM})$, sodium ascorbate $(10 \mathrm{mM})$, and sodium phosphate $(100 \mathrm{mM} ; \mathrm{pH} 8.0)$. The reaction was allowed to proceed at $37^{\circ} \mathrm{C}$ for $18 \mathrm{~h}$. The peptidyl-RNA was purified by denaturing polyacrylamide gel electrophoresis. Briefly, the gel $(20 \times 20 \times 0.1 \mathrm{~cm})$, [acrylamide $(12 \%, w / v)$, bis-acrylamide $(4.4 \%, w / v)$, urea $(8 \mathrm{M})$, tetramethylethylenediamine (TEMED, $0.04 \% \mathrm{v} / \mathrm{v})$, ammonium persulfate $(0.08 \% \mathrm{w} / \mathrm{v}$ ), and TBE buffer ( $89 \mathrm{mM}$ Tris, $89 \mathrm{mM}$ boric acid, $2 \mathrm{mM}$ EDTA, pH 8.2)] was loaded (lane width $6 \mathrm{~mm}$ ) with the crude cycloaddition reaction $(20 \mu \mathrm{l})$, which was lyophilized, dissolved in $2 \mu \mathrm{l}$ of DMF, and supplemented with $5 \mu \mathrm{l}$ of loading buffer [ $50 \%$ glycerol v/v containing $0.25 \%(\mathrm{w} / \mathrm{v})$ bromophenol blue]. Electrophoresis was performed for $100 \mathrm{~min}$ at $600 \mathrm{~V}$. The gel was stained with ethidium bromide $\left(0.5 \mathrm{mg} \mathrm{mL}^{-1}\right)$ and 
imaged with a Herolab E.A.S.Y 429K camera. RNA-containing band was cut off from gel with a sterile scalpel (Figure S2a) and electroeluted in TBE buffer for $2 \mathrm{~h}$ at $100 \mathrm{~V}$ in MINI GeBaFlex-tube, $8 \mathrm{kDa}$ cutoff; Gene Bio-Application, L.T.D.). The potential was inverted for $30 \mathrm{~s}$ and the lipid analogue was dialyzed for $30 \mathrm{~min}$ against RNAse-free water (Sigma). The concentration of peptidyl-RNA adduct was determined by spectrophotometry $\left(\varepsilon_{260 \mathrm{~nm}}=180,000 \mathrm{M}^{-1} \mathrm{~cm}^{-1} ; 232 \mathrm{pmol}\right.$; yield: $\left.18 \%\right)$ and analyzed by LC-MS.

Synthesis of neryl-PP-disaccharide-peptide-RNA (8b and 8c, Scheme S5). For neryl-containing analogues, the Huisgen-Sharpless cycloaddition reaction was performed in a volume of $10 \mu \mathrm{l}$ containing lipid II analogues (1 $\mathrm{mM})$, the azido-RNA helix $(0.5 \mathrm{mM})$, tris(3hydroxypropyltriazolylmethyl)amine (THPTA) $(3.5 \mathrm{mM})$, copper sulfate $(0.5 \mathrm{mM})$, sodium ascorbate $(10 \mathrm{mM})$, sodium phosphate (100 mM; pH 8.0). The lipid II analogues and the azido-RNA helix were lyophilized together prior to the addition of the remaining components. Incubation was performed in a PCR thermocycler at $37^{\circ} \mathrm{C}$ for $2 \mathrm{~h}$. The peptidyl-RNAs were purified by anion exchange chromatography (DNAPAc PA100; Dionex) with a linear gradient ( $25 \mathrm{mM}$ to $2.5 \mathrm{M}$ ) of ammonium acetate ( $\mathrm{pH} 8.0$ ) containing $0.5 \%$ acetonitrile $(\mathrm{v} / \mathrm{v}$ ), which was applied between 8.5 and $33.5 \mathrm{~min}$ (Figure S2 $\mathrm{c}$ and d). The peptidyl-RNA adducts were lyophilized twice and dissolved in RNAse-free water (Sigma). The purity of peptidyl-RNA adducts was assessed by denaturing ( $7 \mathrm{M}$ urea) polyacrylamide gel electrophoresis (12\%), by anion exchange chromatography, and by LC-MS. The concentration of peptidyl-RNA adducts was determined by spectrophotometry $\left(\varepsilon_{260 \mathrm{~nm}}=180,000 \mathrm{M}^{-1} \mathrm{~cm}^{-1}\right)$.
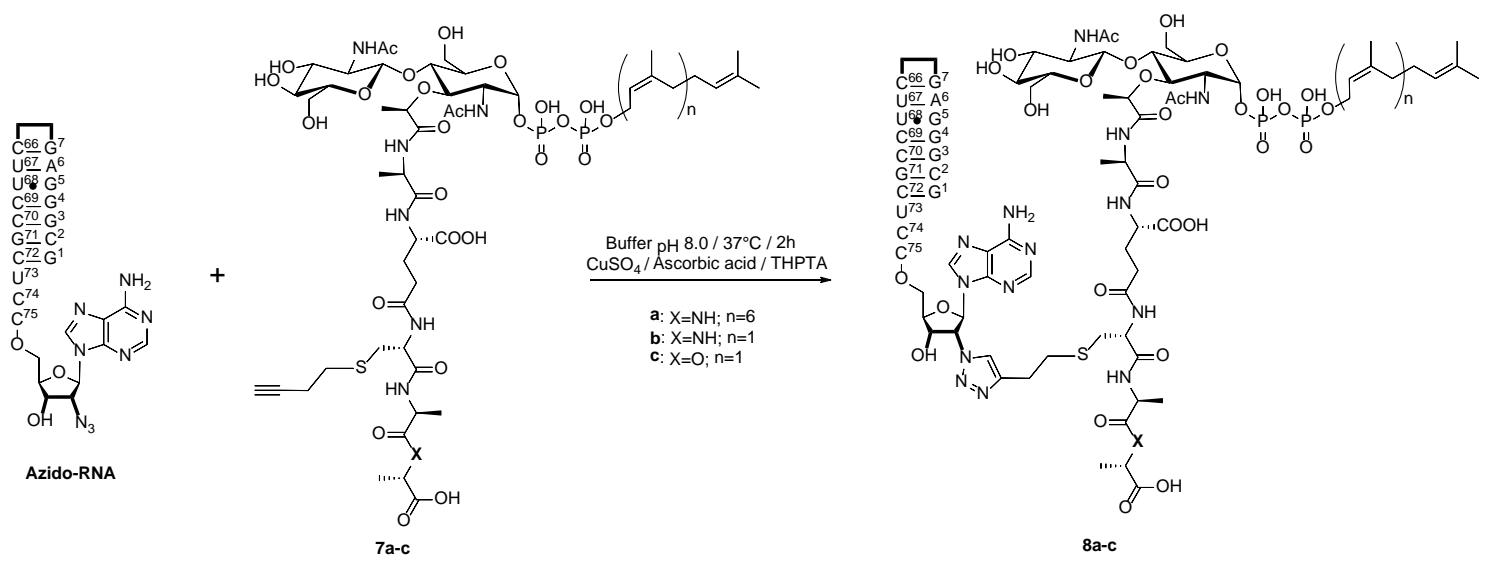

Scheme S5. Coupling of lipid II analogues to RNA by click chemistry. Phosphate buffer, $2 \mathrm{~h}, 37^{\circ} \mathrm{C} ; 2^{\prime}-\mathrm{N}_{3}-$ $\mathrm{RNA} ; \mathrm{CuSO}_{4}$, THPTA, sodium ascorbate, $2 \mathrm{~h}$. Heptaprenyl-phosphate, $\mathrm{n}=6$; neryl-phosphate, $\mathrm{n}=1$. 

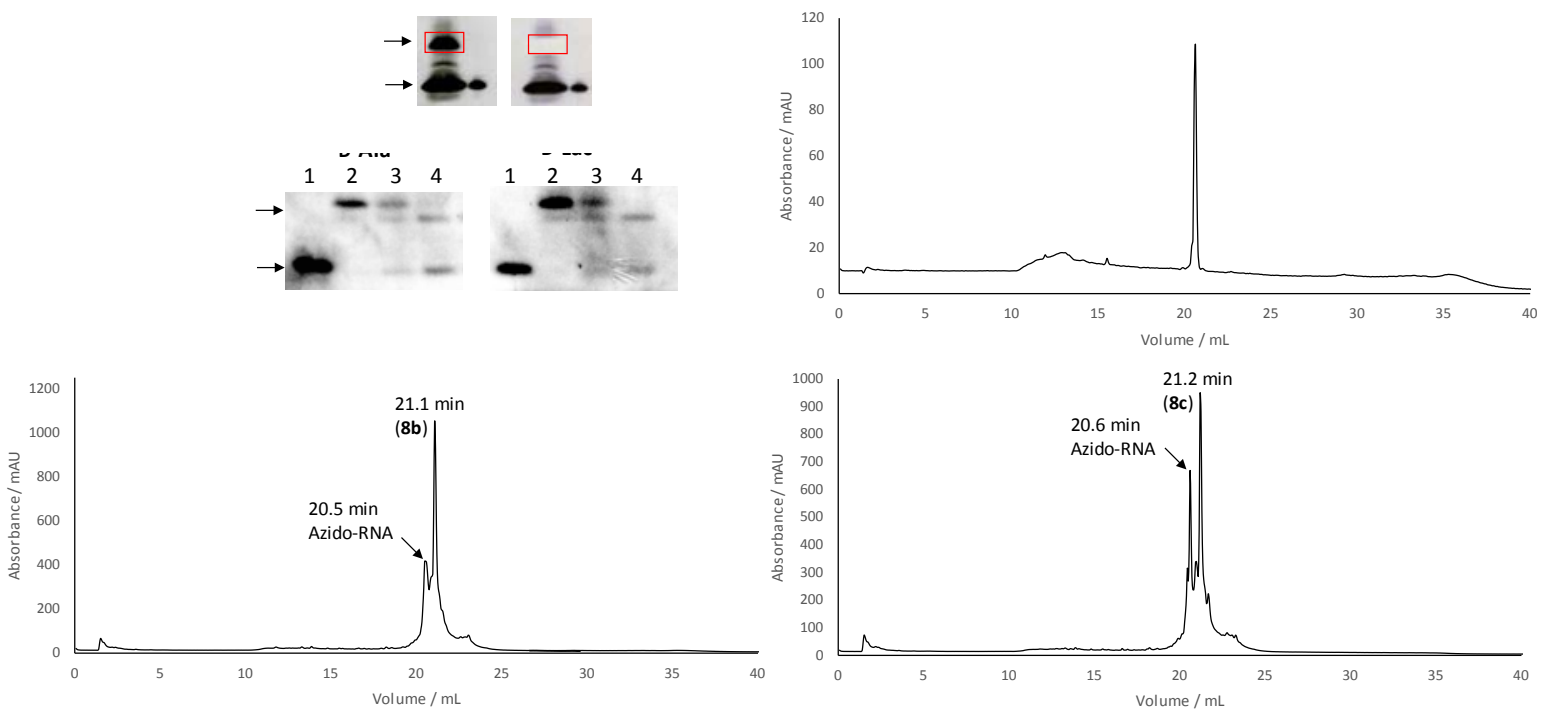

Figure S2. (a) Upper panels: purification of the heptaprenyl-PP-disaccharide-peptidyl-RNA conjugate (8a) by denaturing polyacrylamide gel electrophoresis. Lane 1, reaction; lane 2, purified azido-RNA (160 pmoles). The red box indicates the portion of the gel containing the band of interest prior (left panel) and after (right panel) excision. Lower panels: Analyses of $r p H P L C$ purifications of the cycloaddition of azido-RNA with alkyne-containing neryl-PP-disaccharide-peptide ending in D-Ala or DLac. lane 1, purified azido-RNA (250 pmoles), lanes 2 to $4, r p H P L C$ fractions from panel b and c. (b) $r p H P L C$ analysis of purified azido-RNA by anionic $r p H P L C$ (RT $=20.6 \mathrm{~min}$ ). (c and d) Purification of nerylPP-disaccharide-peptidyl-RNA conjugates ending in D-Ala (8b) or D-Lac (8c). Anionic rpHPLC was performed on an analytical DNAPac PA-100 column (Thermofisher Scientific, $4.6 \times 250 \mathrm{~mm}$ ) at a flow rate of $1 \mathrm{~mL} \mathrm{~min}^{-1}$ with a linear gradient (0 to 100\% B) applied between 8 and $33 \mathrm{~min}$. Buffer $A, 25 \mathrm{mM}$ ammonium acetate ( $\mathrm{pH} 8.0)$ containing $0.5 \% \mathrm{ACN}(\mathrm{v} / \mathrm{v})$. Buffer $\mathrm{B}, 2.5 \mathrm{M}$ ammonium acetate $(\mathrm{pH} 8.0)$ containing $0.5 \% \mathrm{ACN}(\mathrm{v} / \mathrm{v})$. Absorbance was monitored at $260 \mathrm{~nm}$.

\section{Enzymatic assays}

Aminoacylation of tRNA ${ }^{\text {Gly }}$ by the GlyRS amino-acyl-tRNA synthetase. The acceptor capacity of tRNA ${ }^{\text {Gly }}$ obtained by in vitro transcription was evaluated in a volume of $15 \mu$ l containing RNA (ca. $3 \mu \mathrm{M}$, as determined by spectrophotometry, $\left.\varepsilon_{260 \mathrm{~nm}}=708,000 \mathrm{M}^{-1} \mathrm{~cm}^{-1}\right)$, GlyRS (0 to $800 \mathrm{nM}$ ), $\left[{ }^{14} \mathrm{C}\right] \mathrm{Gly}$ (3.74 $\mathrm{GBq} / \mathrm{mmol}, 20 \mu \mathrm{M})$, ATP (2.5 mM), Tris-HCl (25 mM; pH 7.5), $\mathrm{MgCl}_{2}$ (7.5 mM), KCl (12.5 mM), DTT (2 $\mathrm{mM})$, and $\mathrm{BSA}\left(0.1 \mathrm{mg} \mathrm{mL}^{-1}\right)$. The reaction mixture was incubated for $8 \mathrm{~min}$ at $30^{\circ} \mathrm{C}$ and the acylated $\left[{ }^{14} \mathrm{C}\right]$ Gly-tRNA ${ }^{\text {Gly }}$ was precipitated by the addition of $1 \mathrm{~mL}$ of cold trichloroacetic acid (7\%) containing $0.5 \%$ casaminoacid $(\mathrm{w} / \mathrm{v})$. The precipitate was filtrated on a GF/C Whattmann filter previously washed three times with $1 \mathrm{~mL}$ of the TCA-casamino acids solution. The filters were washed three times with 1 $\mathrm{mL}$ of the TCA-casamino acids solution and dried at room temperature for $30 \mathrm{~min} .\left[{ }^{14} \mathrm{C}\right] \mathrm{Gly}$-tRNA ${ }^{\mathrm{Gly}}$ was determined with a Beckmann Coulter LS6500 liquid scintillation counter (Figure S3). 


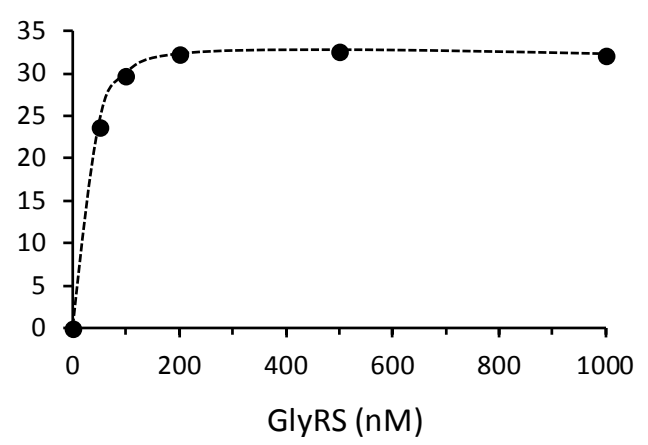

Figure S3. Enzymatic determination of tRNA ${ }^{\text {Gly }}$. The reaction mixtures contained 45 pmoles of tRNA ${ }^{\text {Gly }}$ based on spectrophotometry $\left(\varepsilon_{260 \mathrm{~nm}}=708,000 \mathrm{M}^{-1} \mathrm{~cm}^{-1}\right)$. The radioactive assay indicates that 32 pmoles $(71 \%)$ of tRNA ${ }^{\text {Gly }}$, as determined by spectrophotometry, were acylated by GlyRS.

FmhB-GlyRS coupled assay. The FmhB transferase catalyzes the transfer of a glycyl residue from GlytRNA ${ }^{\text {Gly }}$ to the lipid II peptidoglycan precursor (Figure S4). In this study, Gly-tRNA ${ }^{\text {Gly }}$ was generated in the reaction mixture by a high concentration of GlyRS that maintains full acylation of tRNA ${ }^{\text {Gly }}$ during the entire time course of the reaction (Figure S3, above). ${ }^{[1]}$ The reaction mixture $(25 \mu \mathrm{L})$ contained GlyRS $(0.8 \mu \mathrm{M})$, heptaprenyl- or neryl-containing lipid II analogues $(30 \mu \mathrm{M}),\left[{ }^{14} \mathrm{C}\right] \mathrm{Gly}(50 \mu \mathrm{M} ; 3.74$ $\mathrm{GBq} / \mathrm{mmol}^{2}$, tRNA ${ }^{\mathrm{Gly}}(0.4 \mu \mathrm{M})$, Tris- $\mathrm{HCl}(50 \mathrm{mM} ; \mathrm{pH} 7.5), \operatorname{ATP}(7.5 \mathrm{mM}), \mathrm{MgCl}_{2}(12.5 \mathrm{mM})$ and DTT (2 $\mathrm{mM})$. The reaction was initiated by the addition of $\mathrm{FmhB}(0.05 \mu \mathrm{M}$ and $0.17 \mu \mathrm{M}$ for heptaprenyl- and neryl-containing lipid II, respectively). The heptaprenyl-containing lipid II analogues were extemporaneously lyophilized prior to dissolution in a $10 \%$ Triton $^{\mathrm{TM}} \mathrm{X}-100$ solution. The final concentration of Triton ${ }^{\mathrm{TM}} \mathrm{X}-100$ in the assay was $1 \%$. The inhibitors were used at concentrations ranging from 0 to $2.5 \mu \mathrm{M}$. The reactions were allowed to proceed at $30^{\circ} \mathrm{C}$ and aliquots $(2 \mu \mathrm{l})$ were withdrawn at $1,10,20,30,40,50,60,90$, and $120 \mathrm{~min}$. The reactions were stopped at $80^{\circ} \mathrm{C}$ for $2 \mathrm{~min}$, cooled in ice for $1 \mathrm{~min}$, and centrifuged at 12,000 $\mathrm{g} g$ for $5 \mathrm{~min}$. The supernatants were spotted on chromatography paper (Whatman 4MM, Elancourt, France) or on pre-coated cellulose TLC-sheet (ALUGRAM CEL 300; Macherey-Nagel) for heptaprenyl- and neryl-containing lipid II, respectively. $\left[{ }^{14} \mathrm{C}\right]$ Gly and the heptaprenyl- or neryl $\left[{ }^{14} \mathrm{C}\right] \mathrm{Gly}$-lipid II analogues were separated by descending paper chromatography or ascending thin-layer chromatography, respectively (Fig. S5 for representative results). Isobutyric acid/1 $\mathrm{M}$ ammonia $(5: 3 \mathrm{v} / \mathrm{v})$ was used as the mobile phase in both methods. The radioactive spots were identified by autoradiography, cut off, and counted by liquid scintillation.

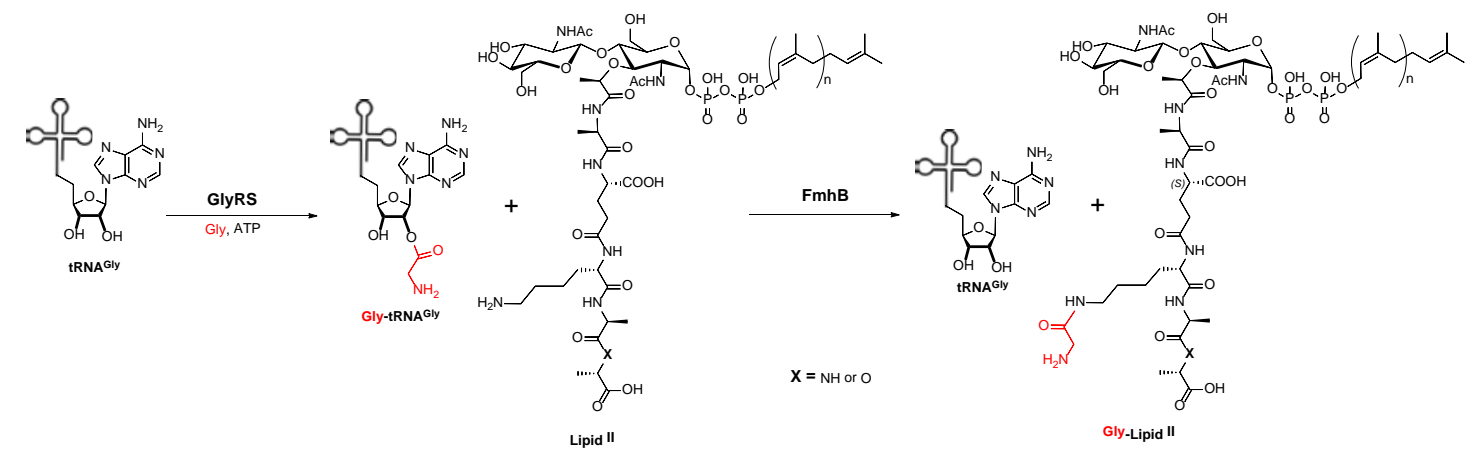

Figure S4. Reactions catalyzed by GlyRS and FmhB. The glycyl-tRNA synthetase (GlyRS) acylates tRNA ${ }^{\text {Gly }}$ (depicted as a clover leaf). FmhB transfers Gly from Gly-tRNA ${ }^{\text {Gly }}$ to the lipid II analogues. Heptaprenylphosphate, $n=6$; neryl-phosphate, $n=1$. 

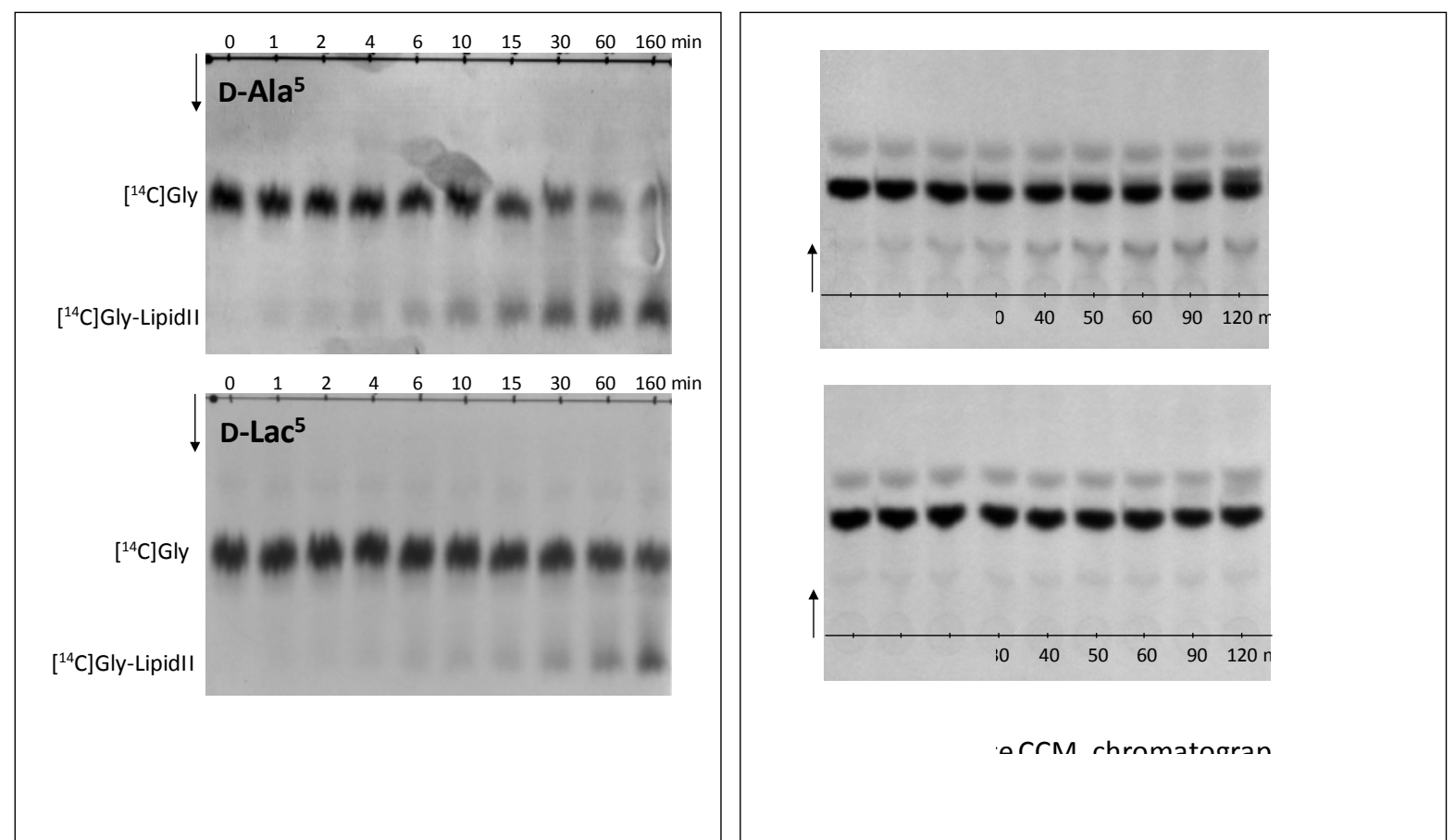

Figure S5. (a) and (b) Kinetics of transfer of $\left[{ }^{14} \mathrm{C}\right]$ Gly from Gly-tRNA ${ }^{\text {Gly }}$ to heptaprenyl- and nerylcontaining lipid II analogues, respectively. The reactions products were analyzed by descending paper chromatography and ascending thin-layer chromatography, respectively.

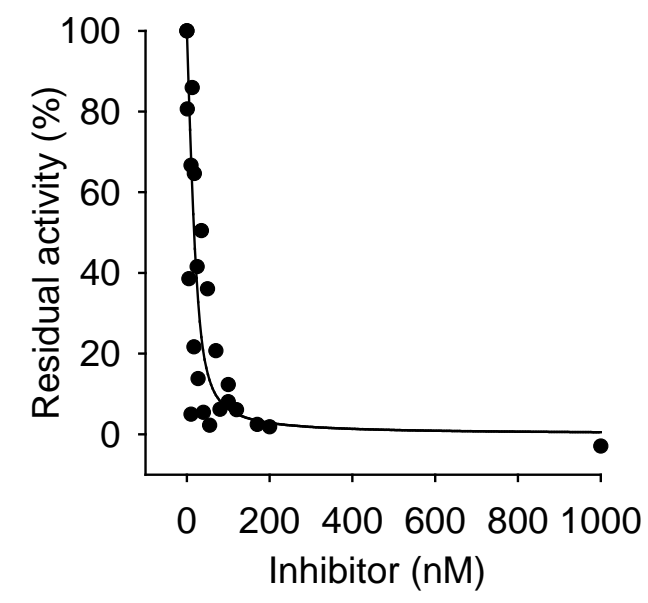

Figure S6. Inhibition of FmhB by D-Ala- and heptaprenyl-containing disaccharide-peptidyl-RNA conjugate (8a). The $I C_{50}$ value $(5 \pm 3 \mathrm{nM})$ was deduced by fitting the Morrison equation to the data of three independent experiment. 


\section{7- Mass spectrometry analyses of synthesized compounds}

\begin{tabular}{|c|c|c|c|c|}
\hline Compound & $N^{\circ}$ & Formula & Calculated & Observed \\
\hline UM-pentapeptide & $1 \mathrm{a}$ & $\mathrm{C}_{40} \mathrm{H}_{64} \mathrm{~N}_{9} \mathrm{O}_{26} \mathrm{P}_{2}^{-}$ & {$[\mathrm{M}-\mathrm{H}]^{-}=1,148.34$} & $1,148.33$ \\
\hline UM-pentadepsipeptide & $1 \mathrm{~b}$ & $\mathrm{C}_{40} \mathrm{H}_{63} \mathrm{~N}_{8} \mathrm{O}_{27} \mathrm{P}_{2}^{-}$ & {$[\mathrm{M}-\mathrm{H}]^{-}=1,149.33$} & $1,149.27$ \\
\hline D-Ala ${ }^{5}$ containing hepta-prenyl-lipid II & $2 a$ & $\mathrm{C}_{74} \mathrm{H}_{124} \mathrm{~N}_{8} \mathrm{O}_{26} \mathrm{P}_{2}^{-}$ & {$[\mathrm{M}-\mathrm{H}]^{-}=1,601.81$} & $1,601.84$ \\
\hline D-Lac ${ }^{5}$ containing hepta-prenyl-lipid II & $2 b$ & $\mathrm{C}_{74} \mathrm{H}_{123} \mathrm{~N}_{7} \mathrm{O}_{27} \mathrm{P}_{2}^{-}$ & {$[\mathrm{M}-\mathrm{H}]^{-}=1,602.79$} & $1,602.87$ \\
\hline D-Ala ${ }^{5}$ containing neryl-lipid II & 3a & $\mathrm{C}_{49} \mathrm{H}_{83} \mathrm{~N}_{8} \mathrm{O}_{26} \mathrm{P}_{2}^{-}$ & {$[\mathrm{M}-\mathrm{H}]^{-}=1,261.49$} & $1,261.47$ \\
\hline D-Lac ${ }^{5}$ containing neryl-lipid II & $3 b$ & $\mathrm{C}_{49} \mathrm{H}_{82} \mathrm{~N}_{7} \mathrm{O}_{27} \mathrm{P}_{2}^{-}$ & {$[\mathrm{M}-\mathrm{H}]^{-}=1,262.47$} & $1,262.33$ \\
\hline UM-L-Ala-D-iGlu-cystine-D-Ala-D-Ala & $4 a$ & $\mathrm{C}_{40} \mathrm{H}_{64} \mathrm{~N}_{9} \mathrm{O}_{28} \mathrm{P}_{2} \mathrm{~S}_{2}{ }^{+}$ & {$[\mathrm{M}+\mathrm{H}]^{+}=1,244.26$} & $1,244.27$ \\
\hline UM-L-Ala-D-iGlu-cystine-D-Ala-D-Lac & $4 b$ & $\mathrm{C}_{40} \mathrm{H}_{63} \mathrm{~N}_{8} \mathrm{O}_{29} \mathrm{P}_{2} \mathrm{~S}_{2}^{+}$ & {$[\mathrm{M}+\mathrm{H}]^{+}=1,245.25$} & $1,245.27$ \\
\hline UM-L-Ala-D-iGlu-dha-D-Ala-D-Ala & $5 a$ & $\mathrm{C}_{37} \mathrm{H}_{55} \mathrm{~N}_{8} \mathrm{O}_{26} \mathrm{P}_{2}^{-}$ & {$[\mathrm{M}-\mathrm{H}]^{-}=1,089.27$} & $1,089.33$ \\
\hline UM-L-Ala-D-iGlu-dha-D-Ala-D-Lac & $5 b$ & $\mathrm{C}_{37} \mathrm{H}_{54} \mathrm{~N}_{7} \mathrm{O}_{27} \mathrm{P}_{2}^{-}$ & {$[\mathrm{M}-\mathrm{H}]^{-}=1,090.25$} & $1,090.33$ \\
\hline UM-L-Ala-D-iGlu-(R)-thio-butynyl-D-Ala-D-Ala & $6 a$ & $\mathrm{C}_{41} \mathrm{H}_{61} \mathrm{~N}_{8} \mathrm{O}_{26} \mathrm{P}_{2} \mathrm{~S}^{-}$ & {$[\mathrm{M}-\mathrm{H}]^{-}=1,175.33$} & $1,175.29$ \\
\hline UM-L-Ala-D-iGlu-(R)-thio-butynyl-D-Ala-D-Lac & $6 b$ & $\mathrm{C}_{41} \mathrm{H}_{60} \mathrm{~N}_{7} \mathrm{O}_{27} \mathrm{P}_{2} \mathrm{~S}^{-}$ & {$[\mathrm{M}-\mathrm{H}]^{-}=1,176.20$} & $1,176.27$ \\
\hline GM-heptaprenyl-L-Ala-D-iGlu-(R)-thio-butynyl-D-Ala-D-Ala & $7 a$ & $\mathrm{C}_{75} \mathrm{H}_{120} \mathrm{~N}_{7} \mathrm{O}_{26} \mathrm{P}_{2} \mathrm{~S}^{-}$ & {$[\mathrm{M}-\mathrm{H}]^{-}=1,628.75$} & $1,628.80$ \\
\hline GM-neryl-L-Ala-D-iGlu-(R)-thio-butynyl-D-Ala-D-Ala & $7 \mathrm{~b}$ & $\mathrm{C}_{50} \mathrm{H}_{80} \mathrm{~N}_{7} \mathrm{O}_{26} \mathrm{P}_{2} \mathrm{~S}^{-}$ & {$[\mathrm{M}-\mathrm{H}]^{-}=1,288.44$} & $1,288.53$ \\
\hline GM-neryl-L-Ala-D-iGlu- $(R)$-thio-butynyl-D-Ala-D-Lac & 7c & $\mathrm{C}_{50} \mathrm{H}_{79} \mathrm{~N}_{6} \mathrm{O}_{27} \mathrm{P}_{2} \mathrm{~S}^{-}$ & {$[\mathrm{M}-\mathrm{H}]^{-}=1,289.42$} & $1,289.47$ \\
\hline tRNA Gly & - & $\mathrm{C}_{710} \mathrm{H}_{881} \mathrm{~N}_{274} \mathrm{O}_{529} \mathrm{P}_{75}$ & {$[\mathrm{MW}]=24,040$} & 24,043 \\
\hline Azido-RNA & - & $\mathrm{C}_{182} \mathrm{H}_{238} \mathrm{~N}_{70} \mathrm{O}_{133} \mathrm{P}_{18}$ & {$[\mathrm{MW}]=6,091.8$} & $6,092.0$ \\
\hline Heptaprenyl-PP-GM-pentapeptide-RNA (D-Ala) & $8 a$ & $\mathrm{C}_{257} \mathrm{H}_{359} \mathrm{~N}_{77} \mathrm{O}_{159} \mathrm{P}_{20} \mathrm{~S}$ & {$[\mathrm{MW}]=7,722.6$} & $7,723.0$ \\
\hline Neryl-PP-GM-pentapeptide-RNA (D-Ala) & $8 b$ & $\mathrm{C}_{232} \mathrm{H}_{319} \mathrm{~N}_{77} \mathrm{O}_{159} \mathrm{P}_{20} \mathrm{~S}$ & {$[\mathrm{MW}]=7,382.0$} & $7,381.9$ \\
\hline Neryl-PP-GM-pentadepsipeptide-RNA (D-Lac) & $8 c$ & $\mathrm{C}_{232} \mathrm{H}_{318} \mathrm{~N}_{76} \mathrm{O}_{160} \mathrm{P}_{20} \mathrm{~S}$ & {$[\mathrm{MW}]=7,383.0$} & $7,383.4$ \\
\hline
\end{tabular}

dha, dehydroalanine; UM, UDP-MurNAc; GM, GIcNAc-MurNAc. 
UDP-MurNAC-pentapeptide (1a)

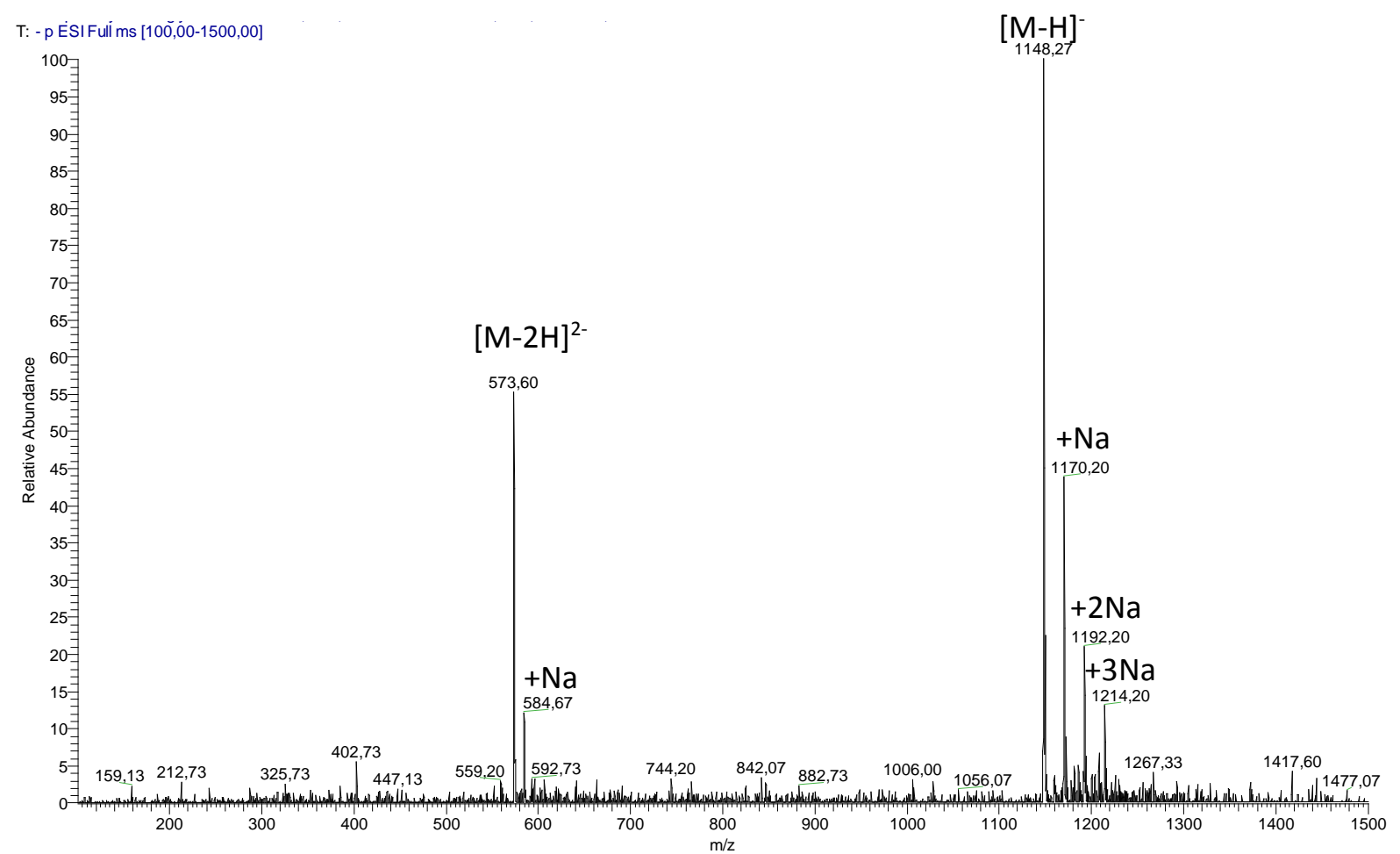

UDP-MurNAc-pentadepsipeptide (1b)

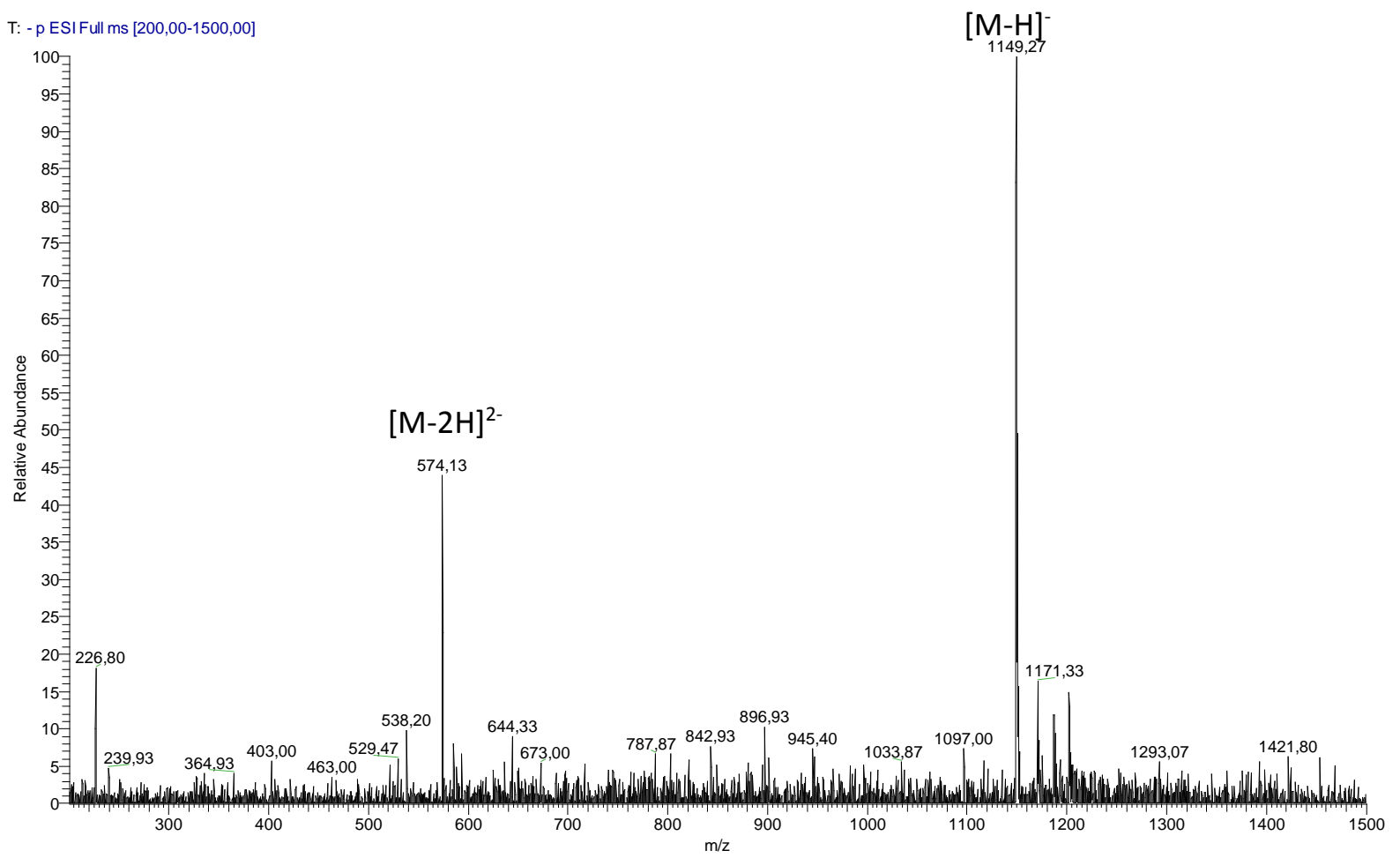


D-Ala-and heptaprenyl-containing Lipid II (2a)

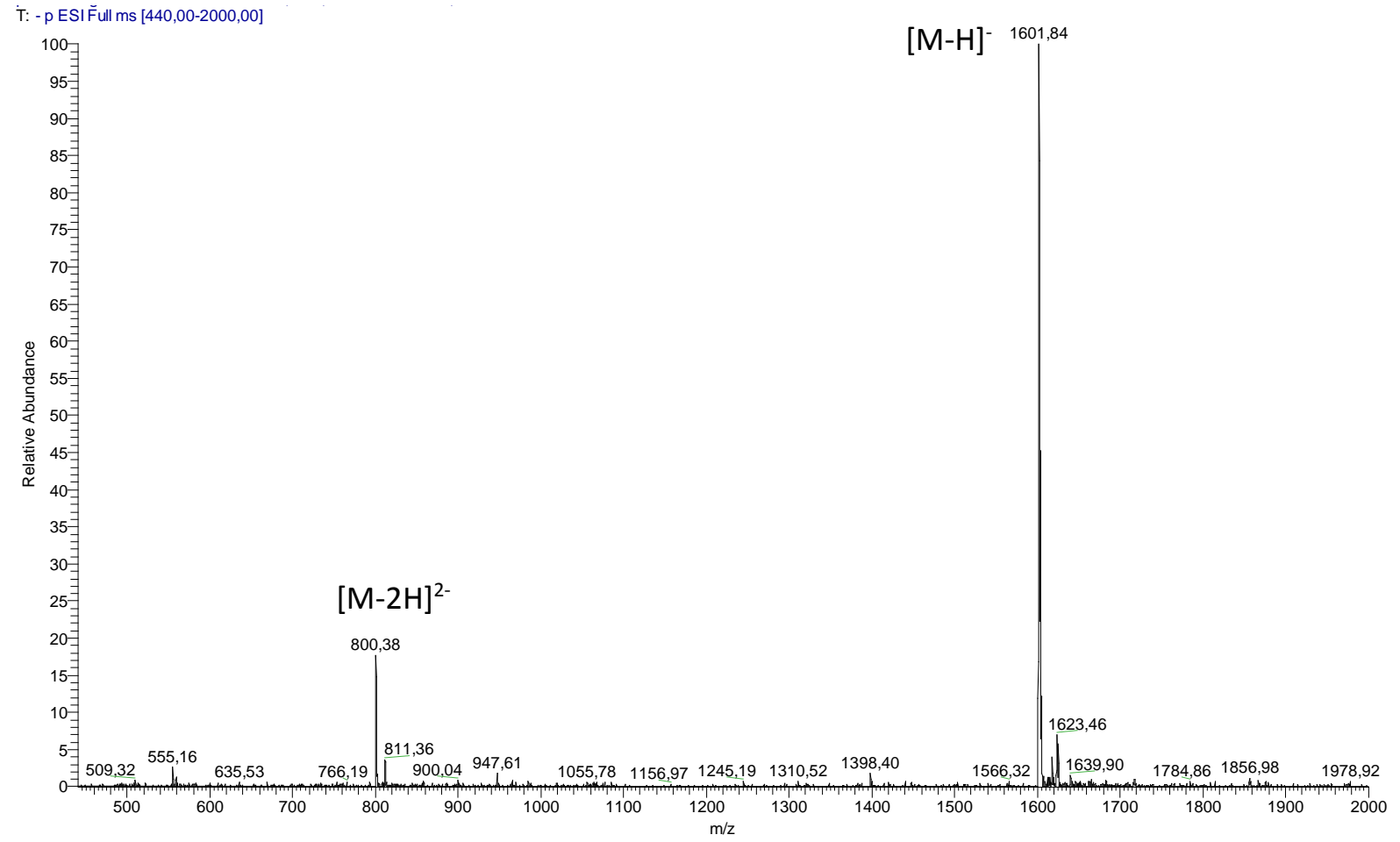

D-Lac- and heptaprenyl-containing Lipid II (2b)

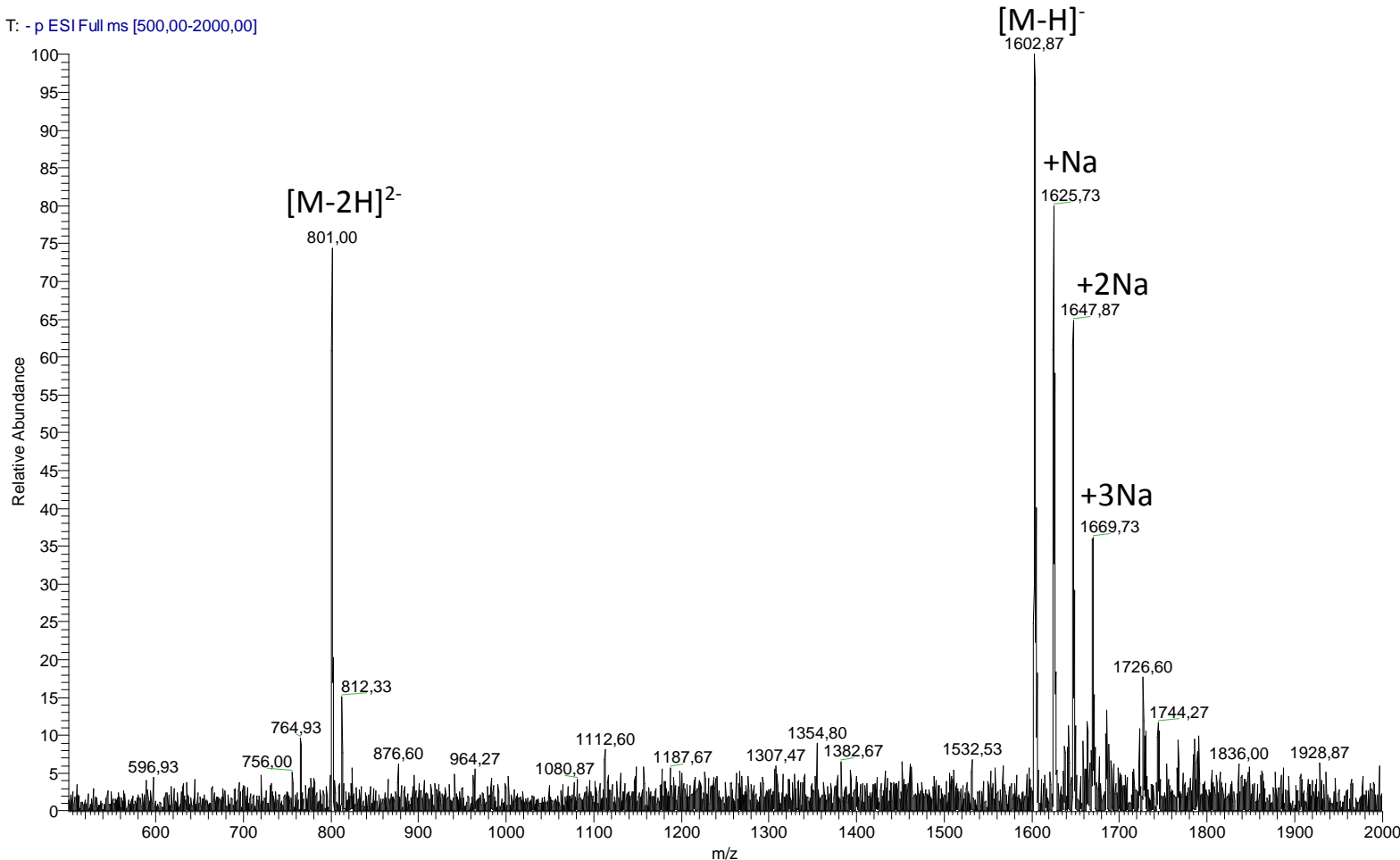


D-Ala- and neryl-containing lipid II (3a)

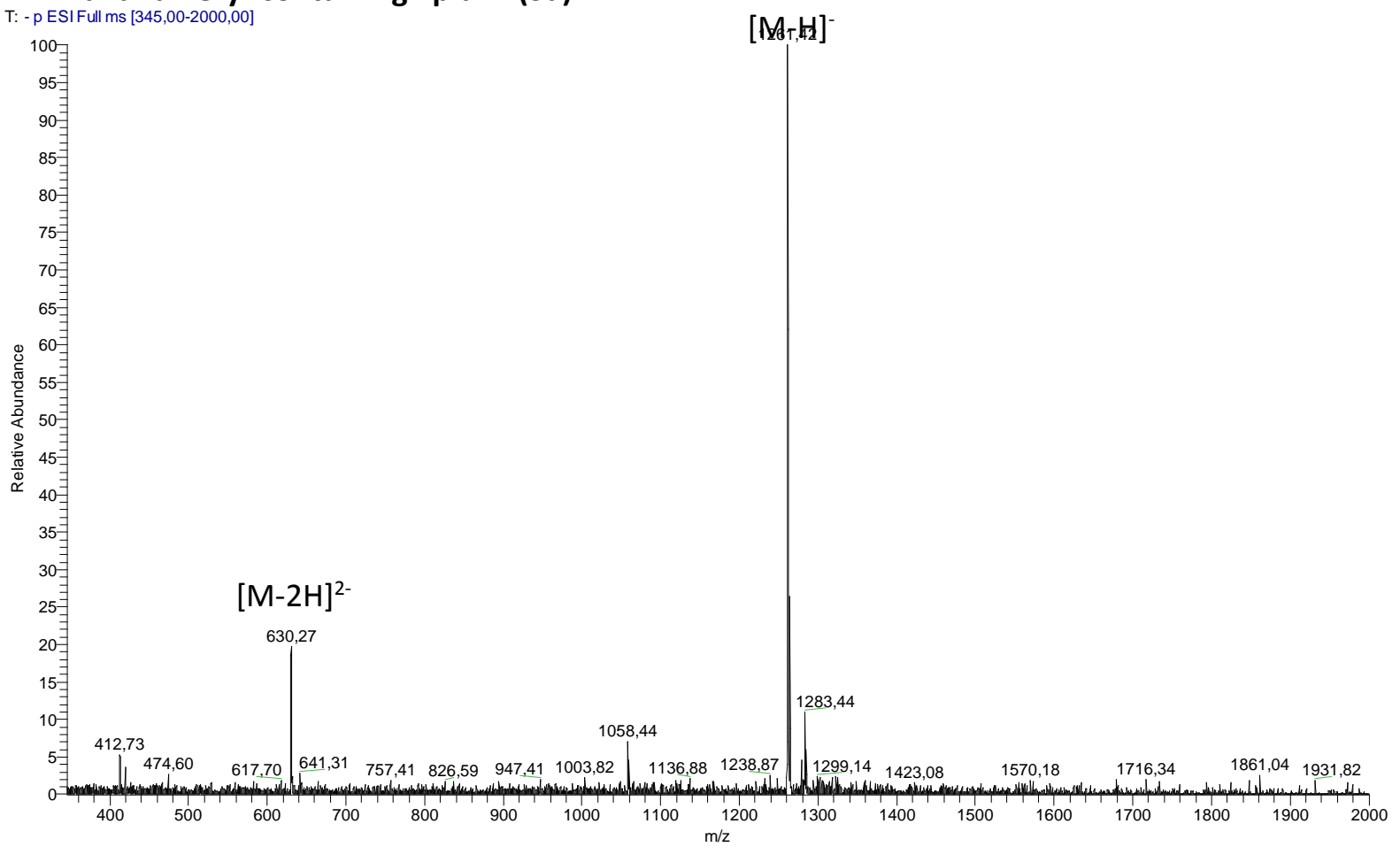

D-Lac- and neryl-containing lipid II (3b)

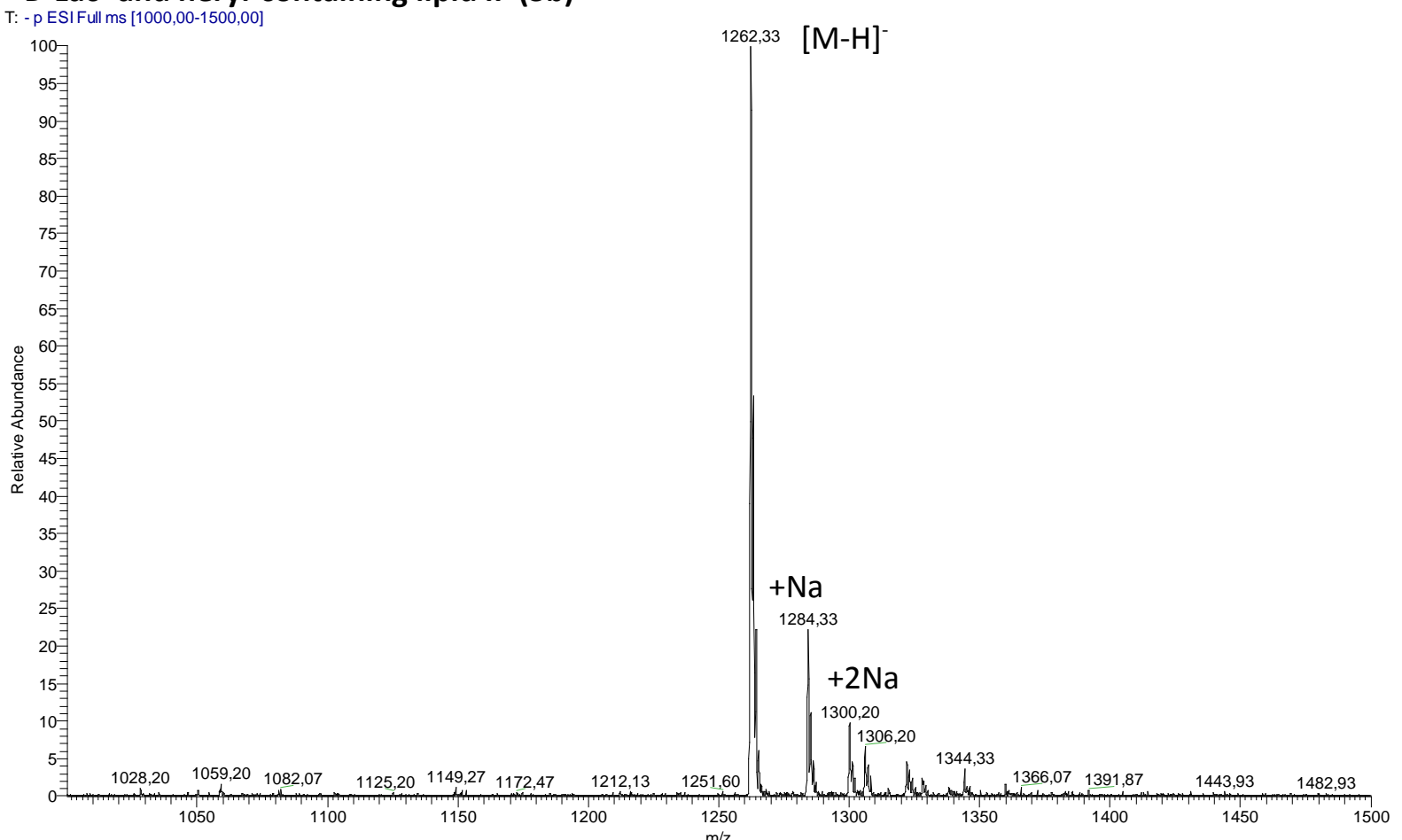


UDP-MurNAC-L-Ala-D-iGlu-cystinyl-D-Ala-D-Ala (4a)

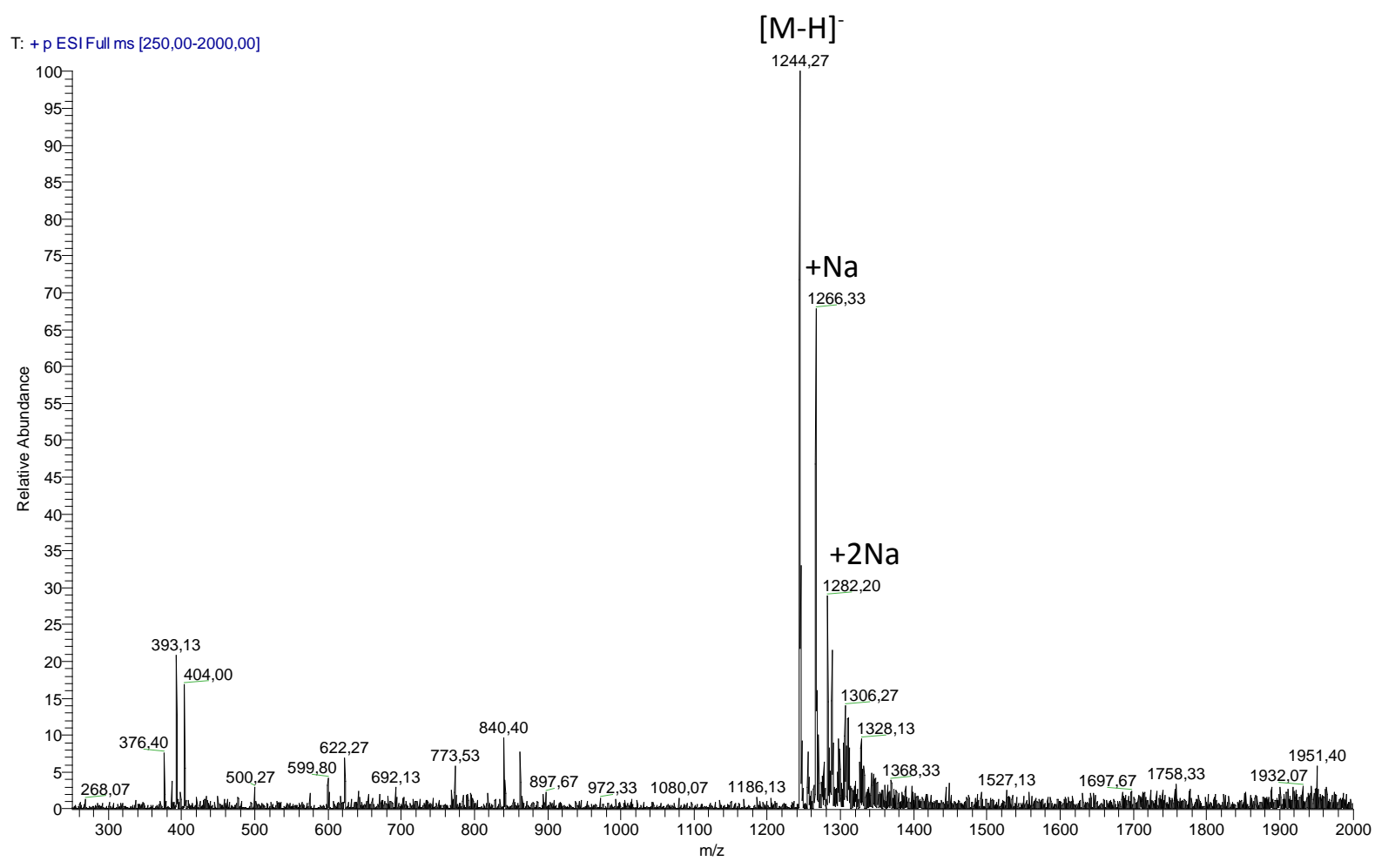

UDP-MurNAC-L-Ala-D-iGlu-cystinyl-D-Ala-D-Lac (4b)

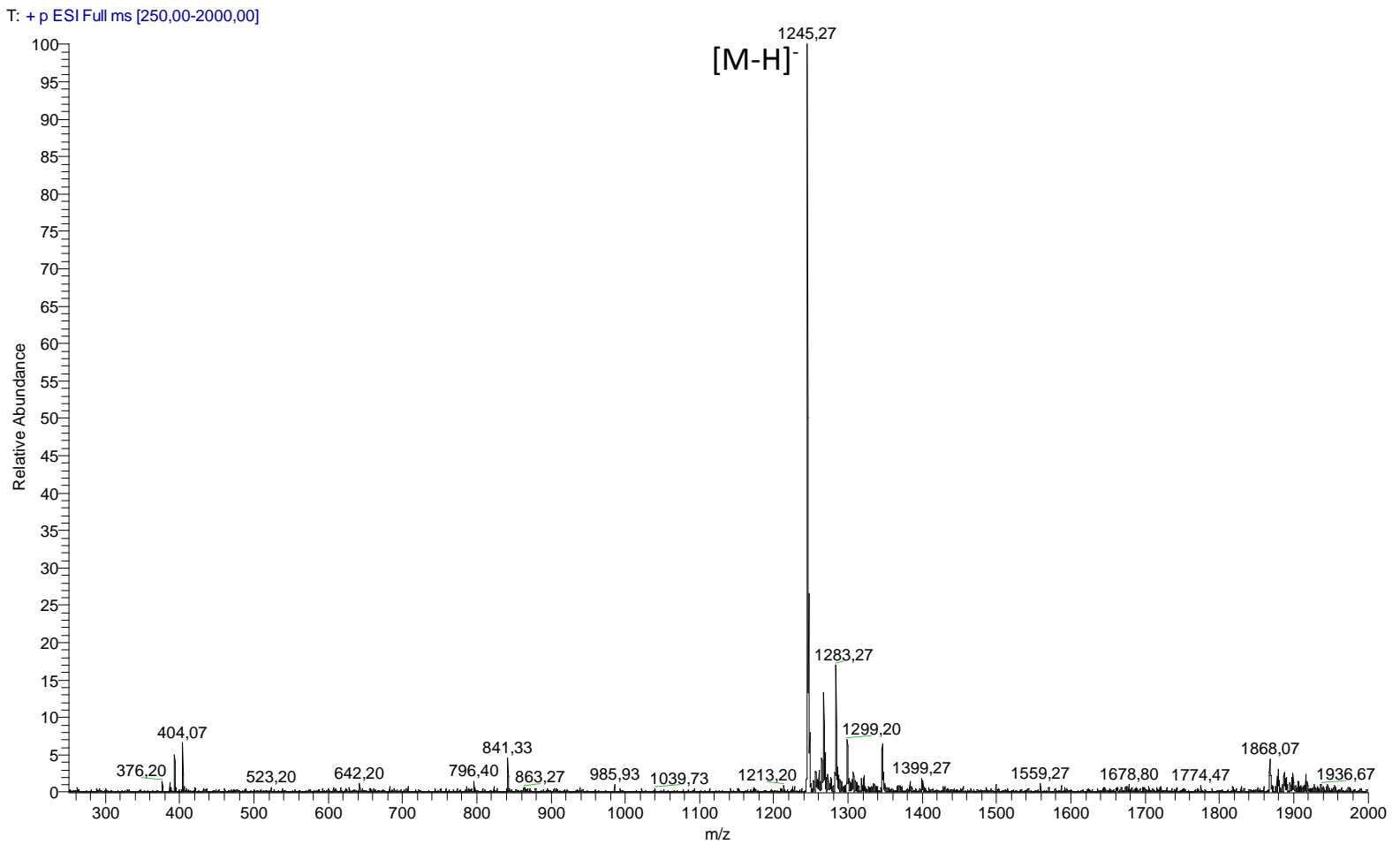


UDP-MurNAC-L-Ala-D-iGlu-dha-D-Ala-D-Ala (5a)

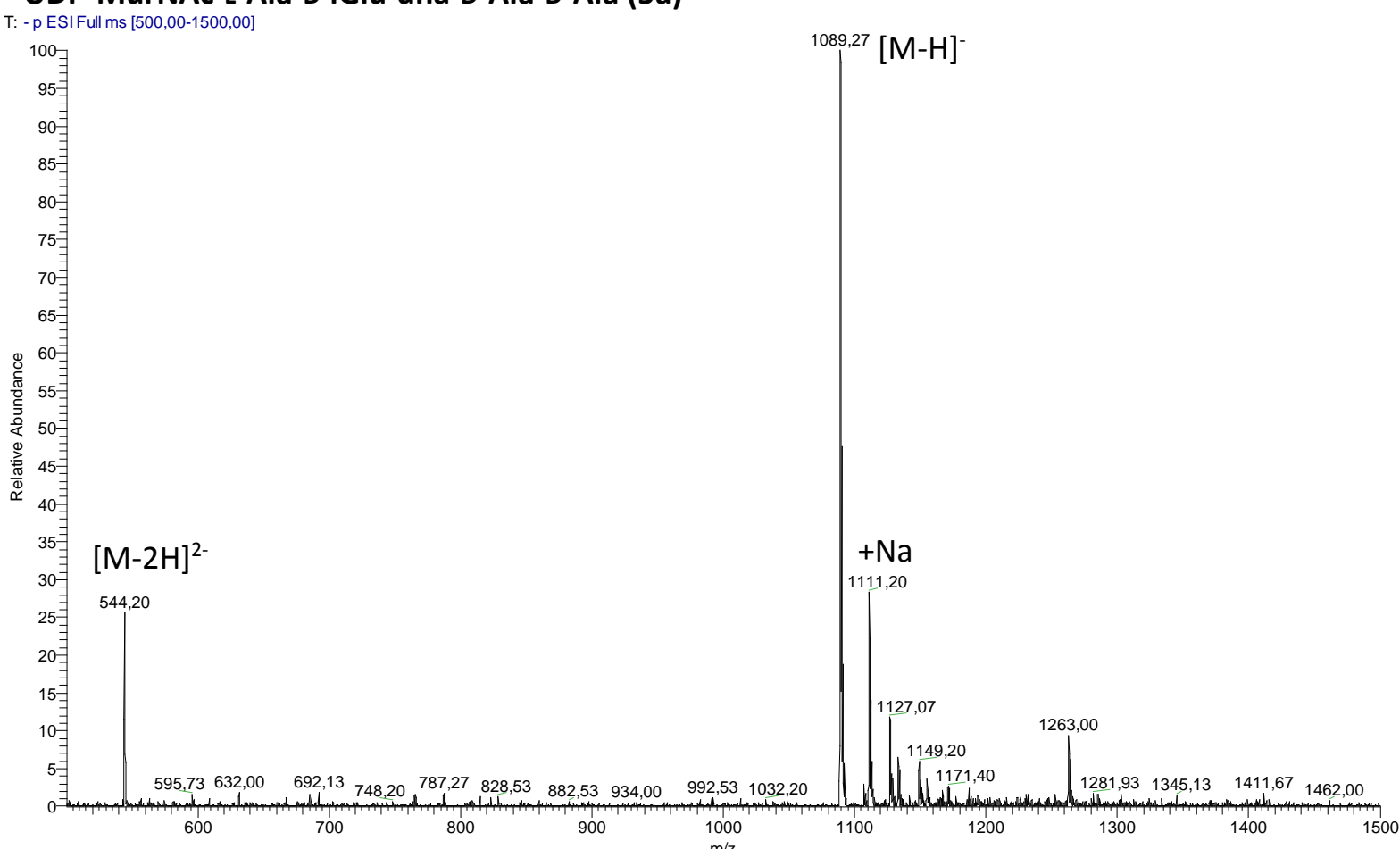

UDP-MurNAC-L-Ala-D-iGlu-dha-D-Ala-D-Lac (5b)

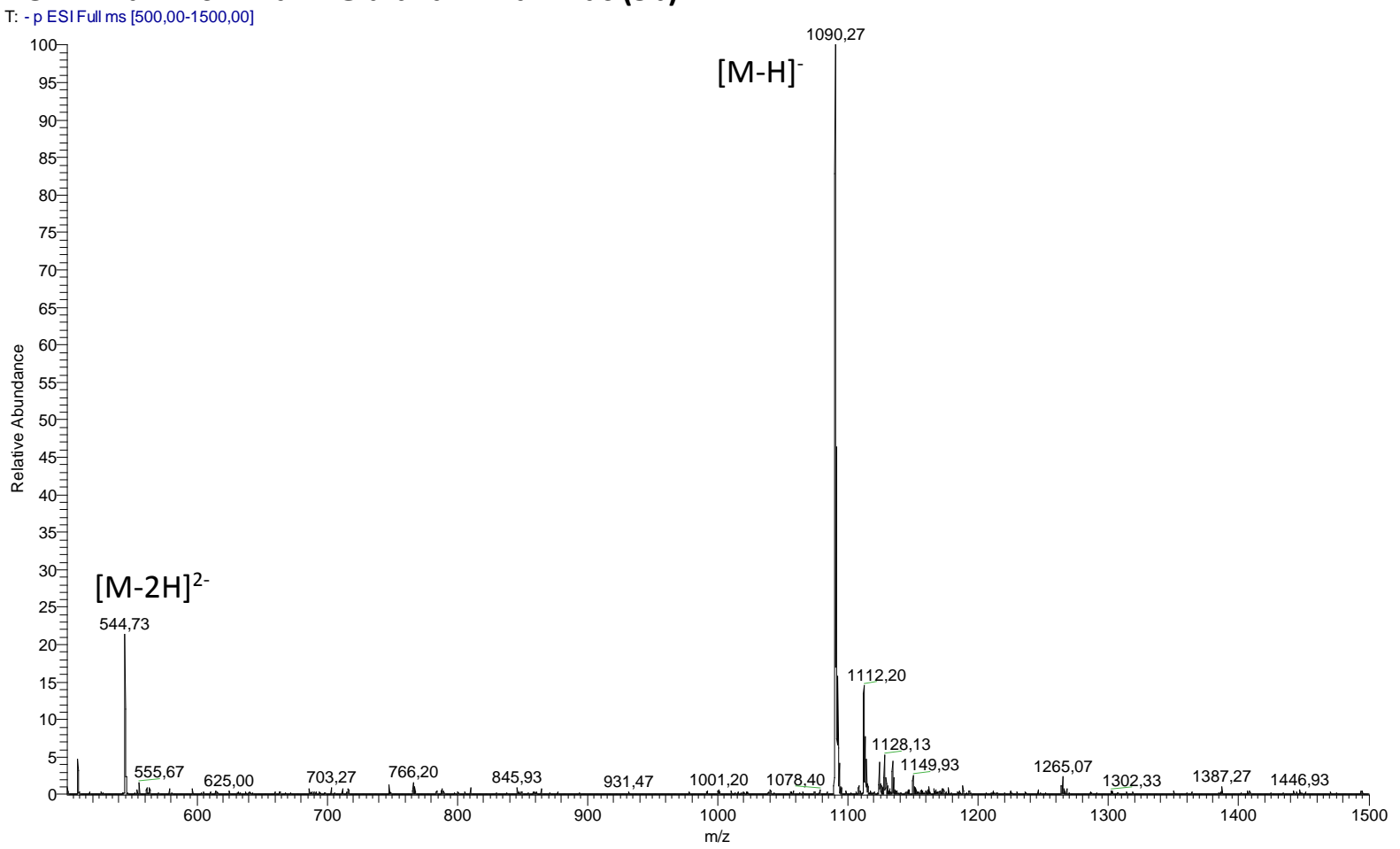




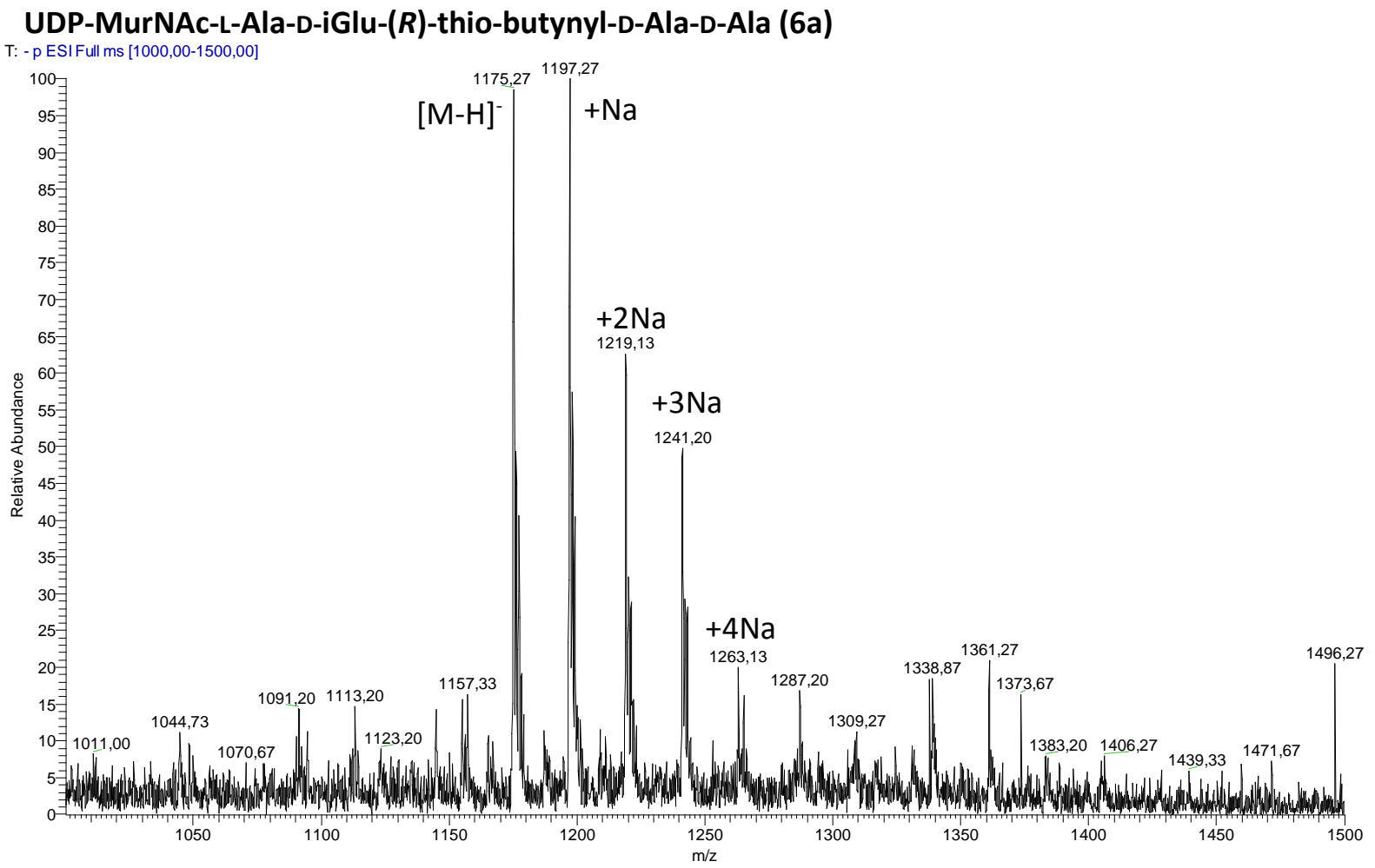

UDP-MurNAC-L-Ala-D-iGlu-(R)-thio-butynyl-D-Ala-D-Lac (6b)

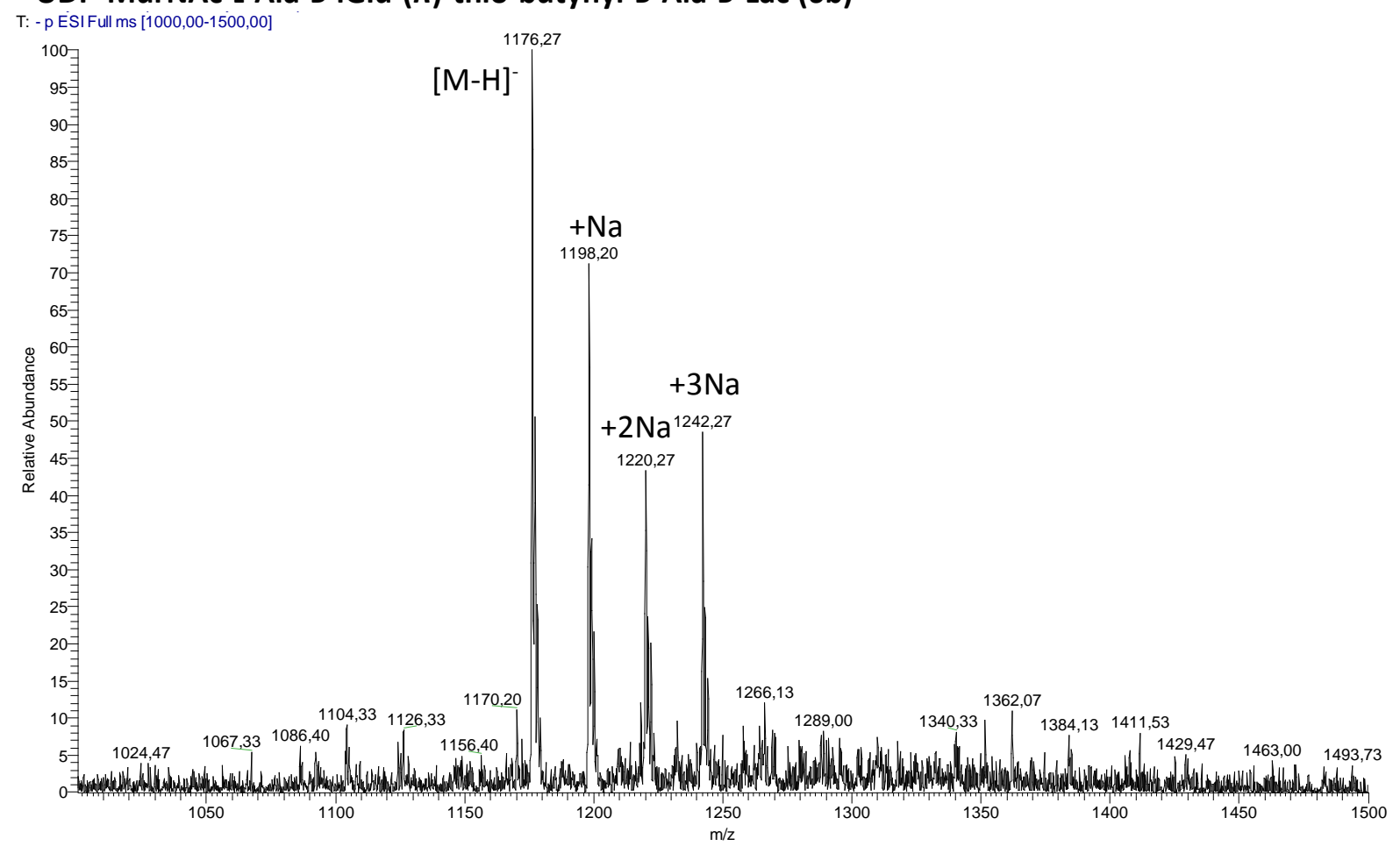


GIcNAC-MurNAC[L-Ala-D-iGlu-(R)-thio-butynyl-D-Ala-D-Ala]-PP-hepta-prenyl (7a)

T: - p ESI Full ms [500,00-2000,00]

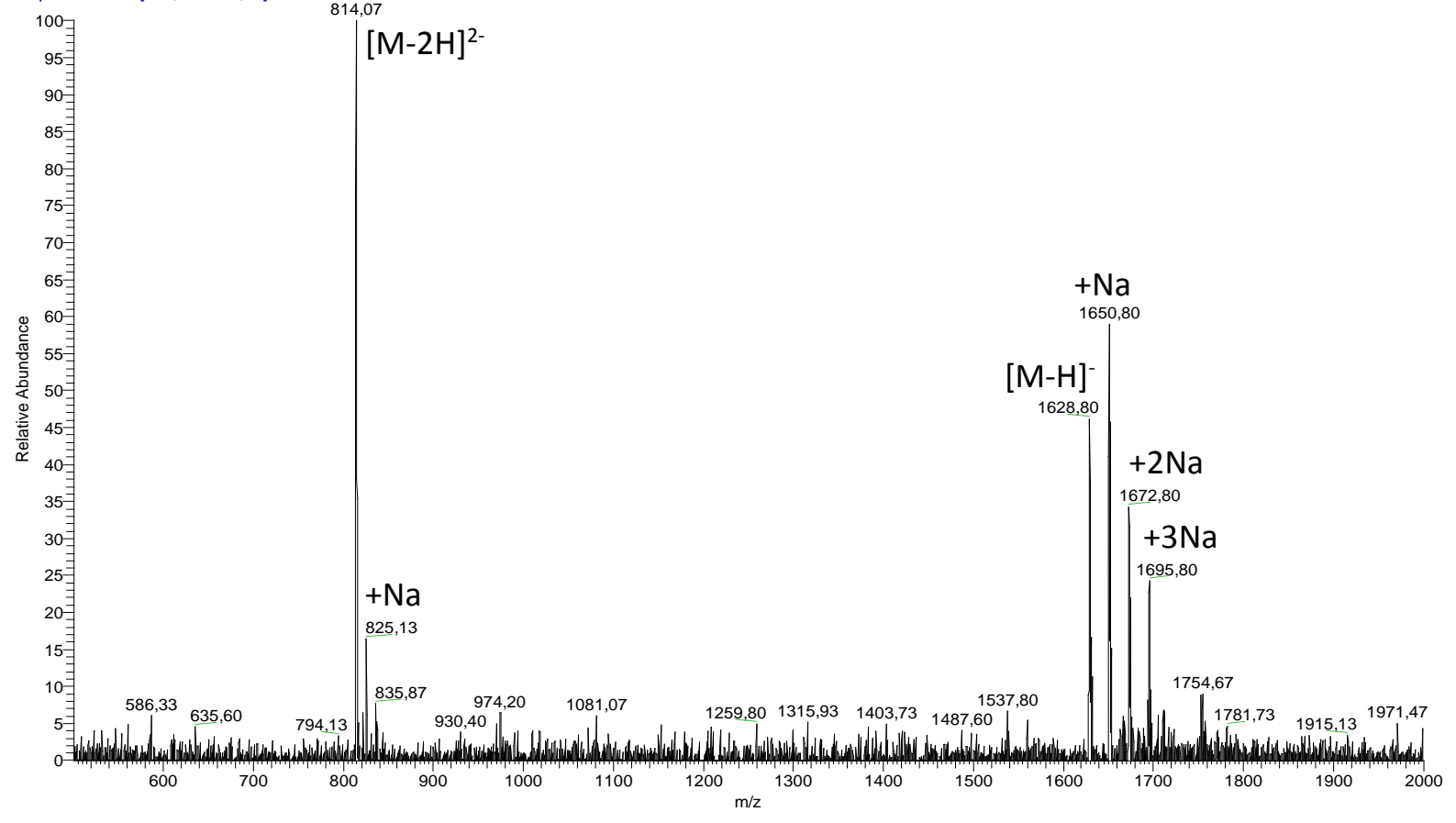

GIcNAc-MurNAc[L-Ala-D-iGlu-(R)-thio-butynyl-D-Ala-D-Ala]-PP-neryl (7b)

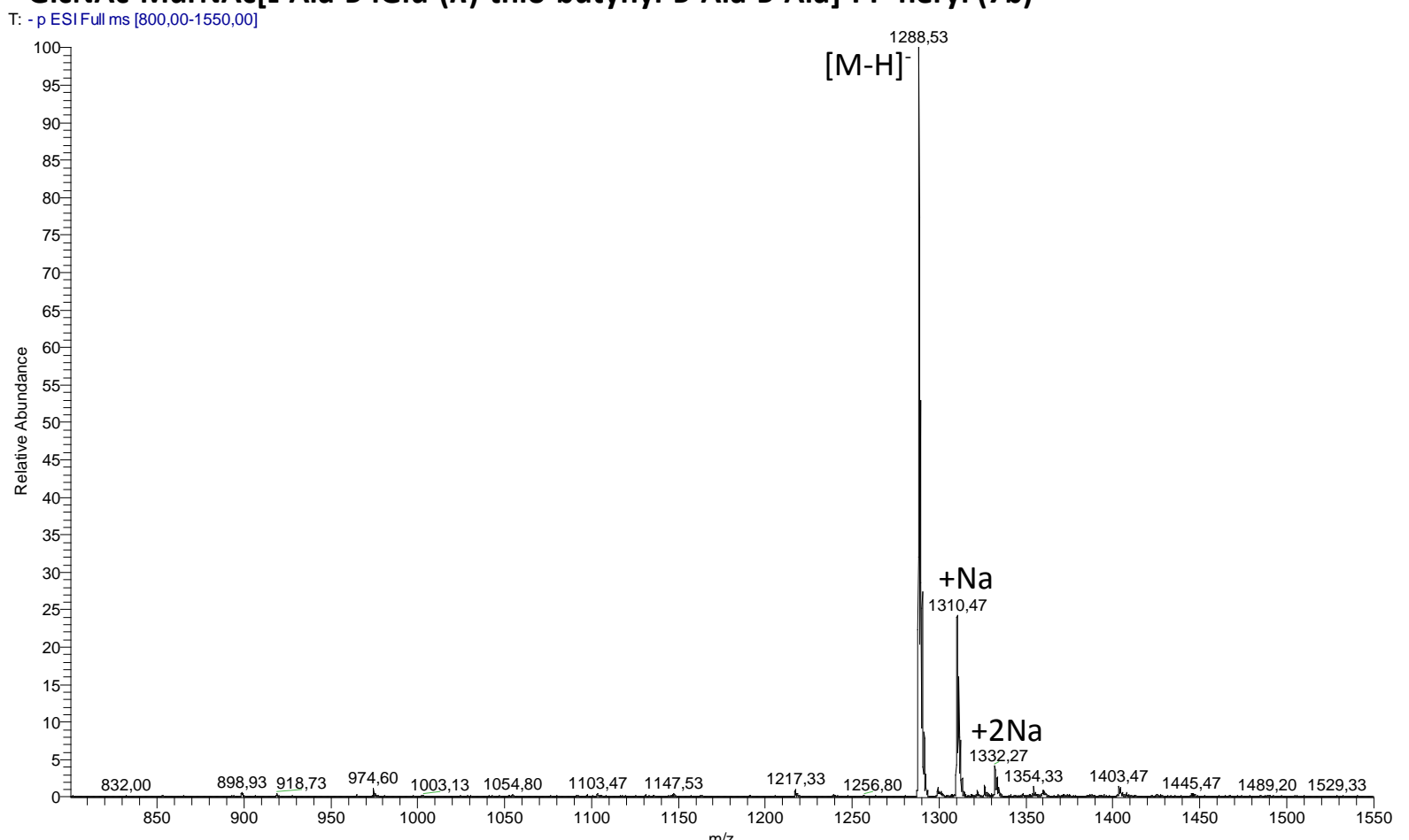




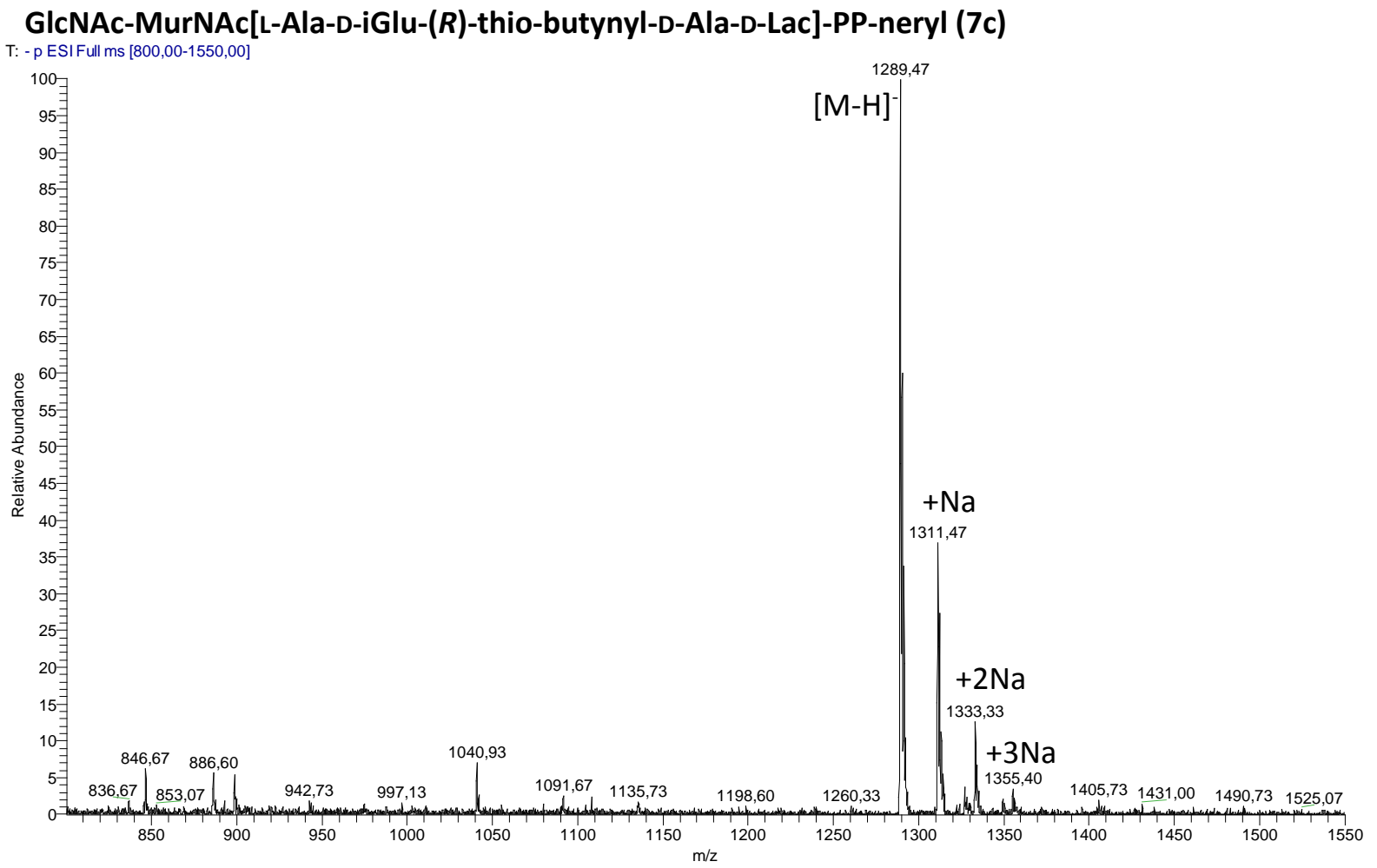

tRNA $^{\text {Gly }}$

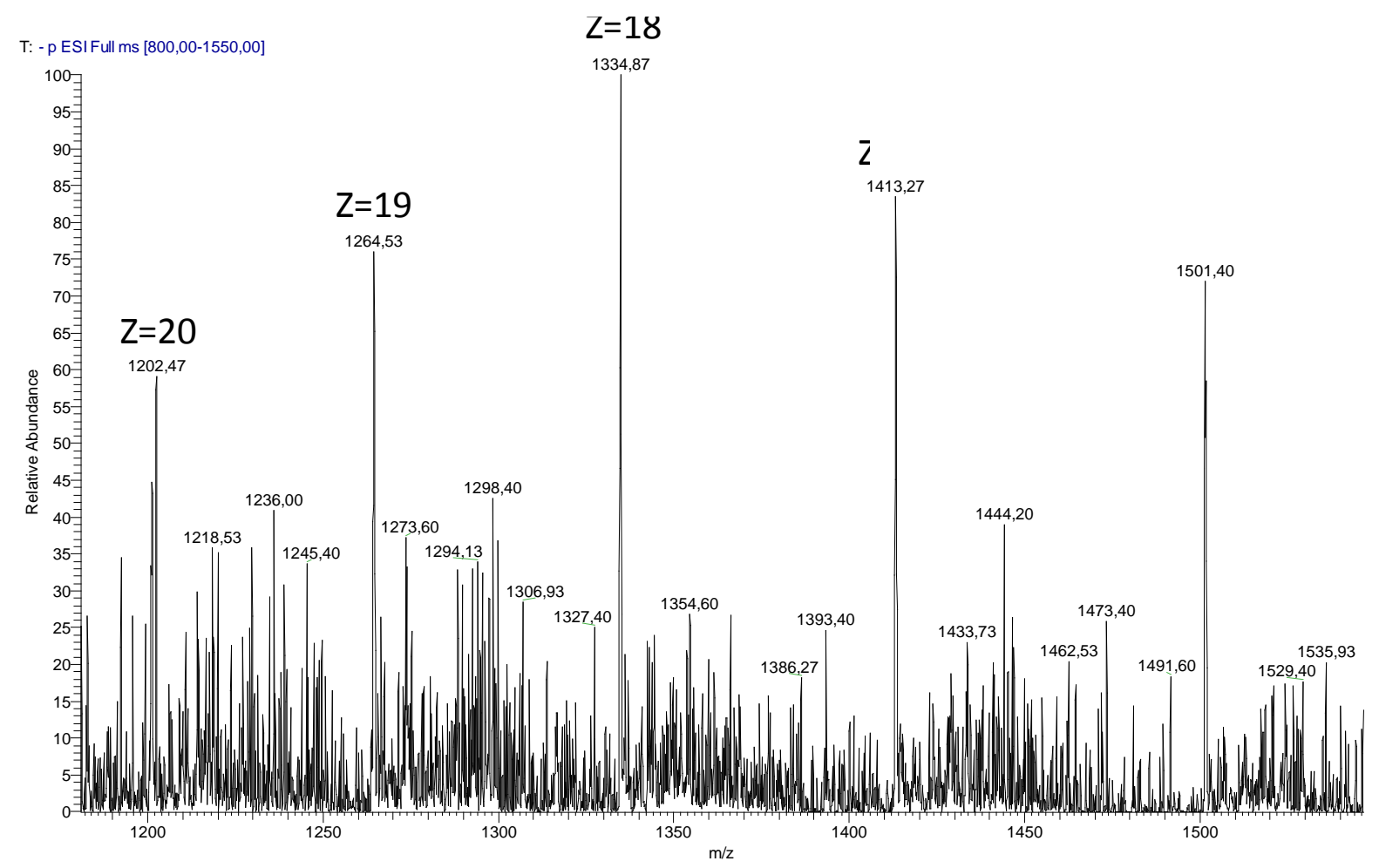




\section{Azido-RNA}

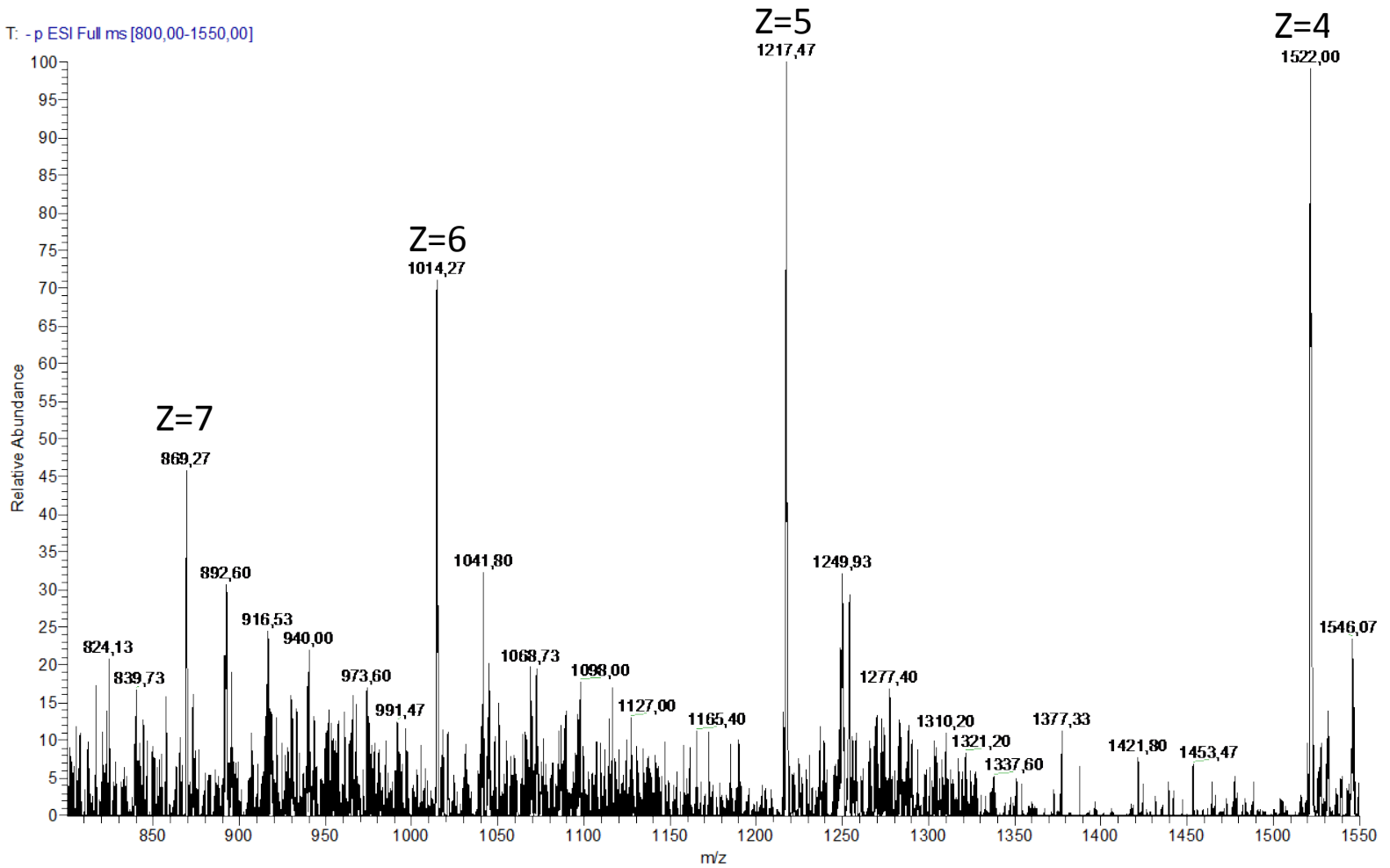


D-Ala- and heptaprenyl-containing disaccharide-peptidyl-RNA conjugate (8a)

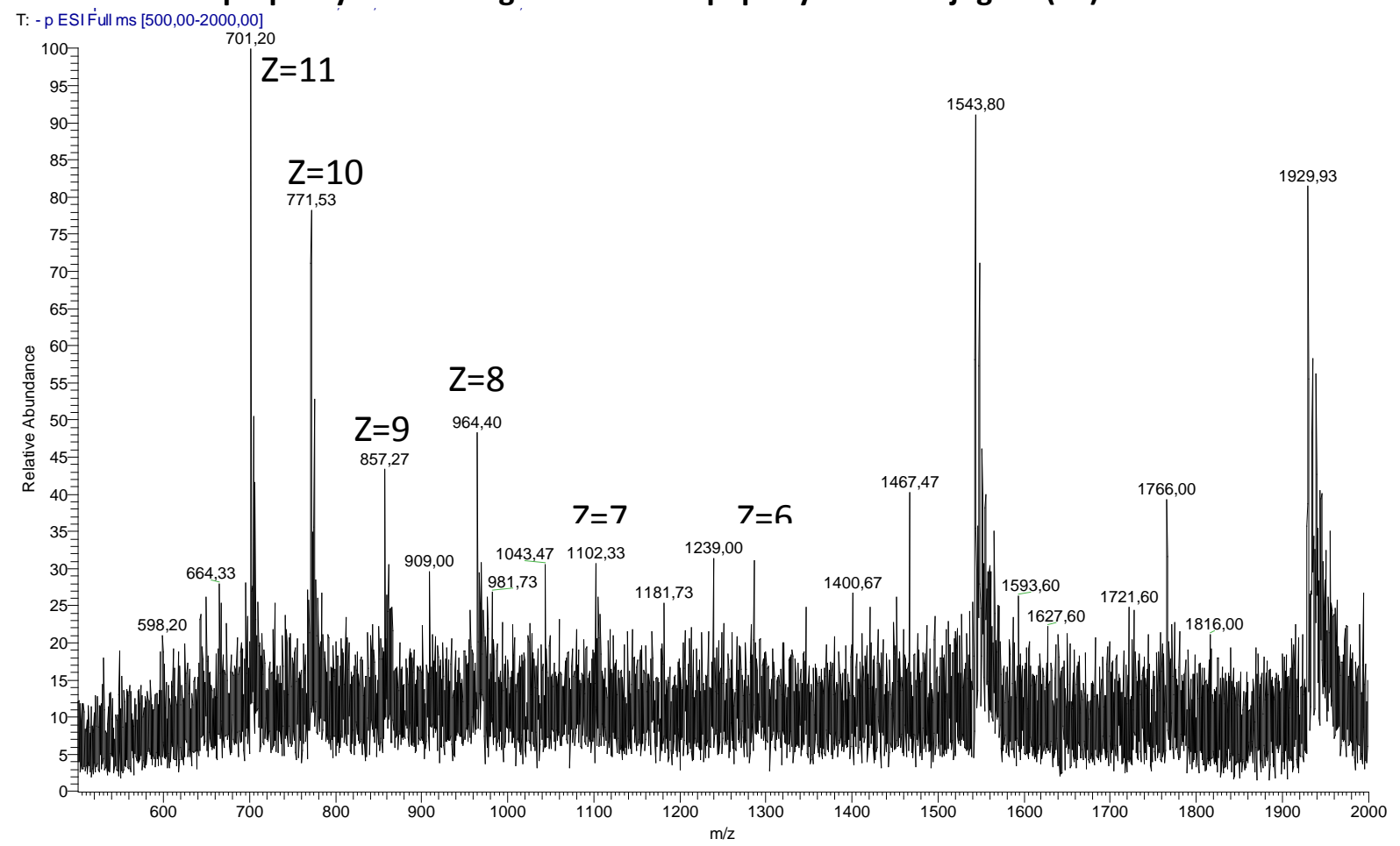

D-Ala- and neryl-containing disaccharide-peptidyl-RNA conjugate (8b)

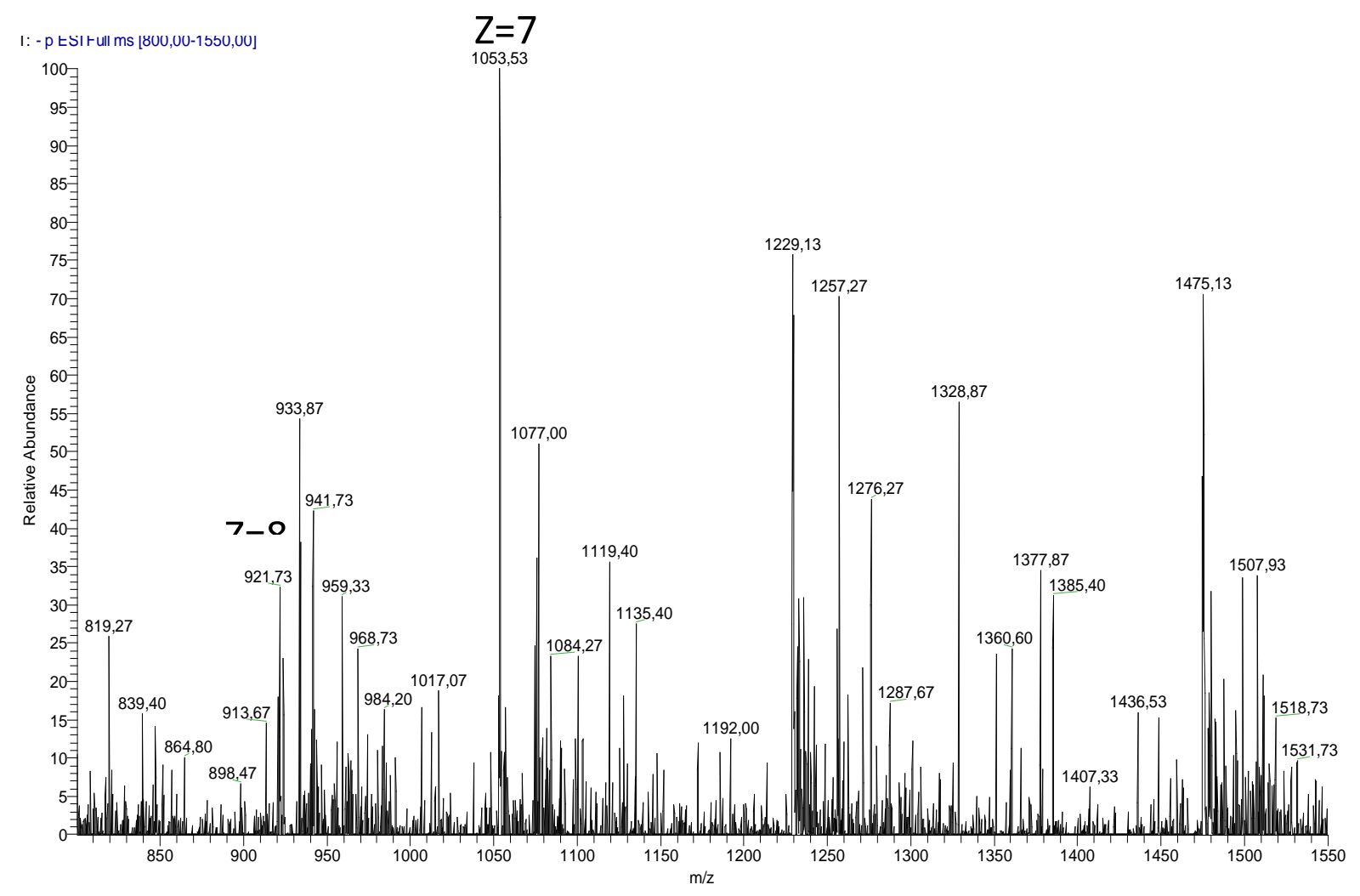


D-Lac- and neryl-containing disaccharide-peptidyl-RNA conjugate (8c)

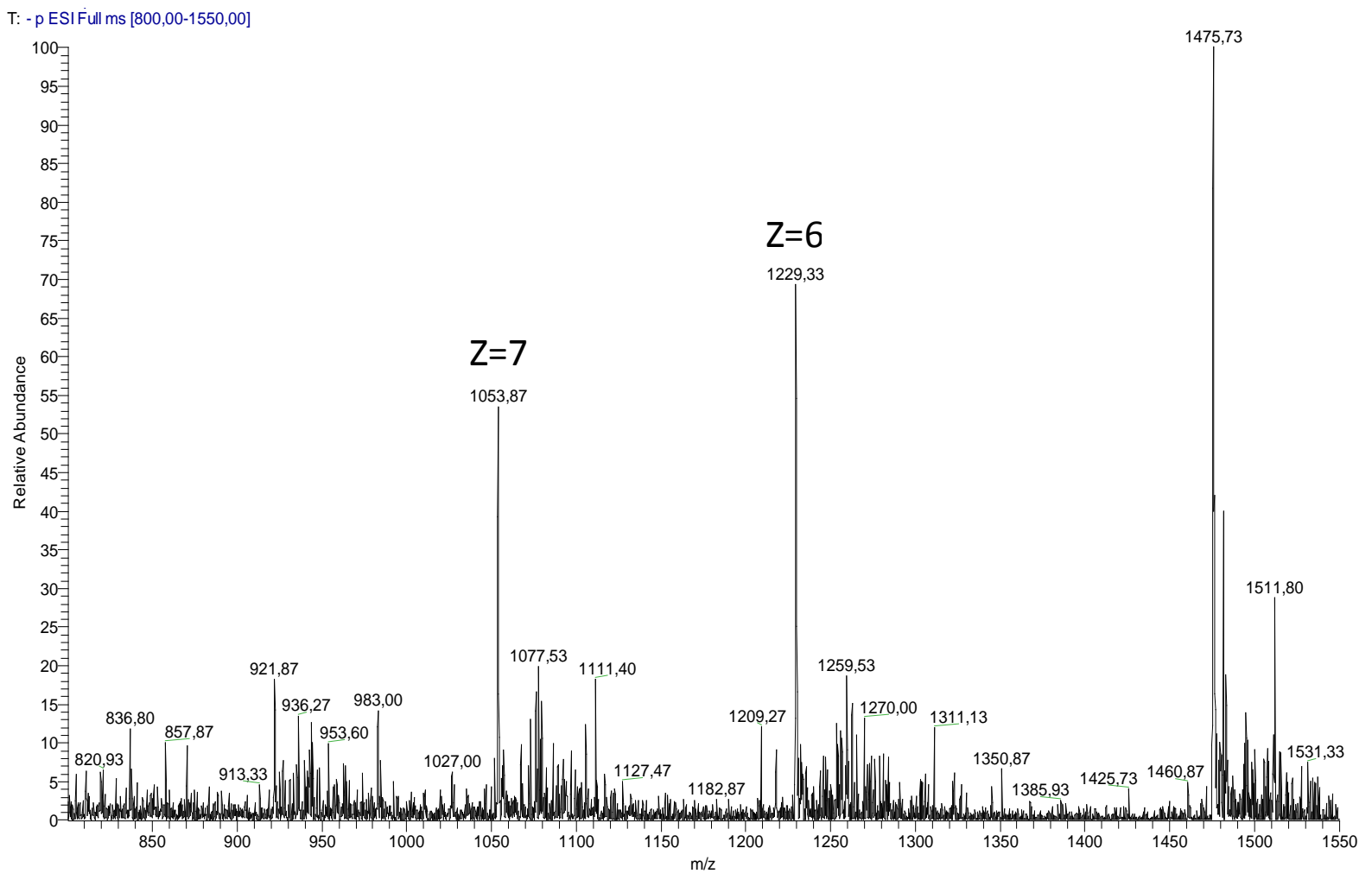




\section{8- rpHPLC analysis of synthesized compounds}

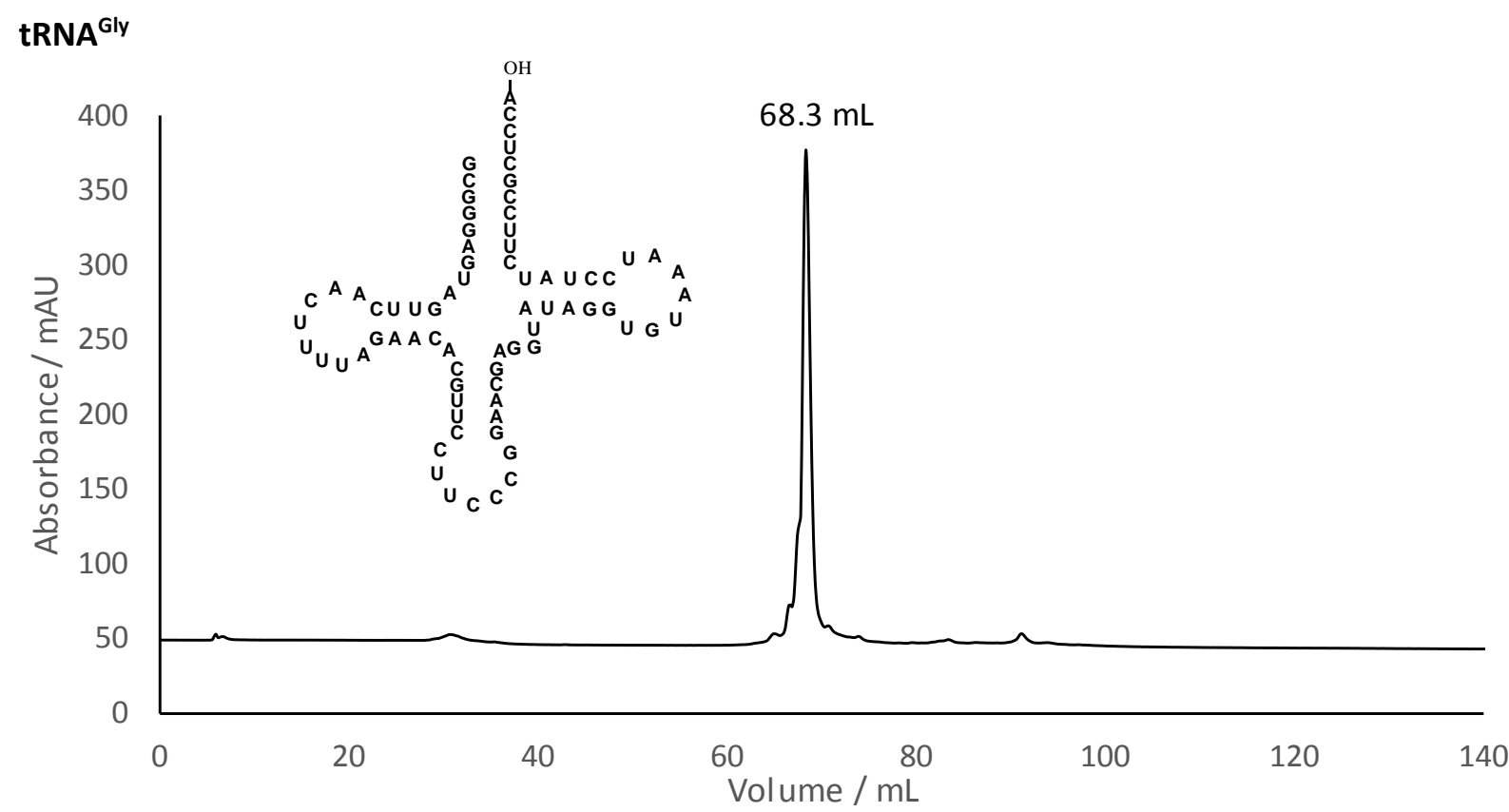

Anionic $r p$ HPLC on semi-preparative DNAPac PA-100 (Thermofisher Scientific, $10 \times 250 \mathrm{~mm}$ ) at $3.5 \mathrm{~mL}$ $\mathrm{min}^{-1}$ with a 30 min gradient from $25 \mathrm{mM}$ to $2.5 \mathrm{M}$ ammonium acetate $\mathrm{pH} 8.0$ containing $0.5 \% \mathrm{ACN}$ (absorbance measured at $260 \mathrm{~nm}$ ).

\section{Azido-RNA}

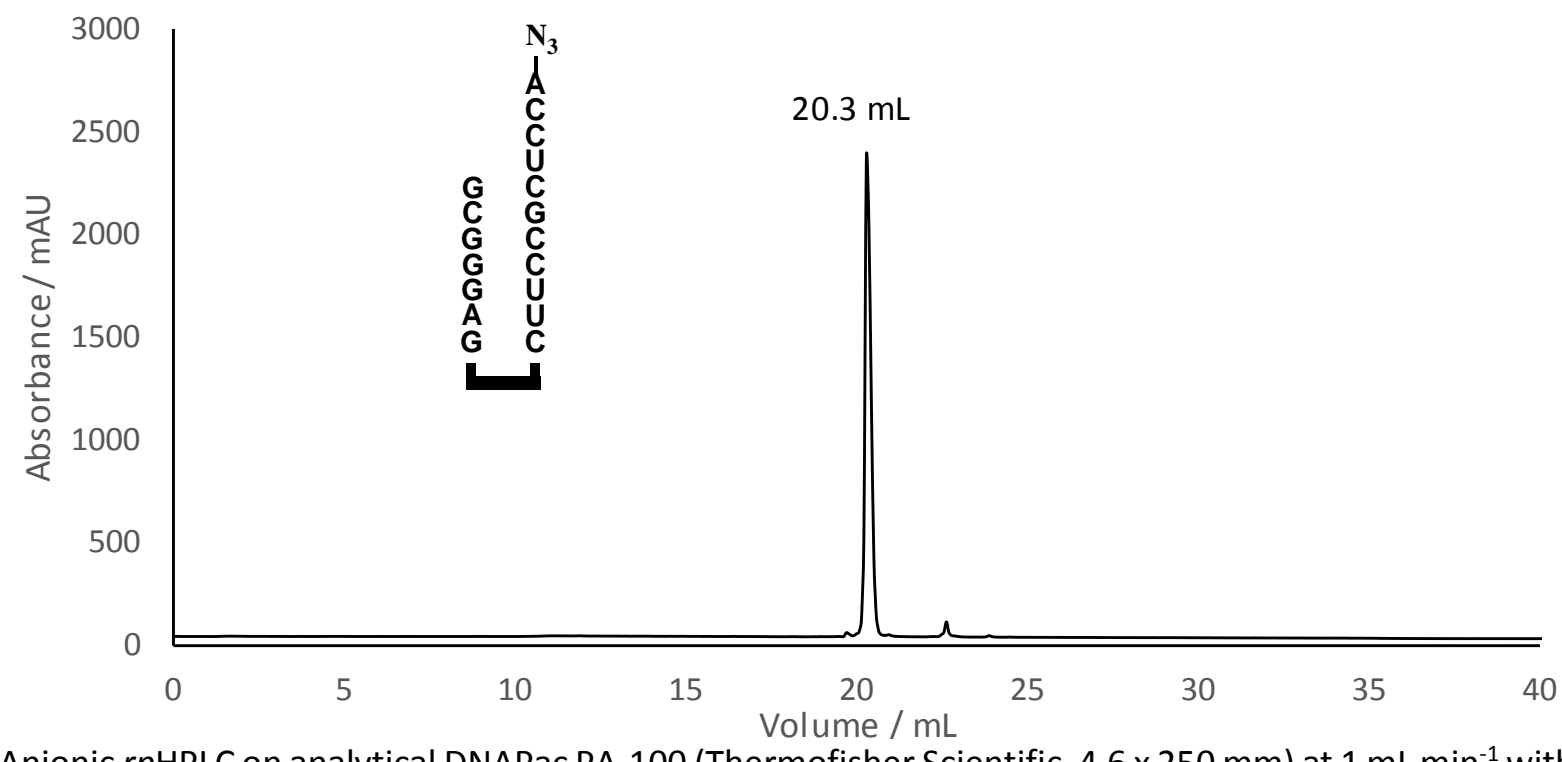

Anionic $r p$ HPLC on analytical DNAPac PA-100 (Thermofisher Scientific, $4.6 \times 250 \mathrm{~mm}$ ) at $1 \mathrm{~mL} \mathrm{~min}^{-1}$ with a $25 \mathrm{~min}$ gradient applied between 8 and $33 \mathrm{~min}$ from $25 \mathrm{mM}$ to $2.5 \mathrm{M}$ ammonium acetate $\mathrm{pH} 8.0$ containing $0.5 \%$ ACN (absorbance measured at $260 \mathrm{~nm}$ ). 


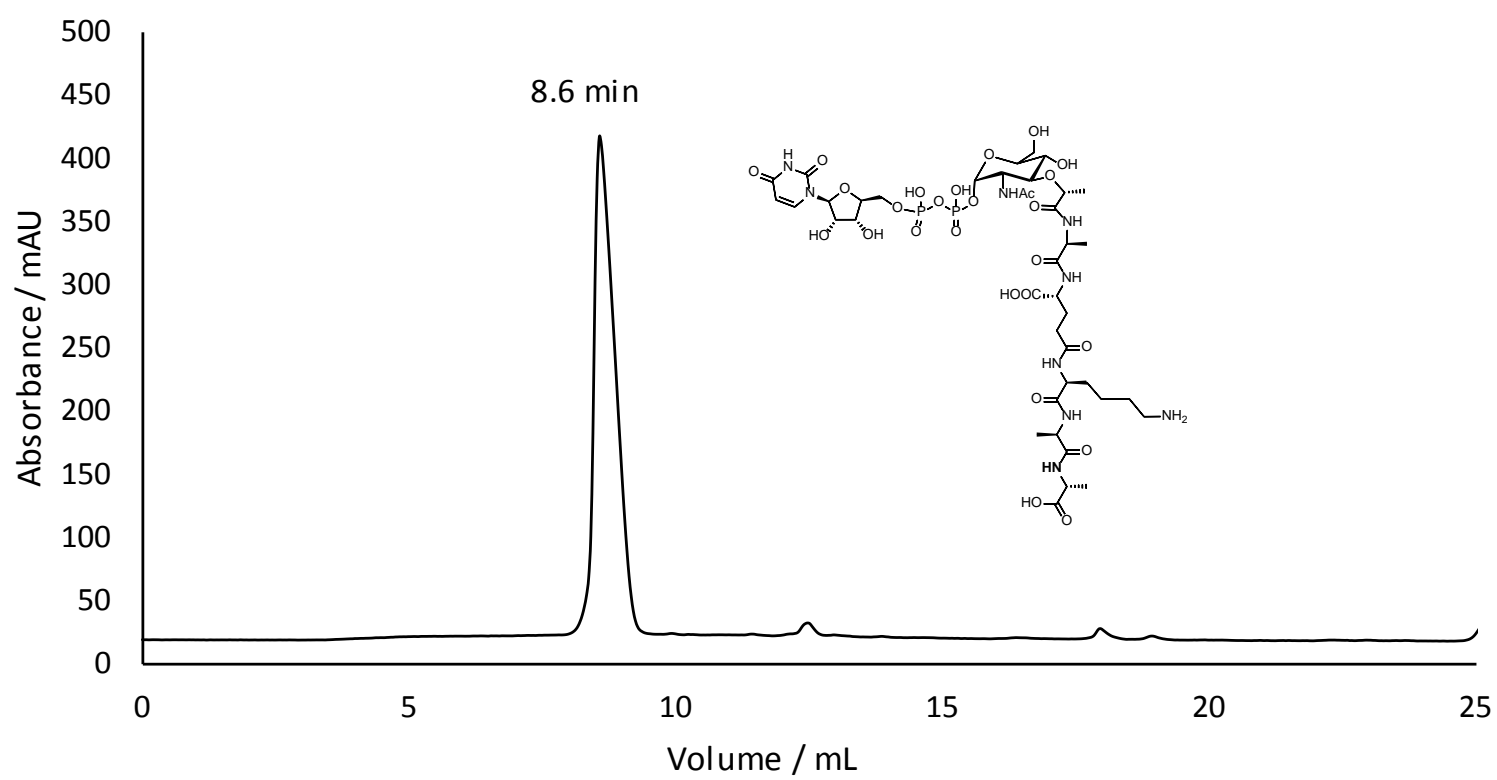

Anionic rpHPLC on analytical DNAPac PA-100 (Thermofisher Scientific, $4.6 \times 250 \mathrm{~mm}$ ) at $1 \mathrm{~mL} \mathrm{~min} \mathrm{~m}^{-1}$ with a 22 min gradient from $25 \mathrm{mM}$ to $375 \mathrm{mM}$ ammonium acetate $\mathrm{pH} 8.0$ containing $0.5 \%$ ACN between 1 and 23 min (absorbance measured at $260 \mathrm{~nm}$ ).

\section{UDP-MurNAc-pentadepsipeptide (1b)}

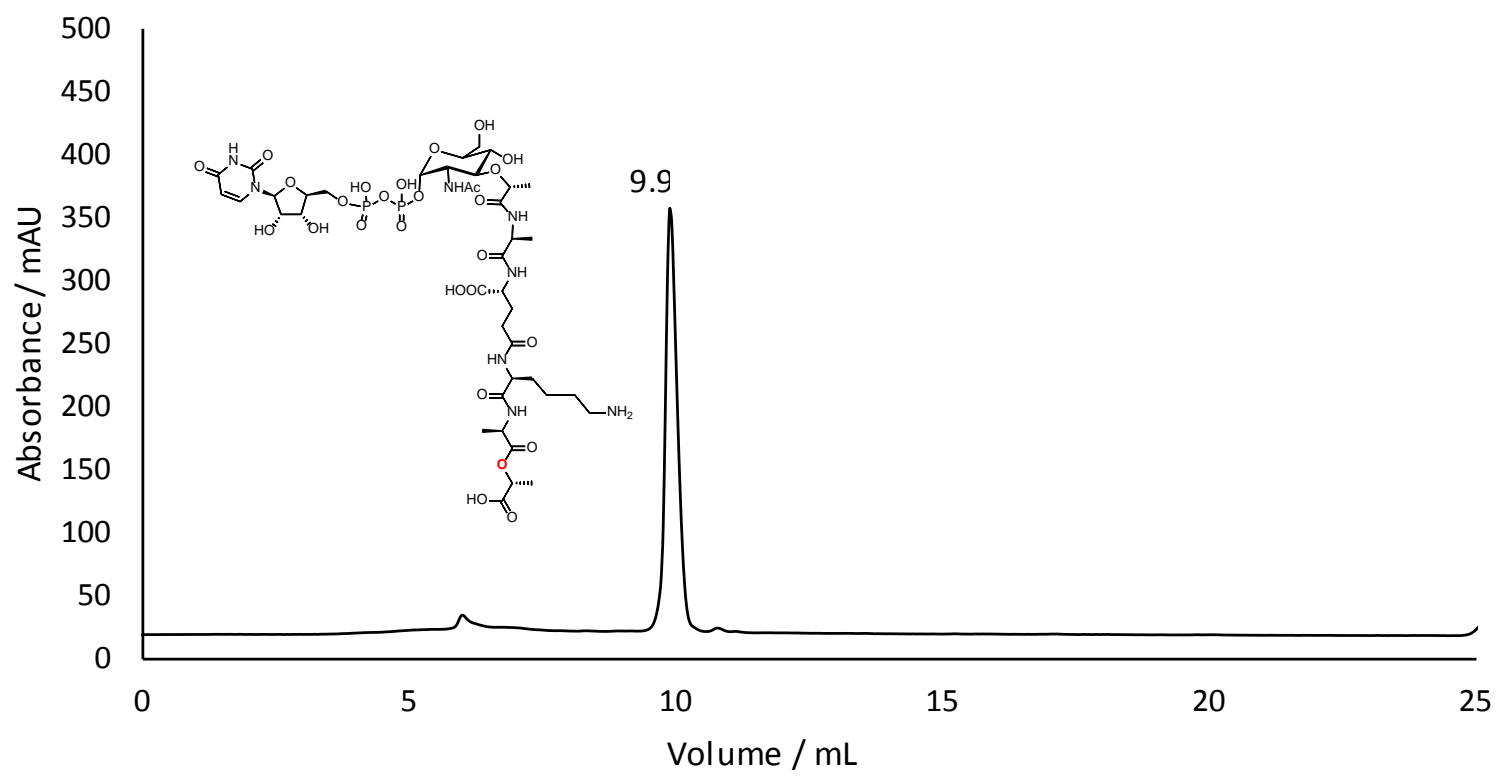

Anionic rpHPLC on analytical DNAPac PA-100 (Thermofisher Scientific, $4.6 \times 250 \mathrm{~mm}$ ) at $1 \mathrm{~mL} \mathrm{~min}{ }^{-1}$ with a 22 min gradient from $25 \mathrm{mM}$ to $375 \mathrm{mM}$ ammonium acetate $\mathrm{pH} 8.0$ containing $0.5 \%$ ACN between 1 and 23 min (absorbance measured at $260 \mathrm{~nm}$ ). 
D-Ala- and neryl-containing lipid II (3a)

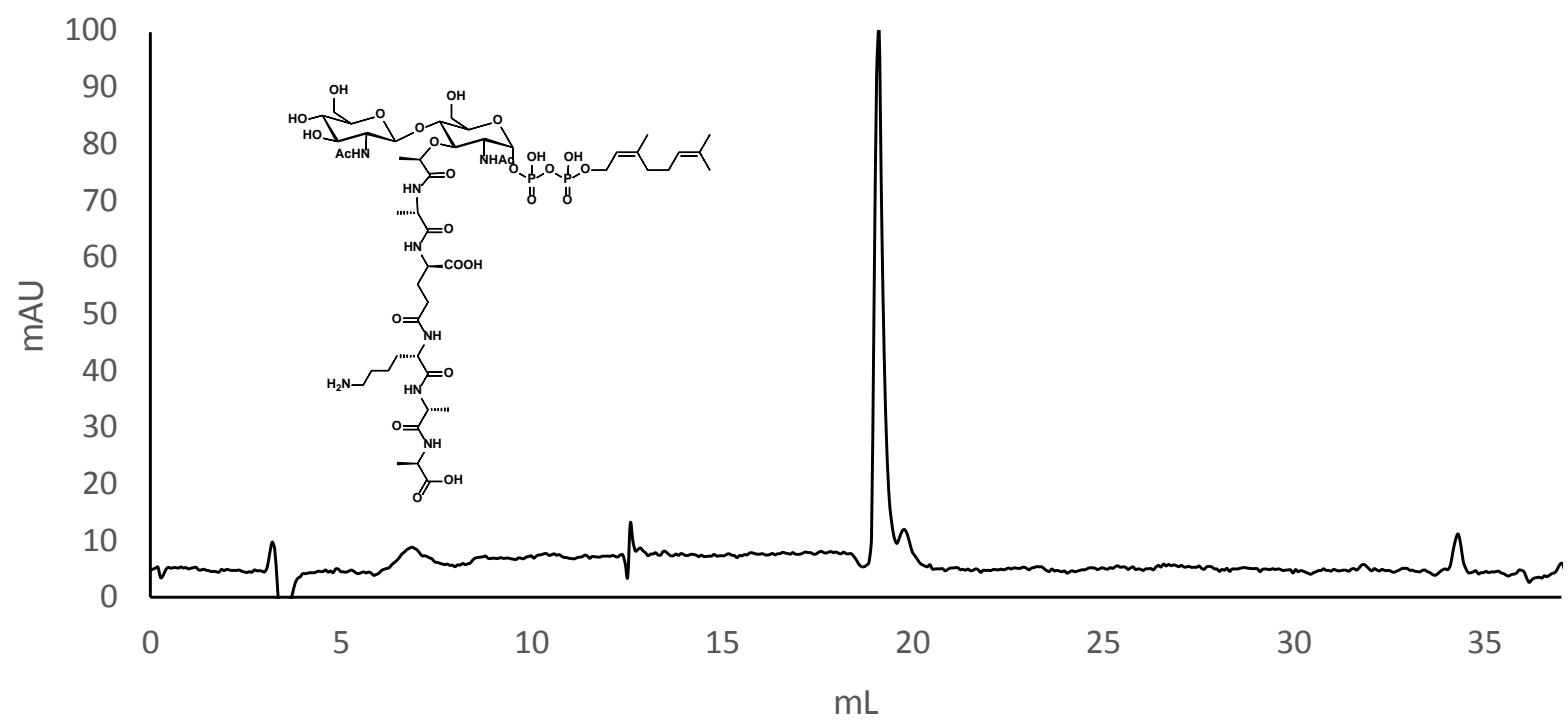

$r p H P L C$ on analytical $100-5 \mathrm{C}_{18}$ Nucleosil column $(4.6 \times 250 \mathrm{~mm}$; Macherey-Nagel), $10 \mathrm{mM}$ ammonium formate $\mathrm{pH}$ 5.0; 30 min linear gradient from 0 to 50\% ACN applied between 6.5 and $36.5 \mathrm{~min}$ (absorbance measured at $214 \mathrm{~nm}$ ).

D-Lac- and neryl-containing lipid II (3b)

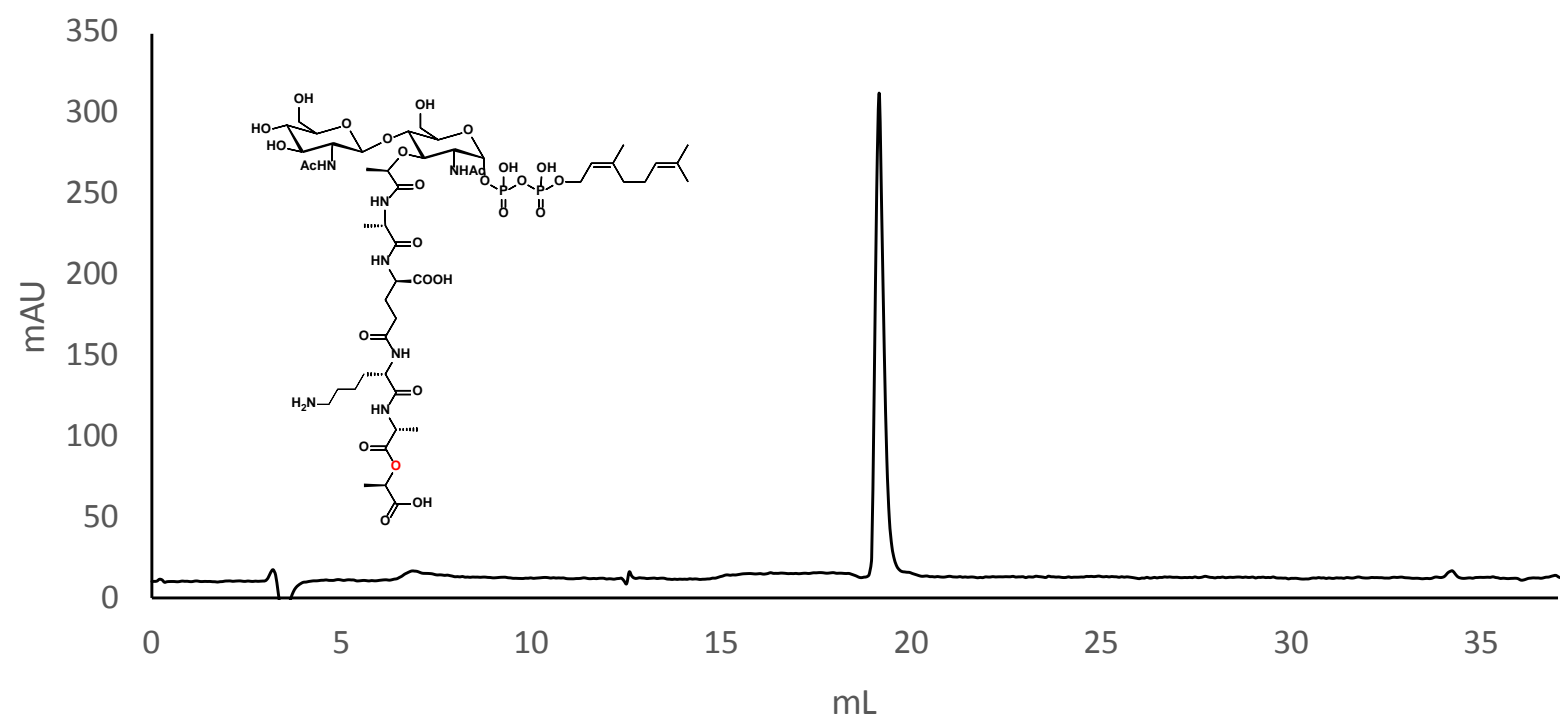

$r p H P L C$ 100-5 $\mathrm{C}_{18}$ Nucleosil (4.6 x $250 \mathrm{~mm}$; Macherey-Nagel), 10mM ammonium formate $\mathrm{pH}$ 5.0; 30 min linear gradient from 0 to $50 \%$ ACN applied between 6.5 and 36.5 min (absorbance measured at $214 \mathrm{~nm})$. 
UDP-MurNAC-L-Ala-D-iGlu-cystine-D-Ala-D-Ala (4a)

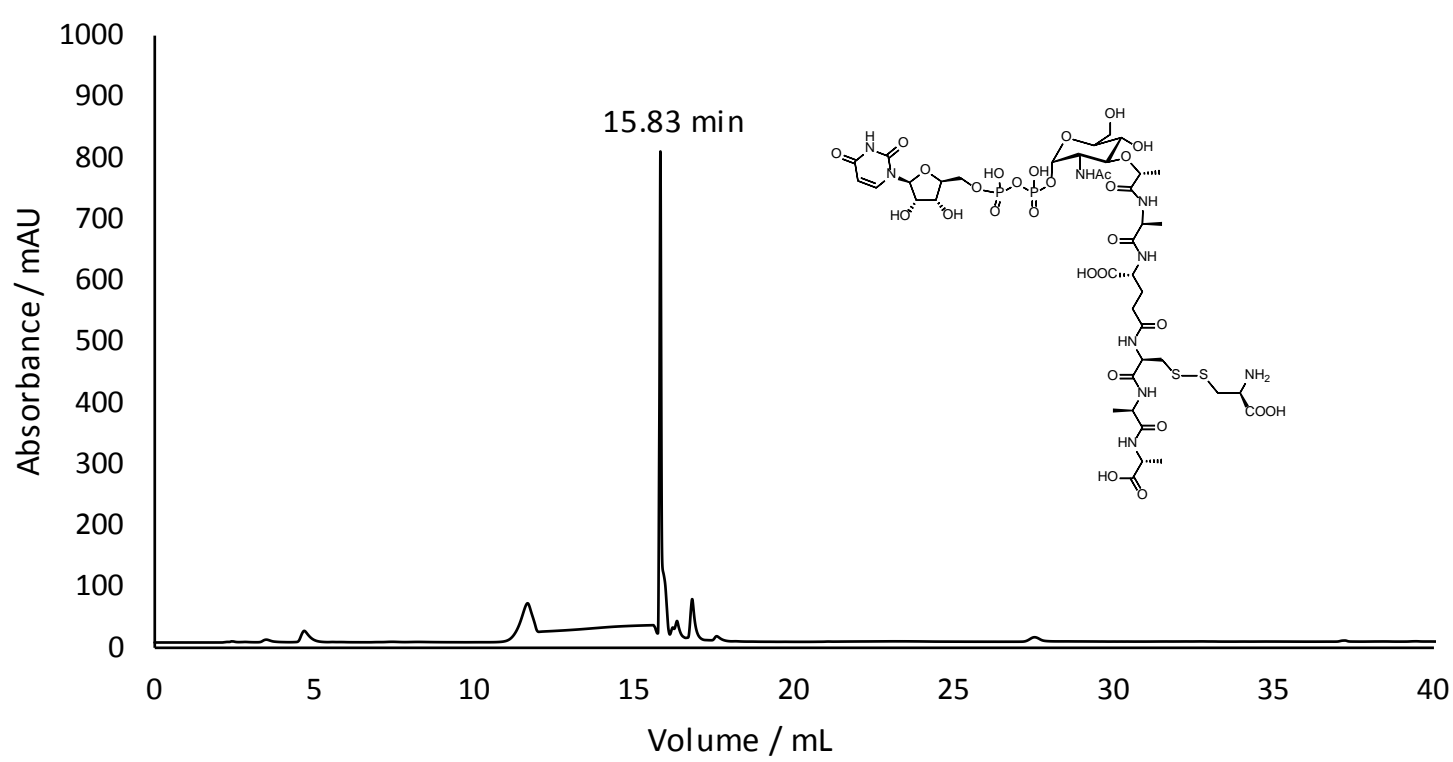

$r p H P L C$ on analytical 100-5 $\mathrm{C}_{18}$ Nucleosil column (4.6 x $250 \mathrm{~mm}$; Macherey-Nagel), $10 \mathrm{mM}$ ammonium formate $\mathrm{pH}$ 5.0; 30 min linear gradient from 0 to 50\% ACN applied between 10 and 40 min (absorbance measured at $214 \mathrm{~nm}$ ).

UDP-MurNAc-L-Ala-D-iGlu-cystine-D-Ala-D-Lac (4b)

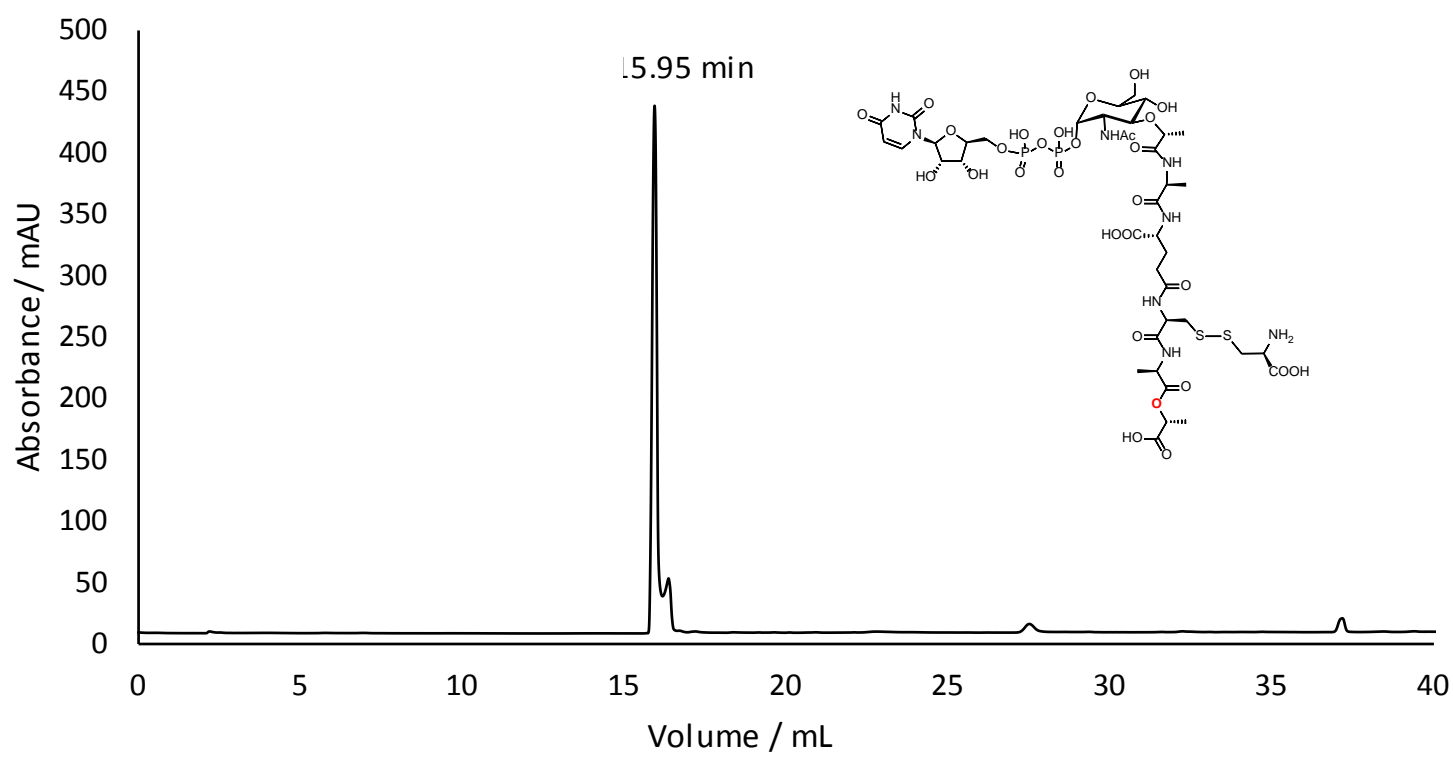

$r p \mathrm{HPLC}$ on analytical 100-5 $\mathrm{C}_{18}$ Nucleosil column (4.6 $250 \mathrm{~mm}$; Macherey-Nagel), $10 \mathrm{mM}$ ammonium formate $\mathrm{pH}$ 5.0; 30 min linear gradient from 0 to 50\% ACN applied between 10 and $40 \mathrm{~min}$ (absorbance measured at $214 \mathrm{~nm}$ ). 


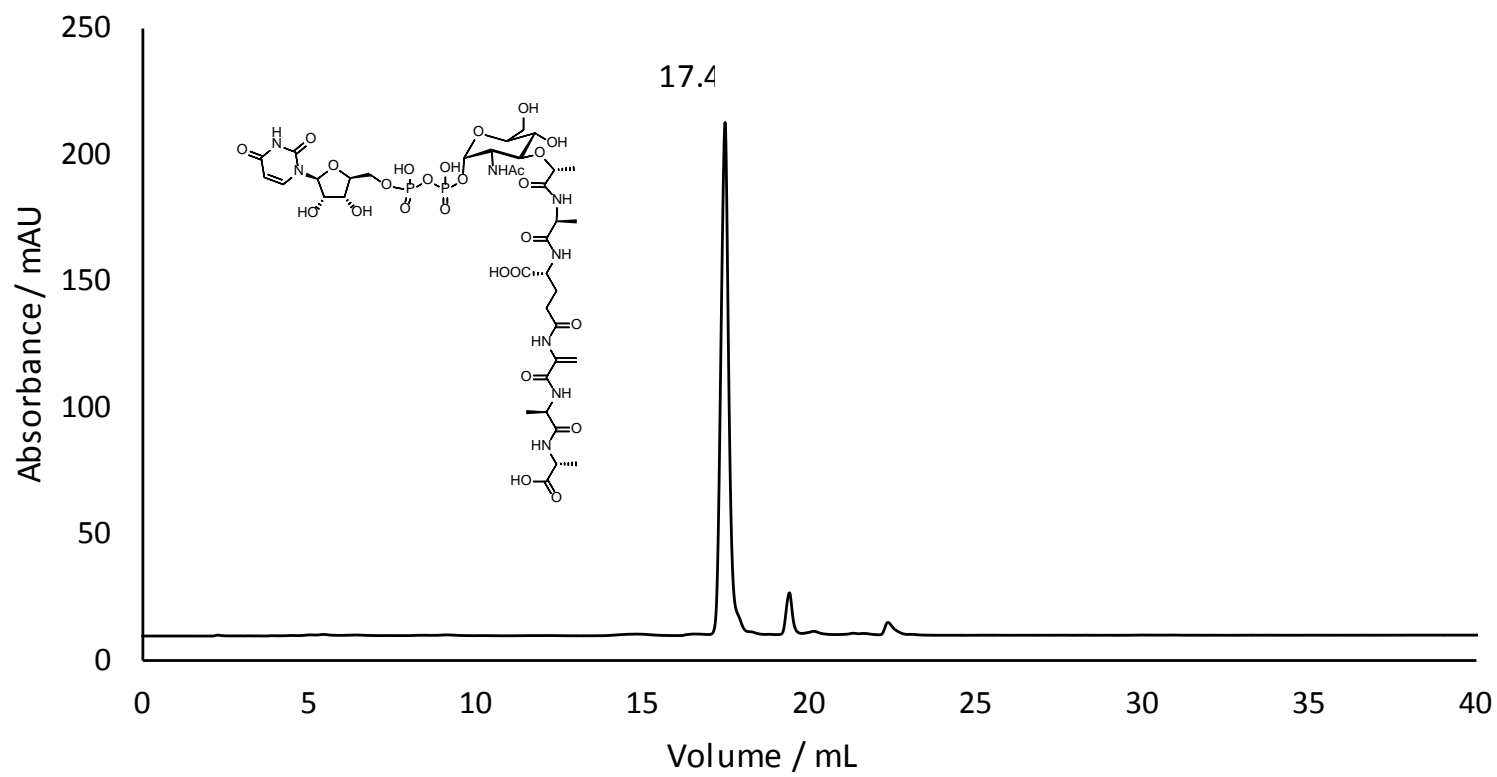

$r p H P L C$ analytical 100-5 $\mathrm{C}_{18}$ Nucleosil column (4.6 x $250 \mathrm{~mm}$; Macherey-Nagel), $10 \mathrm{mM}$ ammonium formate $\mathrm{pH}$ 5.0; 30 min linear gradient from 0 to $15 \%$ ACN applied between 10 and 40 min (absorbance measured at $214 \mathrm{~nm}$ ).

\section{UDP-MurNAc-L-Ala-D-iGlu-dha-D-Ala-D-Lac (5b)}

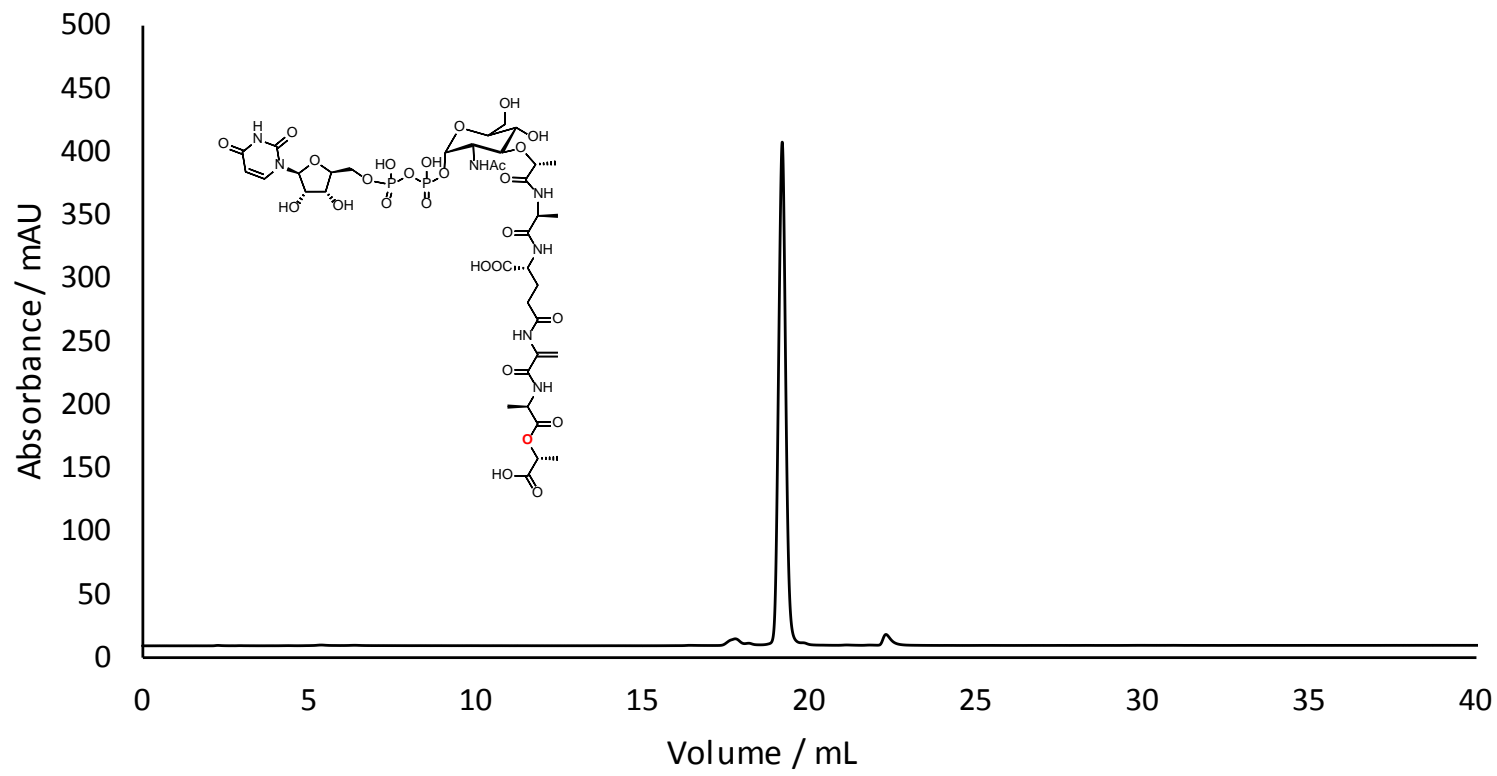

$r p H P L C$ analytical 100-5 $C_{18}$ Nucleosil column (4.6 x $250 \mathrm{~mm}$; Macherey-Nagel), $10 \mathrm{mM}$ ammonium formate $\mathrm{pH}$ 5.0; 30 min linear gradient from 0 to $15 \% \mathrm{ACN}$ applied between 10 and $40 \mathrm{~min}$ (absorbance measured at $214 \mathrm{~nm}$ ). 


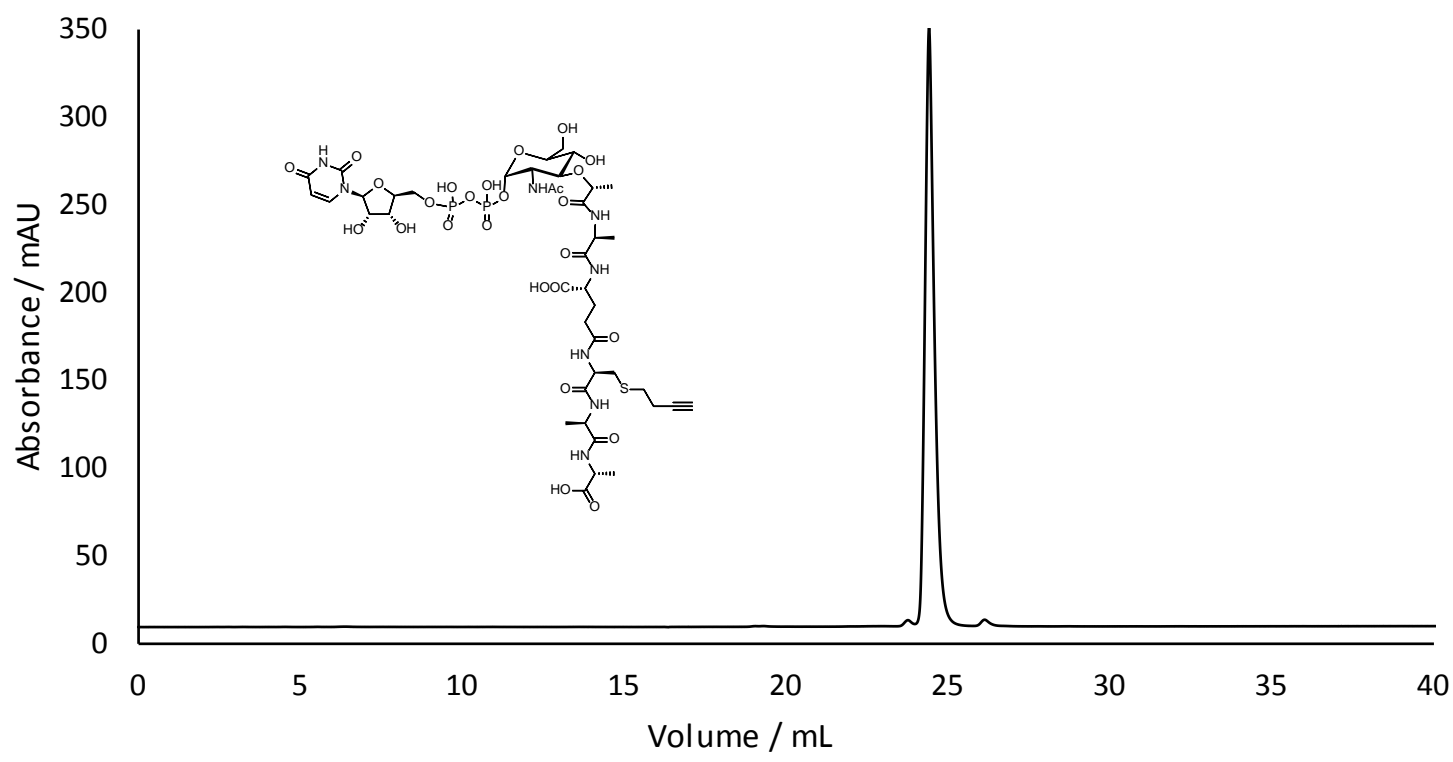

$r p H P L C$ on analytical 100-5 $\mathrm{C}_{18}$ Nucleosil column (4.6 x $250 \mathrm{~mm}$; Macherey-Nagel), $10 \mathrm{mM}$ ammonium formate $\mathrm{pH}$ 5.0; 30 min linear gradient from 0 to 15\% ACN applied between 10 and 40 min (absorbance measured at $214 \mathrm{~nm}$ ).

UDP-MurNAC-L-Ala-D-iGlu-(R)-thio-butynyl-D-Ala-D-Lac (6b)

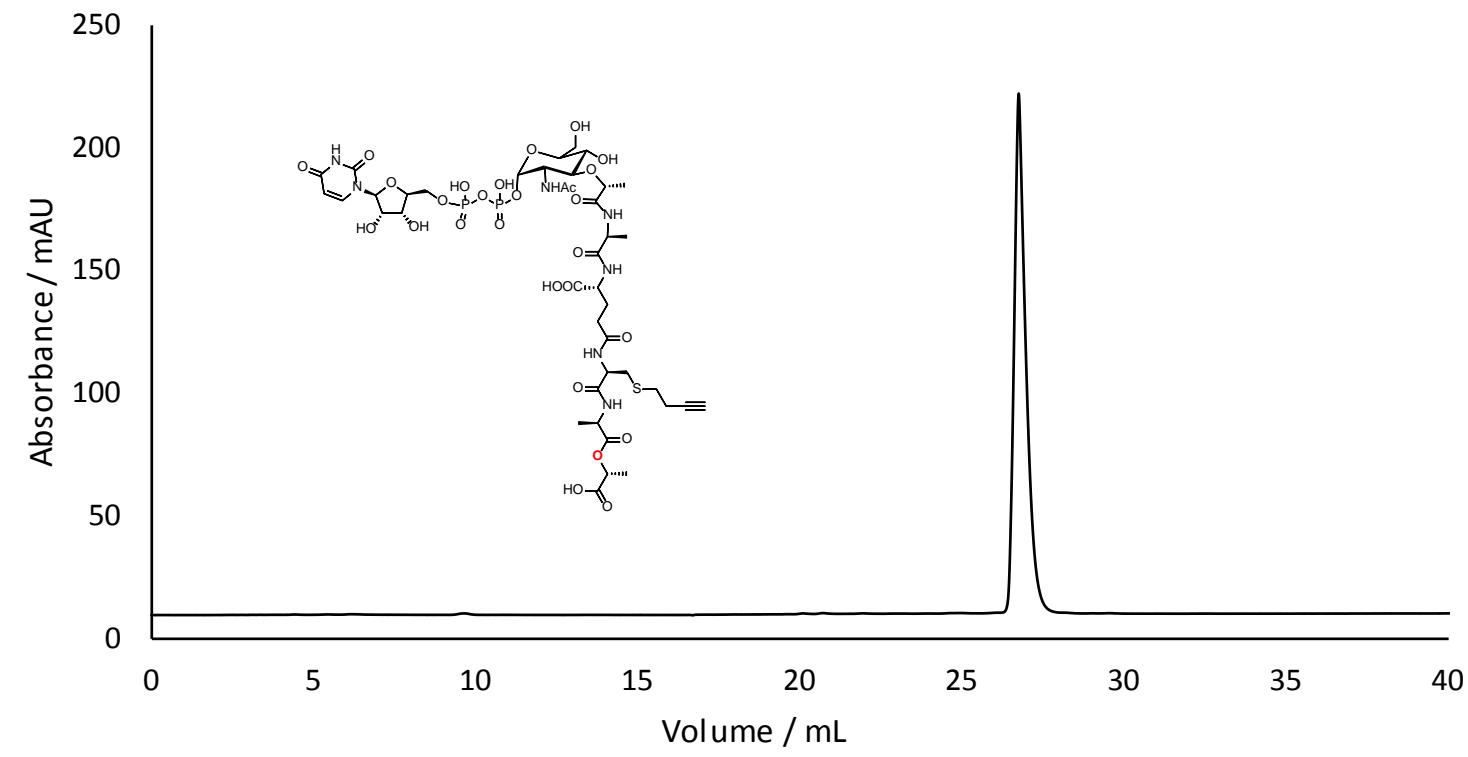

$r p H P L C$ on analytical 100-5 $\mathrm{C}_{18}$ Nucleosil $(4.6 \times 250 \mathrm{~mm}$; Macherey-Nagel), $10 \mathrm{mM}$ ammonium formate $\mathrm{pH} 5.0 ; 30$ min linear gradient from 0 to $15 \%$ ACN applied between 10 and 40 min (absorbance measured at $214 \mathrm{~nm}$ ). 


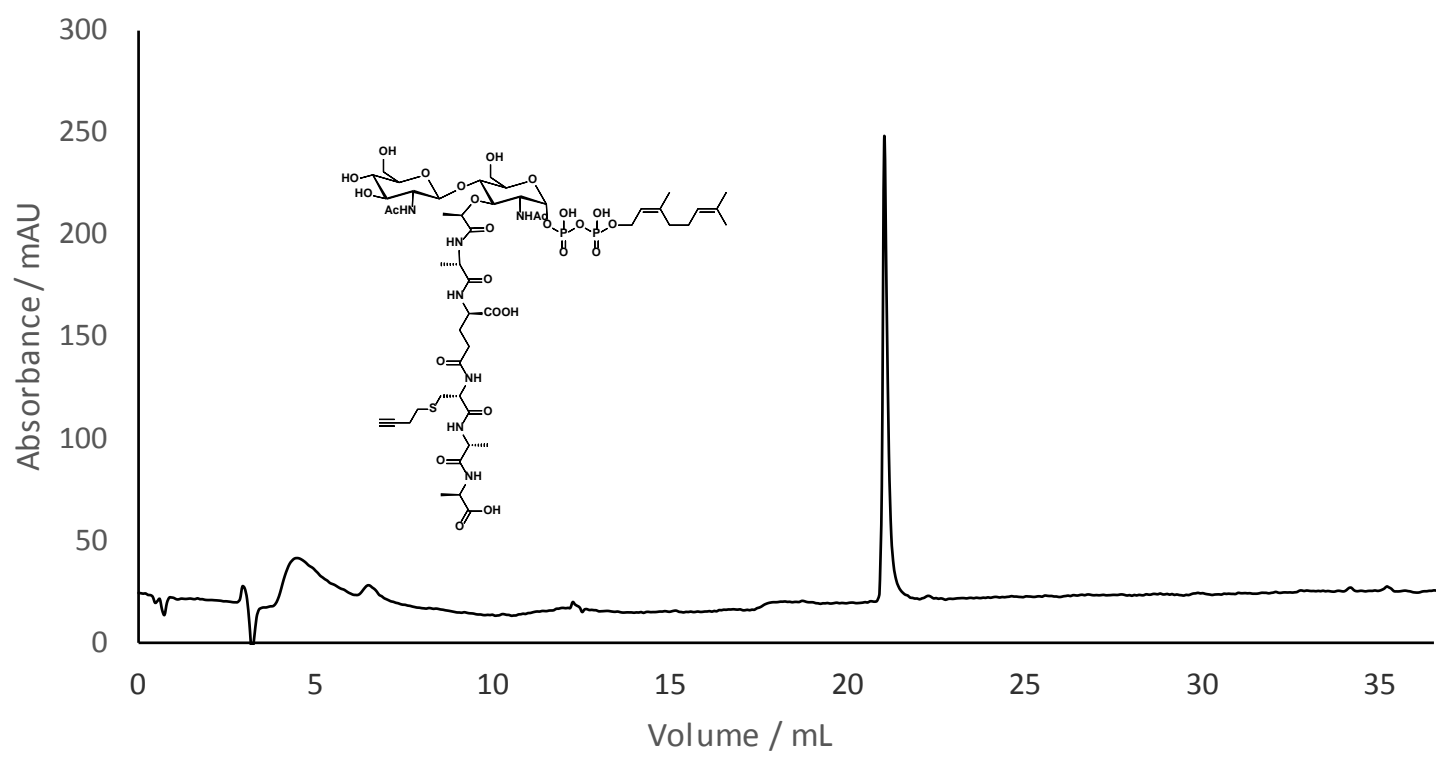

rpHPLC analytical 100-5 $\mathrm{C}_{18}$ Nucleosil column (4.6 x $250 \mathrm{~mm}$; Macherey-Nagel), $10 \mathrm{mM}$ ammonium formate $\mathrm{pH}$ 5.0; 30 min linear gradient from 0 to 50\% ACN applied between 6.5 and $36.5 \mathrm{~min}$ (absorbance measured at $214 \mathrm{~nm}$ ).

\section{GIcNAc-MurNAc[L-Ala-D-iGlu-(R)-thio-butynyl-D-Ala-D-Lac]-PP-neryl (7c)}

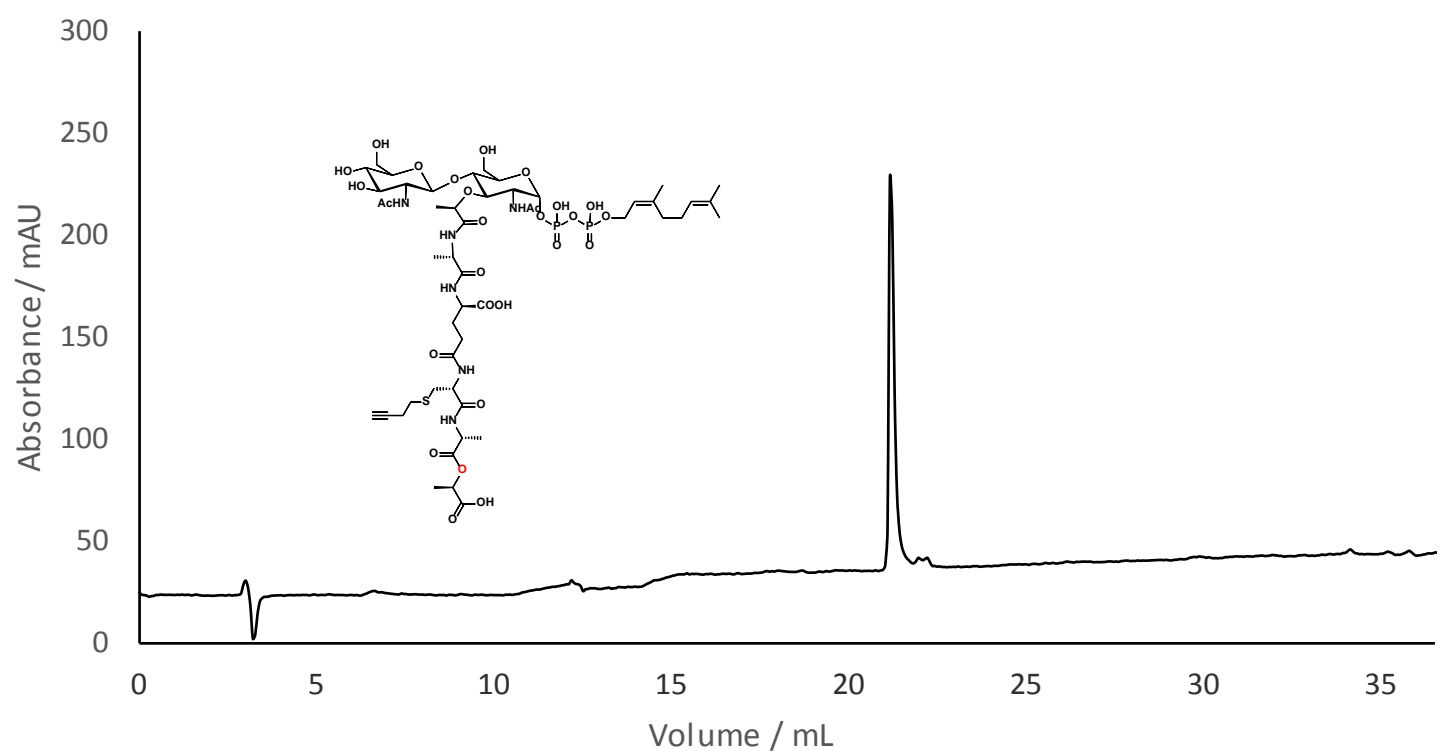

$r p H P L C$ on analytical 100-5 $\mathrm{C}_{18}$ Nucleosil column (4.6 x $250 \mathrm{~mm}$; Macherey-Nagel), $10 \mathrm{mM}$ ammonium formate $\mathrm{pH}$ 5.0; 30 min linear gradient from 0 to $50 \%$ ACN applied between 6.5 and $36.5 \mathrm{~min}$ (absorbance measured at $214 \mathrm{~nm}$ ). 


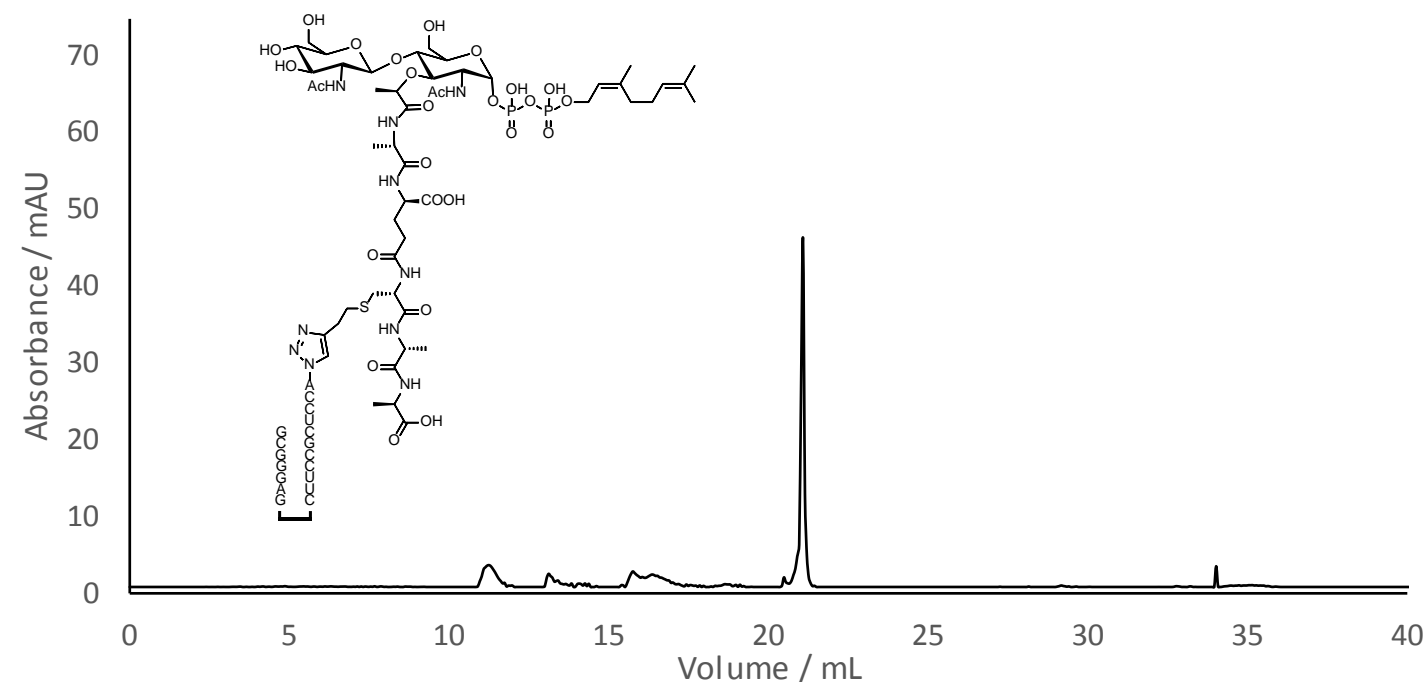

Anionic $r p$ HPLC on analytical DNAPac PA-100 column (Thermofisher Scientific, $4.6 \times 250 \mathrm{~mm}$ ) at $1 \mathrm{~mL}$ $\mathrm{min}^{-1}$ with a 25 min gradient applied between 8 and $33 \mathrm{~min}$ from $25 \mathrm{mM}$ to $2.5 \mathrm{M}$ ammonium acetate $\mathrm{pH} 8.0$ containing $0.5 \% \mathrm{ACN}$ (absorbance measured at $260 \mathrm{~nm}$ ).

D-Lac- and neryl-containing disaccharide-peptidyl-RNA conjugate (8c)

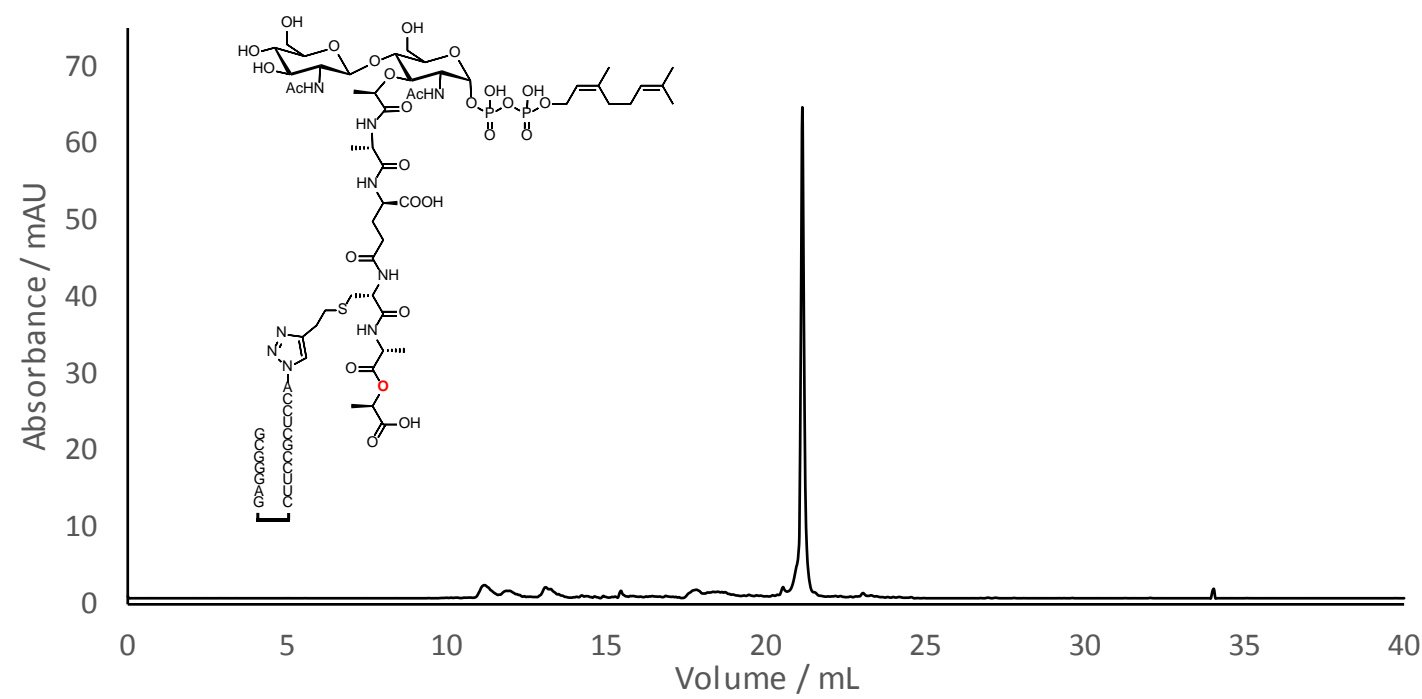

Anionic $r p H P L C$ on analytical DNAPac PA-100 column (Thermofisher Scientific, $4.6 \times 250 \mathrm{~mm}$ ) at $1 \mathrm{~mL}$ $\mathrm{min}^{-1}$ with a $25 \mathrm{~min}$ gradient applied between 8 and $33 \mathrm{~min}$ from $25 \mathrm{mM}$ to $2.5 \mathrm{M}$ ammonium acetate $\mathrm{pH} 8.0$ containing $0.5 \%$ ACN (absorbance measured at $260 \mathrm{~nm}$ ). 
[1] R. Villet, M. Fonvielle, P. Busca, M. Chemama, A. P. Maillard, J. E. Hugonnet, L. Dubost, A. Marie, N. Josseaume, S. Mesnage, C. Mayer, J. M. Valery, M. Etheve-Quelquejeu, M. Arthur, Nucleic Acids Res 2007, 35, 6870-6883.

[2] aM. Crouvoisier, G. Auger, D. Blanot, D. Mengin-Lecreulx, Biochimie 2007, 89, 1498-1508; bG. Zysk, B. K. Schneider-Wald, J. H. Hwang, L. Bejo, K. S. Kim, T. J. Mitchell, R. Hakenbeck, H. P. Heinz, Infect Immun 2001, 69, 845-852.

[3] S. Giannouli, A. Kyritsis, N. Malissovas, H. D. Becker, C. Stathopoulos, Biochimie 2009, 91, 344351.

[4] M. Fonvielle, I. Li de La Sierra-Gallay, A. H. El-Sagheer, M. Lecerf, D. Patin, D. Mellal, C. Mayer, D. Blanot, N. Gale, T. Brown, H. van Tilbeurgh, M. Etheve-Quelquejeu, M. Arthur, Angew Chem Int Ed Engl 2013, 52, 7278-7281.

[5] M. Fonvielle, D. Mellal, D. Patin, M. Lecerf, D. Blanot, A. Bouhss, M. Santarem, D. MenginLecreulx, M. Sollogoub, M. Arthur, M. Etheve-Quelquejeu, Chemistry 2013, 19, 1357-1363.

[6] A. Bouhss, N. Josseaume, A. Severin, K. Tabei, J. E. Hugonnet, D. Shlaes, D. Mengin-Lecreulx, J. Van Heijenoort, M. Arthur, J Biol Chem 2002, 277, 45935-45941.

[7] D. Panesso, P. J. Planet, L. Diaz, J. E. Hugonnet, T. T. Tran, A. Narechania, J. M. Munita, S. Rincon, L. P. Carvajal, J. Reyes, A. Londono, H. Smith, R. Sebra, G. Deikus, G. M. Weinstock, B. E. Murray, F. Rossi, M. Arthur, C. A. Arias, Emerg Infect Dis 2015, 21, 1844-1848.

[8] J. Cremniter, J. L. Mainardi, N. Josseaume, J. C. Quincampoix, L. Dubost, J. E. Hugonnet, A. Marie, L. Gutmann, L. B. Rice, M. Arthur, J Biol Chem 2006, 281, 32254-32262.

[9] aL. Y. Huang, S. H. Huang, Y. C. Chang, W. C. Cheng, T. J. Cheng, C. H. Wong, Angew Chem Int Ed Eng/ 2014, 53, 8060-8065; bD. Patin, H. Barreteau, G. Auger, S. Magnet, M. Crouvoisier, A. Bouhss, T. Touze, M. Arthur, D. Mengin-Lecreulx, D. Blanot, Biochimie 2012, 94, 985-990. 